
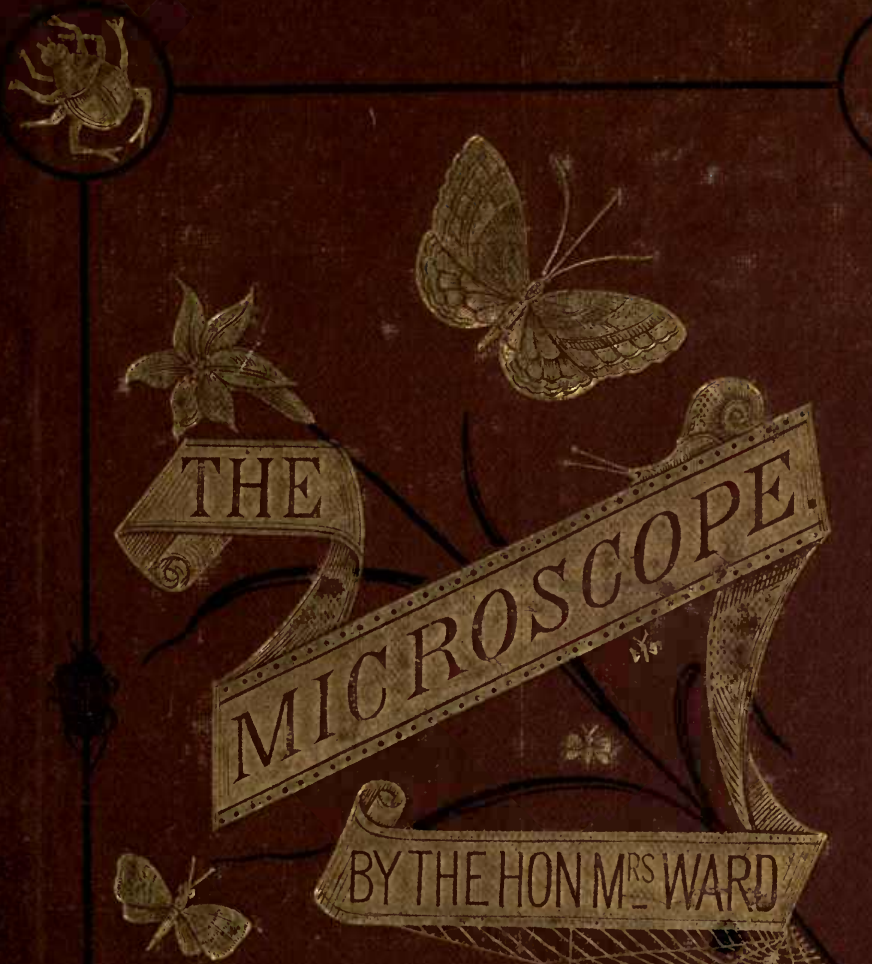

BYTHE HON MESWARI
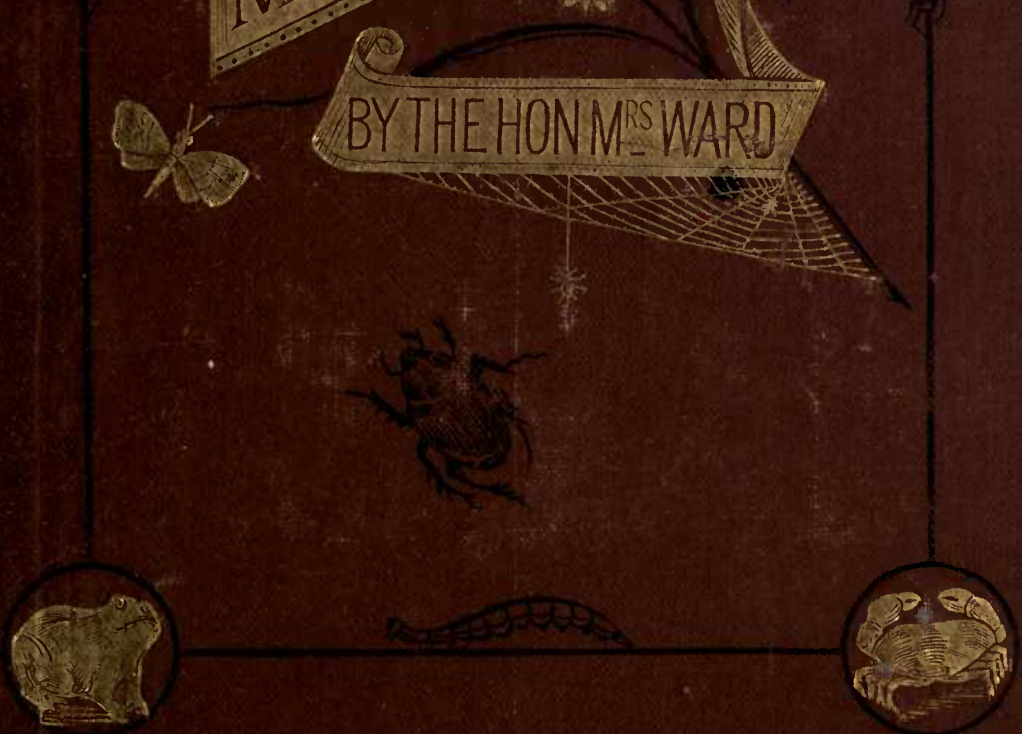


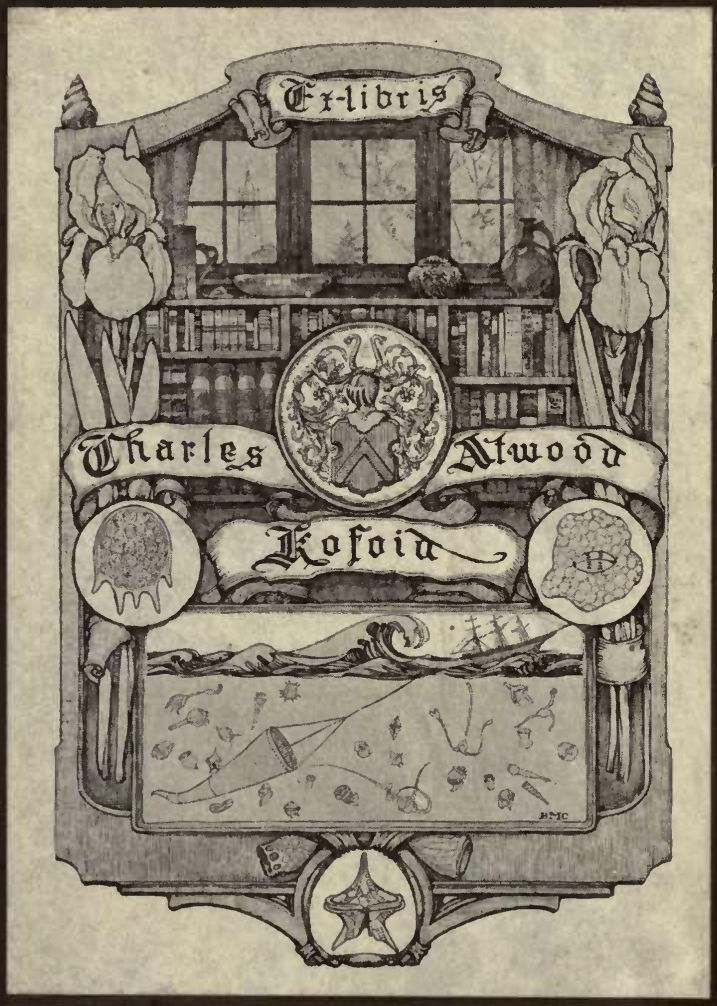




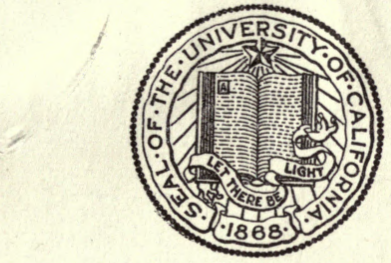

\section{THE LIBRARY $\mathrm{OF}$ \\ THE UNIVERSITY OF CALIFORNIA}

PRESENTED BY

PROF. CHARLES A. KOFOID AND MRS. PRUDENCE W. KOFOID 


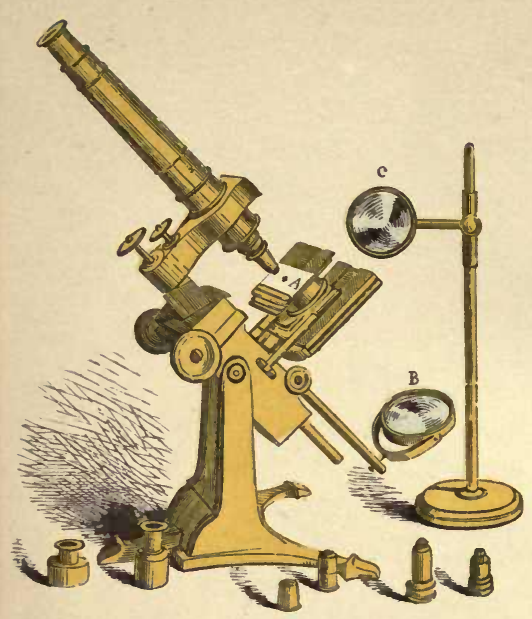

J

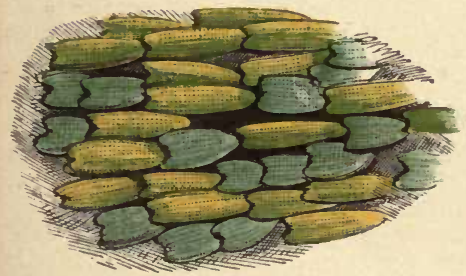

5

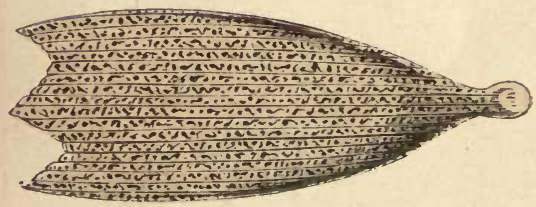

s

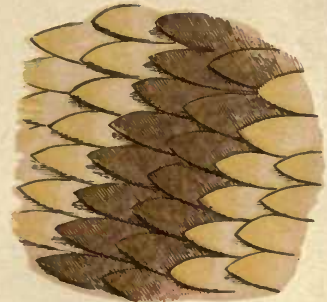

2
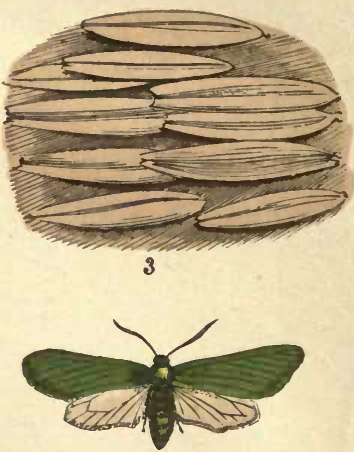

4

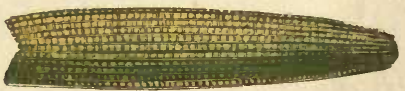

6

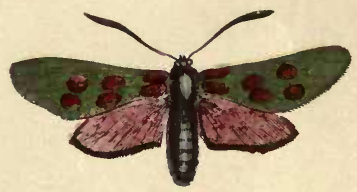

7

1. The Microscope. 2. Seales of Ghost Moth, magnifled 80 diameters.

3. Scales on the under side of Ghost Moth's wing, magil. 100 diams. 4. Green Furester Moth. 5. Scales of Green Forester Moth, magd. 100 diams. 6. Scale, mag. 300 diams.

7. Six-spotted Burnet Moth. 8, Scale of Burnet Moth, magnified 420 diameters. 


\section{THE}

\section{MICROSCOPE,}

OR

DESCRIPTIONS OF VARIOUS OBJECTS OF ESPECIAL INTEREST AND BEAUTY,

ADAPTED FOR

\section{MICROSCOPIC OBSERVATION.}

WITH DIRECTIONS FOR THE ARRANGEMENT OF A MICROSCOPE, AND THE COLLECTION AND MOUNTING OF OBJECTS.

\section{BY THE HON. MRS. WARD, AUTHOR OF " THB TELESCOPB."}

ILLUSTRATED BY THE AUTHOR'S ORIGINAL DRAWINGS.

Chírơ êritionn.

LONDON :

GROOMBRIDGE AND SONS,

5, PATERNOSTER ROW

MDCCCLxx. 


\section{LoNDON :}

Printed by Srmmons \& Botren, Shoe Lane, E.C. 


\section{$K-Q H 211$ W25 Bul. Lier.}

\section{CONTENTS.}

\section{CHAPTER I.}

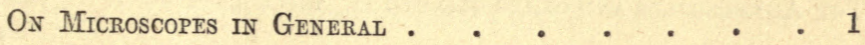

CHAPTER II.

The Microscope Unpacked . . . . . . . 10

CHAPTER III.

Collection and Mounting of Objects .

CHAPTER IV.

Structure of Insects' Wings.$\quad \cdot \quad \cdot \quad \cdot \quad$. 30

CHAPTER V.

Scales of Insects and Fisi . . . . . . . . 37

CHAPTER VI.

IIATRS aNd Featilers 
CHAPTER VII.

Eyes and otiler ObJects • • • • • 62

CHAPTER VIII.

Vegetable Productions • • • • • • • 79

\section{CHAPTER IX.}

Organic Remains, Crystals, and Artipicial Objects • • 93

\section{CHAPTER X.}

The Animalcules and other Minute Inhabitants of Water 105

CHAPTER XI.

The Animalcules, continued • • • • • • . 321

CHAPTER XII.

Circulation of the Blood $•$ • 


\section{PREF A C E.}

Sosre years ago, when the beautiful microscope represented in our Frontispiece was a somewhat recent possession of mine, I took much pleasure in exhibiting its wonders to my friends, at the same time explaining the objects seen.

To write an illustrated account of these wonders was a step which followed. The little book, with its coloured plates, aided by minute descriptions, was intended as a substitute for the actual exhibition. My object was rather to present these wonders successively to view in the manner of a panorama, than to guide my readers to the practical use of the microscope; for, at the time when I wrote, good microscopes were in the hands only of the few.

The case is now altered; excellent instruments, which will answer most purposes, can be purchased for three or four guineas, and the microscope is likely to become, as one of its exponents remarks, "the companion of every intelligent family." Therefore, in again employing pen and pencil in the service of the microscope, my object will be to unite the provinces of the Guide Book and the Panorana; attending to the former, in the hope of making my remarks useful to those who are already in possession of a microscope, while I continue to preserve the latternamely, the Panoramic method-selecting a few from the multitude of lovely scenes presented by the microscope, in order to attract those readers who, unversed in micro- 
scopic marvels, might possibly feel repelled by a complete and lengthened treatise.

The utmost care has, however, been taken to make this work strictly accurate in its statements, and exact in its pictorial representations of the objects described.

The Author can desire no better success for the book than that its perusal may now and then induce a reader to obtain a microscope, and by its aid enjoy those realities which far surpass all pictures and descriptions.

In the days of my microscopic displays, a working man came, half shily and half pleased, at the persuasions of a few of my young friends, to look through the instrument at some striking object. He gazed attentively for a moment, and then exclaimed, in considerable surprise, "It is beantiful-but, is it true?" "Yes, my friend," (might have been the reply,) "it is true; it is itself a truth and a reality." And in this consists the charm of microscopic research. With a suitable instrument, and a little leisure time at command, how happily is the observer brought face to face with the minuter parts of God's creation, and how easy it seens at once to enjoy and to learn. It is like visiting a rich, but hitherto undiscovered region-like opening a page, hitherto unread; of a treasured volume. And while we explore and study, we feel a new sense of the unfailing power and infinite wisdom of the Great Creator, whose mercies are over all His works.

Betuatr, Moate, Irefaitd, 


\section{THE MICROSCOPE.}

\section{CHAPTER I.}

ON MICROSCOPES IN GENERAL.

MICROSCOPE - a complete and beautiful instrument by Ross-stands on my table. I have had it so long that it feels almost like a thing indispensable. Yet I recall the time when its purchase was decided on by a kind parent as a desirable help to the researches in which I delighted, and which I had already pursued with a good deal of diligence, aided only by a common magnifying-glass. A costly instrument was obtained, worthy too of its high price, from the excellence of its glasses, the extreme finish of all its parts, and the multitude of appliances which accompanied it. It arrived one day from London; its mahogany box was carefully lifted from the packing-case, and the doors were opened. And then I remember feeling somewhat disheartened; firstly by a difficulty in finding the uses of all the bright apparatus which met my eye; and next by the want of suitable objects to examine. From various sources informalion 
on these points was collected; and to convey it in a simple manner to others is my present object. There is also another kind of information-of which I was at the outset made personally independent, by the possession of an excellent microscope, chosen, indeed especially bespoken, by an unusually competent judge of such a matter-but which I have endeavoured to obtain for the sake of others; I mean as to what points are especially worthy of attention in the choice of a microscope, and what luxuries in its apparatuscan be dispensed with, with a view to obtain a sufficiently good instrument at a low price.

To convey this information, a few words on microscopes in general are desirable. These instruments, however various in their details, are made on just two different plans-the simple and the compound. An explanation of the principle of each will presently be given; meanwhile, it will be sufficient to state that a compound microscope has a long tube, and at least two glasses, one near each end of the tube, while the latter has no tube, and may have only one lens.

Reading-glasses, hand-magnifiers, and Coddington lenses, are, in principle, simple microscopes, though that name properly belongs to those only which have a fixed stand: of this class is the smart-looking little instrument which is represented at No. 1, A, screwed on to the lid of the mahogany box, into which it packs nicely when not in use. The hand-magnifier, $\mathrm{B}$, is the simplest of all simple microscopes : it consists merely of one lens, in a tortoise-shell frame, made to shut up between two other plates of the same 
material, like a knife-blade in its handle. Sometimes three lenses are thus arranged, and by using one or more of them at a time, the magnifying power is varied. Of this form was the "magnifying-glass" already alluded to, which the writer found very useful before possessing Ross's Microscope. The Coddington lens will be seen represented at woodcut No. 3, among the collector's apparatus-its glass shutting up into a neat little cylindrical frame, with a short handle
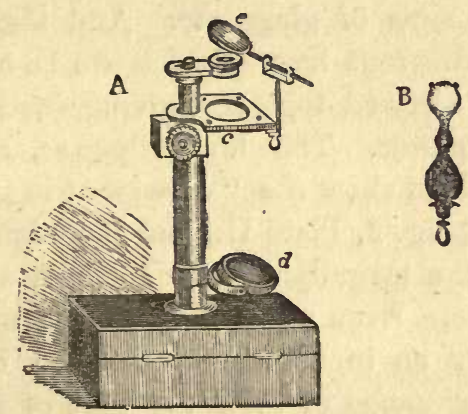

No. 1-A Simple Microscope.

B. Hand-magnifier.

to which a chain or string can be attached. This instrument, and a good little hand-magnifier, like that shown at No. 1, B, will always be found useful appendages to the watch-chain-always at hand to examine objects out of doors. The Coddington lens has by far the higher power of the two, but from its requiring to be held very close to objects it cannot always be used to advantage. The magnifying-glass becomes a microscope when its lens (or combiration 
of lenses) is fixed to a stand of any kind; and in its complete form it should have a little plate of metal, $c$, No. 1, called the stage, on which the objects are placed; a mirror, $d$, to throw light on the objects from below; and a condensing lens, $e$, for the illumination of objects from above. Probably there will be a screw head fixed to rackwork for bringing the lens to the correct distance required for showing the object clearly. There will also be various useful pieces, of apparatus, as a pair of forceps, a box for holding minute live things, some slips of glass, etc. And there will be two or three different lenses, which can be used either separately or screwed together, giving good variety of magnifying power. The lowest power of such a microscope would show the "earwig's wing" slightly larger than at fig. 2, Plate II., and the highest might nearly reach the magnifying power shown at fig. 9 in the same Plate. Even a higher degree of magnifying is attained by an ingenious combination of lenses; but the performance of even the best of these high powers of the simple microscope is unsatisfactory, compared to the corresponding power of the compound microscope; and for still greater magnifying the latter instrument alone supplies our need.

The difference between its principle and that of the simple microscope should now be explained. In the simple microscope we look directly at the object, with the lens close to the eye; but in the compound microscope we use the lens to look, not at the object, but at an image formed by another lens placed furthest from our eye, and next to the object; that image is 
formed (as it were, in the air,) between the two lenses. It is already larger than the object, and is further magnified by the upper lens. A very great increase to the magnifying power is thus obtained, but to obtain it with perfect clearness, and with freedom from various drawbacks and inconveniences, has long exercised the cleverness of opticians. The combination of lenses next the object, called "the objectglass," requires great care and trouble in its construction. The proper length for the tube, and due form for the upper set of lenses (or "eye-glass") also demand much attention; but this care and attention have not been bestowed in vain, as great excellence has been attained.

Compound microscopes bear a general resemblance to each other in external appearance, (see fig. 1, Plate I.,) yet a distinction may be made among them into two principal classes; namely, the large, substantial, and complete instruments, in which perfection has been the aim, and the smaller and lighter ones, which have been made with a view to cheapuess, although no trouble has been spared to render them as good as possible for the price. And for full information about various simple and compound microscopes, with most interesting details about their principle and construction, I would refer the reader to Dr. Carpenter's valuable book, "The Microscope and its Revelations." While studying the opening chapters of that work, the reader feels as if visiting the establishments of various opticians, at home and abroad, arm-in-arm with an ever ready exponent of every point of interest 
connected with the microscope, free from the bewilderment and fatigue which would doubtless attend an actual inspection of a number of instruments.

The intending purchaser of a microscope, if limited as to price, should at least take care that the microscope shows objects clearly, and is perfectly achromatic, that is, without those fringes of rainbow colours always seen surrounding objects in inferior microscopes. It should also be constructed to lean backward, (see fig. 1, frontispiece,) as being far less fatiguing to the observer than the upright position. It should have at least two different degrees of magnifying, and one of these should be of low power, with large field of view, for the purpose of showing as much as possible of an object at once. These, with the condensing lens and mirror, to throw light on or through objects, are the things indispensable. Among the luxuries are screws for moving the stage back and forward, and from side to side; apparatus for exhibiting the beautiful effects of what is called "the polarization of light," and several additional magnifying powers. An observer with some prospect of leisure, and likely to use the microscope a good deal, might do well to purchase an instrument to which additions could be made from time to time. The object-glasses are the most expensive part of the microscope, and the purchase of an additional one therefore adds a good deal to the total cost.*

* The object-glasses supplied with microscopes are generally known as the "two-inch". power, the "quarter-inch," etc. These 
While describing the different kinds of microscope, a few words should be said on the binocular microscope, and the solar and oxy-hydrogen microscopes.

The binocular microscope (No. 2) is an ingenious application of the principle of the stereoscope to the compound microscope. Some objects are extremely well suited to this mode of observation, and some details which appear confused and unmeaning when viewed with only one eye, appear to assume form and solidity in the binocular instrument.

The solar microscope is pronounced in an excellent article, published more than twenty years ago in the "Penny Cyclopædia," to be nearly superseded by the oxy-hydrogen instrument. The principle is the same in both; the rays from the sun or from the brilliant artificial light are thrown on the object, and then through a kind of simple microscope to a large

names were originally given to convey an idea of the performance of the compound microscope, as compared with that of the simple (see Quekett on the Microscope, chap. ii.) It may be useful to state the powers of each of the object-glasses with the lowest eye-piece of the microscope used in this work. It will give a general idea of the powers of object.glasses, but as these vary slightly in each microscope, the purchaser of an instrument should always obtain a table of its powers.

Lowest eye-glass and two-inch object-glass ..... 20 diameters.

Ditto, and one-inch object-glass ................... 60 "

Ditto, and half-inch object-glass.................. 100 "

Ditto, and quarter-inch object-glass ............. 200 "

Ditto, and one-eighth of an inch object-glass ... 420 ",

The expression "diameters" will be found explained at page 31. The two other eye-glasses supply intermediate powers, and the following higher powers, 670,900 . 
screen placed at a considerable distance. These in. struments cannot be said really to magnify as much as the compound microscope. The farther the screen is removed, the larger will be the image, but it will be at the expense of its light and clearness; this sort

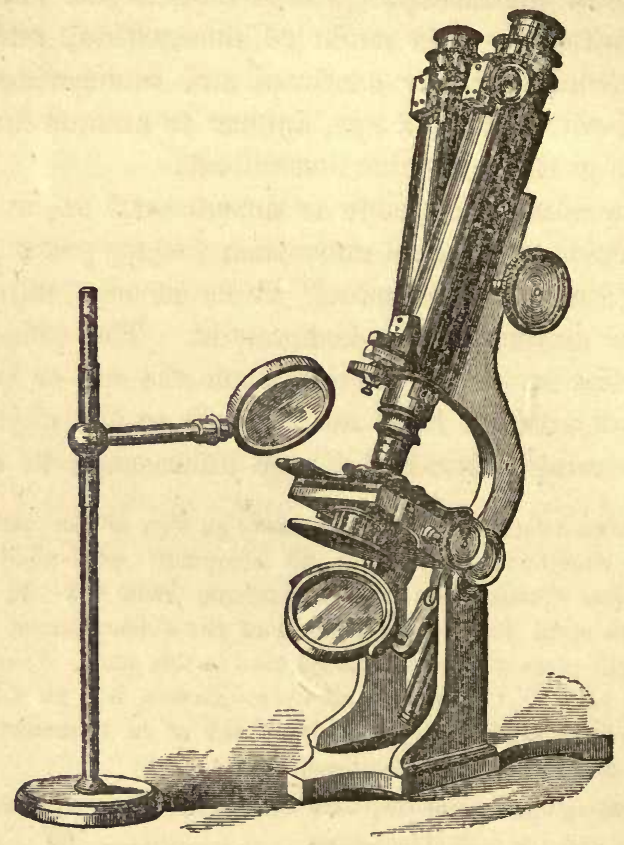

No. 2.-Binocular Microscope.

of instrument is not intended for the purposes of investigation, but rather as an amusing and instructive exhibition.

The oxy-hydrogen microscope, though cumbrous 
in its appliances, works of course at the pleasure of the exhibitor: that light shines when wanted; far different is the case with the solar instrument, at least in this climate! It screws into a hole in a window shutter, waiting for the sunshine that often fails to come. A microscope of this sort was the first ever shown to the writer, who afterwards became its owner, and recalls to mind the exceeding interest with which parties of young people would look together at the objects, imaged in gigantic proportions, the grief they evinced when the light suddenly faded, and the good humour with which they consented to watch the picture of the drifting clouds, thrown camera-obscura-wise on the screen by removing part of the machine. Then how often even this faded away, rain came on, and the exhibition closed abruptly. It was at the time a disappointment; but led, I believe, to my trying to draw microscope pictures less transient than those on the screen, and to address a larger number than I could well have assembled around the old solar microscope. 


\section{CHAPTER II.}

THE MICROSCOPE UNPACKED.

Fin $E$ it now be supposed, reader, that you have chosen your microscope, either from a careful study of books, or by the advice of some friend "good at need," and have commenced to unpack it. You will probably find the tube and the stand detached; the eye-glasses, or the single eye-glass, arranged in the case, and the object-glasses put by into little brass boxes. You take out the stand, and place it on your table. Some microscopes have a tall case, capable of holding the microscope ready for use, with the tube attached to the stand. Should yours not be thus arranged, you will screw on the tube; but you had better put on the object-glass first, as there is a kind of "knack" in making it screw on, and an object-glass might easily be injured by letting it fall. Choose the object-glass of lowest power, as easiest to work with; you will know it by looking at any small object or piece of printing through it, as it will show this less magnified than the other object-glass or glasses. You place the eye-glass in the upper end of the tube, if it is not already there.

Is the microscope now ready for looking at an 
object? Not quite; we must arrange for throwing light on the object, for that is a great and important part of the microscopist's craft. You cannot carry the small objects you examine close to the lamp, to examine their surfaces, or hold them between your eyes and the light with a view of seeing their interior structure; but you can bring the light down upon them with what is called the "bull's-eye," or condensing lens, (Plate I., fig. 1, C,) or you can send light through them with a mirror (B). You will find both packed somewhere, the condensing lens perhaps fitting into the case, and the mirror perhaps already attached to the stand. Daylight or lamplight are both suitable for the use of the microscope, but many an observer finds evening hours to be the only leisure time. Fortunately the observation of objects by lamplight is particularly pleasant and satisfactory. Were I asked to give an opinion as to the preferable light of the two, I would say, daylight for some sorts of investigation, as, for instance, for ascertaining the exact colours of objects; but lamplight, unquestionably, for exhibition.

Do not use a candle, it flickers so unpleasantly, and its height changes as it burns down; use a lamp, a small paraffine or other lamp about the same size will answer very well. For illuminating opaque objects, you should raise the lamp on a box, or something of the kind. Try what a bright little focus of light you can make with the bull's-eye lens on a scrap of paper. It will be easier at first to manage by leaving the microscope in its upright position than 
by bending it backward. Now for an object, something fresh, bright, and effective-a little flower, a blade of grass, or a frond of fern. If London-pride be in bloom, you cannot do better than place one of its flowers on the stage, or in the pair of forceps which probably accompanies the microscope. See that the light is properly condensed upon it, then look into the tube! You will see, perhaps, something very white and brilliant, but very indistinct, and placed uncomfortably awry in the field of view; move the object a little till it is nicely in the centre, and turn the screws. which raise and lower the tube, till the little blossom suddenly shows itself like some superb hot-house flower. If you move it slightly, while viewing it through the microscope, you will find that it is inverted-shown upside down; this is the case in all compound microscopes, but you soon become accustomed to it. Now for an attempt with the transmitted light, (that is from the mirror B.) The thickness of the London-pride flower will prevent its being viewed in this way; try a blade of grass, and before changing the mode of illumination, view it as you have just viewed the flower, for that is one comfort in lamplight, you can so easily put successive objects in the bright little focus of light, and there they are at once, visible in the field of view. Thus you can quickly show the blade of grass as an opaque object, lowering the tube a little till you see it clearly - like some rich fabric woven of green and silver, with occasional stripes of plain green, ornamented with lines of long, glassy, colourless beads, and brist- 
ling at each edge with saw-like teeth. Now take away the bull's-eye lens, place the lamp somewhere near the mirror, and move the latter about till you see the light gleaming brightly upward through the blade of grass. You prepare to look at it, but perhaps are dazzled by the lamplight. If the mirror has two sides, one will be concave, the other plane, and the latter will perhaps suit best with a low power; or you may moderate the glare from the concave side by turning the "diaphragm-plate" (see p. 16), or by placing a piece of tracing paper under the object. When all is rightly arranged, you will see the grass, a rich green fabric still, but altered. The long transparent beads have disappeared; the plain green lines are now the brightest part of the object, in consequence of their being the thinnest. The central rib is nearly black, from its real thickness. 'l'he saws at the edge stand out vividly on the bright back-ground, and the whole blade shows a sort of cellular structure, which you would like to see made still larger. If you have a second eye-glass, you may substitute it for the one already in use, and thus gain a higher power, but in many cases you will not find this so satisfactory a method as that of changing the objectglass, while the eye-glass remains undisturbed. Should the object-glass now applied be one of somewhat high power, you will find that, alter the screws as you will, you cannot get the whole of the blade of grass sharp and distinct; that is caused by its want of flatness, and is often an indication that you are employing an unsuitably high magnifier; if, however, 
you cannot ascertain what you want with the lower power, you must be content to see but a small portion of the object clearly "in focus," and cultivate the habit of disregarding the rest.

The beginner will not probably succeed in finding anything nearly so well suited for observation with the high object-glasses as some of the beautiful microscopic preparations supplied by opticians. In these, the object is placed on the centre of a slip of glass, measuring three inches by one, and covered by a little piece of thin glass manufactured for the express purpose, and securely joined to the thicker slip. You will do well to have a few of these at hand, both to assist you in learning the use of your microscope, and because if you wish to prepare objects for yourself, the ready-made ones will show you what your own work ought to resemble.

A single scale of a moth, like that at fig. 8, Plate I., would be suitable for looking at with a powerful object-glass; and a small group of such scales will easily be procured. Let the microscope incline backward to whatever height is most convenient as you sit at your table. Arrange the light properly,* and place the slide upon the stage-the slide, I should explain, means the slip of glass with its prepared object. There will be some sort of ledge on purpose to support it in the inclined position of the microscope. Find the object's place while the least

* A very complete article on the illumination of objects will bo found in the "Intellectual Observer," for January, 1863. Its title is "The Eye and the Microscope," by H. J. Slack, Esq. 
powerful magnifier is still attached to the tube, and getting it into the centre of the field, take off the object-glass of low power and substitute the higher one. Look in-all is hazy, because the increased power requires the tube to be lowered. But lower it carefully, or you may presently find your object-glass and slide meet with a crash, resulting in the breakage of one or both. It is well to do this screwing-down with the eyo removed from the tube, and steadily fixed on the object itself; look edgewise, and screw downward till the object-glass and object nearly touch, then place your eye to the eye-glass, slowly reverse the movement of your hand, and the object will start into clearness when at the proper distance; and if there is an additional screw for what is called the "fine adjustment," you can perhaps gain further exactness in the focus.

With a little practice you will soon estimate the proper distance for each object-glass; and you will also find it tolerably easy to find the object, even without first getting it to the centre of the field with the help of a lower power; you may move the slide somewhat rapidly about with your hands till the object glances across the field, then lay it on the ledge, reverse the motion which inadvertently whisked it away, and you will soon see it coming back into the field of view.

"Which eye shall I shut?" is not an unfrequent question of persons to whom a microscope is shown. Neither, is the answer in which all practised observers seem to agree. Keep open the unemployed eye, and 
for this good reason, that the doing so will go far to prevent injury to your sight. You will perhaps find it easier to do this by making a card-board shade to slip on to the top of the tube; you can shape it by cutting off its corners, and it will be well to cover it with black cloth or velvet. To the rule of keeping both eyes open, Dr. Carpenter adds another, namely, that of not continuing to observe any longer than you can do so without fatigue; and he reports in his own case an entire freedom from any injury to his eyes, after twenty-five years of microscopic study. I can add a somewhat similar testimony to the safety to eye-sight of (at least occasional) microscopic occupation, for I cannot remember ever to have felt my eyes in the slightest degree fatigued (much less injured) by the microscope.

But to return to our unpacking of the instrument. You will find, besides the apparatus now explained, a few other things. There will be the "diaphragm," a metal plate perforated with three or four holes of different sizes, and constructed to turn on a pivot, for the purpose of modifying the light from the mirror, or shutting it out altogether when an opaque object is examined. There may also be, packed into the box, two or more bright little concave mirrors, called Lieberkuhns (from the inventor's name), and intended for the illumination of opaque objects. They fit on to the object-glasses, collect light from the mirror below, and bend it down on the object. A little black cell, to fit somewhere below the stage, is sometimes supplied with them, to cut off direct light from the mirror. 
If you have not this, a round scrap of black velvet or paper gummed under the slide, will answer the same purpose.

Then there will be "stage-forceps," very useful for holding flowers and similar objects for examination with the lower powers; and a "live-box," otherwise called an "animalcule-cage," which you will see represented at No. 3, close to the little bottle; it consists of two pieces of glass in brass fittings, between which small water-animals can be placed in a drop of water, the drop flattened out till the glasses nearly touch. The upper glass being always very thin, stands in particular danger of being broken; a grain of sand or some hard little piece of root in the enclosed drop of water will often cause it to crack across; but this need not much disconcert the observer, as one of the circular pieces of thin glass, generally sent with a microscope for mounting objects, will be likely to fit the live-box, and fastened in with sealing-wax varnish, or some such cement, will replace the broken glass, and make all right again.

If you have any more apparatus requiring explanation, I must refer you to the work of Dr. Carpenter, and that of Mr. Quekett,* from which latter I received much help when beginning to use the microscope.

A few words should be said about the care of the microscope. It should always be put by when not in actual use. Little specks of dust on the glasses are so annoying, that the instrument should be protected London.

* "Practical Treatise on the Use of the Microscope." Baillière, 
from them as much as possible. You should either replace every part of the instrument in the case, ora far more agreeable plan-have a glass shade which will cover the microscope and its accessories, and under which they may be quickly placed, and in doing this the glasses themselves should never be touched by the fingers.

With all precautions, however, the observer may find that the glasses do require cleaning. An old or borrowed instrument may come into your hands, with an evident indistinctness in its performance. If the defect consists of a general paleness in the image, this indicates that the object-glass requires cleaning; while large dark blots tell of dust on the eye-glass, and you can prove it by seeing whether they move when you turn the eye-glass round. You should proceed as carefully as possible about the cleaning. Firstly, dust the surface with a soft camel's-hair brush to remove loose particles, then wipe the glass with either a very soft piece of leather or silk handkèrchief, and keep it for that use only, shut up in a little box. You had best unscrew as little as possible, and replace each lens as soon as clean, lest you might forget its proper position.

Dust inside the object-glasses is difficult to reach, but by holding the open end of the object-glass downwards, the camel's-hair brush generally removes it, or a small pointed bit of wood may be required for pressing a piece of soft leather to clean near the edges of the lens. But all this must be as gentle as possible, and not to be done where it can be avoided. "Hard 
as the materials are (I quote from the Rev. T. W. Webb's book on the Telescope), scratching is an easy process; and the result of ordinary wiping may be seen in an old spectacle-glass held in the sunshine," completely covered with scratches: surely the most valuable part of a good microscope deserves better treatment. 


\section{CHAPTER III.}

\section{COLLECTION AND MOUNTING OF OBJECTB.}

ND now let us discourse about objects for the microscope. I hope the reader, by inspecting the plates, and reading the descriptions which follow these preliminary chapters, will find some objects easy both of attainment and preparation.

The collector of objects for the microscope will most probably have a bias in favour of some particular branch of Natural History. Entomology was my favourite pursuit, and this will account for the prominent place occupied in these pages by specimens taken from the insect world. Some observers may feel inclined rather to devote attention to other departments of nature, to which I have made but scanty allusion; my advice to each would be, collect as much as you can of the things you like best, and learn how to see and study them-all independent research, especially where you note down, and if possible, draw what you see,* is interesting, and may prove to be valuable.

* A camera-lucida is supplied, or an old one can be arranged, to fit on to the eye-piece of the microscope, and enable the observer tu see at once the magnified image of the object, and a sheet of papor on which to trace its outline. When the first difficulty in using it is mastered, it affords a valuable help in obtaining faithful drawings of objects. 
But, besides the class of objects which may happen to be especially interesting to you, you will also like to have a tolerable variety of miscellaneous things; and the collection of these will give interest to many a country ramble. In summer, especially, both land and water abound in wonders for the microscope, you will soon almost instinctively secure the minute lichen, the delicate frond of fern, the floating thistle-down, with a view to its subsequent inspection; and every pond will yield a rich supply both from the animal and regetable world.

No. 3 represents a group of implements suitable to a fisher for the microscope. Observe the little widemouthed bottle to carry your treasures, the long stick, to which a muslin net, a spoon, or a small cutting hook can be screwed-the latter being intended for obtaining pieces of water-weed, to which several microscopic plants and animals will be found adhering, and a live-box, which, with the Coddington lens, will be useful in enabling you to see on the spot what kind of success has attended you. Also the collector will probably ere long set up a box of odds and ends, which may come in usefully. It will look somewhat like the collection of things which the skilful fly-fisher gets together; and a description of it might suggest the contents of the witches' caldron to the reader's memory. For instance, hairs from valuable skins, as those of the tiger, lion, etc., fishes' eyes, remarkable feathers, scraps of eel's and sole's skin, and sundry cast-off entomological specimens, which most collectors of insects have to spare. 
These remarks may sufficiently suggest the methods by which the objects described in this book were got together; for it may be well to mention that I had the pleasure of preparing nearly all of them, as well as of drawing and describing them. I can therefore add from experience a few hints about what is called the "mounting" of microscopic objects, that is, of making preparations on glass slides similar to those supplied by opticians. Many things are fit to look at, especially with the lower powers of the microscope,

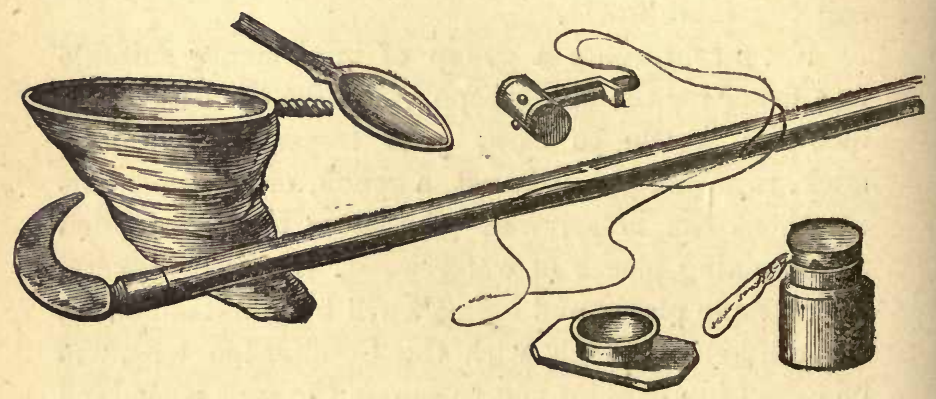

No. 3.-Group of implements for the collector.

by merely placing them on the stage, or holding them in the forceps; some should be put into the livebox; but the glass slide is perhaps the plan most frequently applicable, as a satisfactory way of preserving the object, and because the thin glass cover placed over it tends to produce flatness.

I have already advised that you should examine some slides supplied by an optician. If you do so, it will soon strike you that all are not prepared in the same mode. Some have on the centre a little raised 
cell of glass, or of some black composition, surrounding the object, filled with some oil or fluid, and covered with a thin glass; some appear to have the object merely placed on the slide and covered with the thin glass; while in a great number you will notice a peculiar clearness, as though they were incorporated with the substance of the slide itself. These three modes are known as mounting in fluid, mounting dry, and mounting in Canada balsam. The first mode is suitable for various soft and delicate structures, which require to be kept in a moistened state: it so happens that I have but seldom practised it ; full directions, however, occupying some pages, will be found in Dr. Carpenter's and in other works.

The best plan for mounting objects in the dry method appears to be this:-Take the object, for instance, the insect's wing on Plate II, fig. 2, after you have succeeded in spreading it with water and a camel's-hair brush on a piece of glass, and have carefully removed it when quite dry. Place it on the centre of the slide, and lay over it a little square or round piece of thin glass; hold this steadily down, and apply some thick gold-size neatly round its edges. This will fix on the cover, and can be afterwards neatly trimmed, and a piece of coloured paper with a round hole in the centre, pasted over the slide to preserve the edges of the cover from injury. The reason for using gold-size, instead of paste or gumwater, is that the slight moisture caused by the lastmentioned cements causes a kind of fungus or mouldlike plant to grow on and around the object, and 
disfigure it. I employed gam, however, in preparing several of my favourite slides, so small a quantity being used that but little harm followed. Probably, all preparers of microscopic objects have ways of their own, and this was mine:-The first thing to prepare was the coloured paper cover; and I invariably use emerald green paper, that I may recognize my own slides at a glance. Taking a sheet of this paper (to be had at any fancy stationer's), I make, with a pair of compasses, a number of those charming little concen-
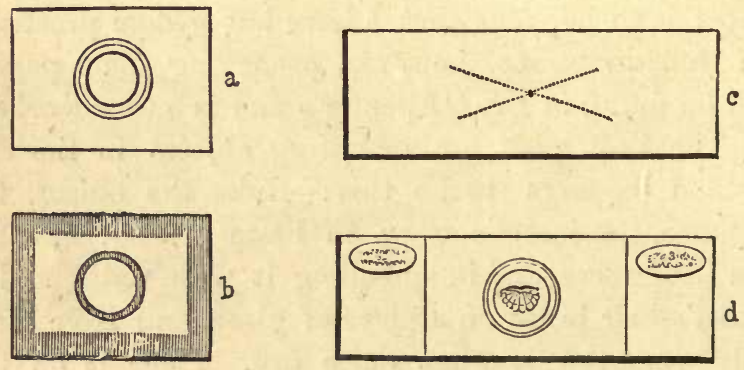

No. 4.-Method of Mounting Objects.

tric rings which are shown at No. 4, a. To cut up the paper into little pieces like $a$, about an inch and a half wide, and somewhat more than an inch high, and to cut out the central circles, are pleasant and easy tasks for spare moments. I generally make a great number, and leave the centres purposely of various sizes. When about to mount some objects-and, as must have been often observed in similar occupations, it is almost as easy to mount ten specimens, when one 
sets about it as only one-I pick out thin glass covers of corresponding sizes, each slightly larger than the circle which it is to fit; these I make perfectly bright and clean by rubbing with a soft handkerchief. Then I lay the little papers white side up, and putting some gum thinly round the aperture, lay the cover on it, $b$, and leave it to dry, endeavouring to put it out of the way of dust. When it is dry (and we know how quickly a thin coat of gum dries, as in an adhesive envelope if we want for any reason to open one which we have lately closed), I get the slide ready to have the object placed upon it, by first making it as bright as possible, and then placing an ink spot on the under surface of it to mark its centre, and of course to be afterwards rubbed off. If I wish the preparation to look very smart and precise, I rapidly rule ink lines from the opposite corners, knowing their crossing-point will be the exact middle of the slide, $c$. Just over that, on the upper surface, I lay the insect's wing; then painting a little gum near the edges of the paper, $b$, I lay it down over the wing, looking to see that the circle frames the object centrally, then I press it down, and lastly trim the projecting edges of green paper with a pair of scissors. If I feel it at all possible that I could forget the name of the specimen, I write it in a temporary way in ink somewhere on the glass; but ultimately, (namely, when I have a number of slides ready,) I place neatly upon the slide, $d$, two little cut-out green labels, ("to make the balance true,") the right-hand one with the name of the object, the left with the mag- 
nifying power and the mode of illumination which suit it, the latter particulars being given in some easily understood abbreviations.

The Canada balsam method involves more difficulty, and is most fully described both by Dr. Carpenter and Mr. Quekett, as well as in almost all works on the microscope. The balsam (which is a very pure turpentine) is placed warm on the slide, and the object is completely immersed in it. The glass cover is then put on, and in time, sometimes in a few hours, the balsam becomes quite hard, and the object remains fixed and bright, as a fly in amber. This method of mounting has many advantages : it adds greatly to the transparency of objects, thus allowing the details of their structure to be clearly seen, and it preserves them better than the dry method. Being a very "sticky" substance, it should be used in a careful and methodical manner. It ought to be kept in a wide-mouthed bottle, with a tall hollow stopper, like the bottles for gum, but instead of a brush there should be a glass rod, not fastened to the stopper, but projecting into it, while its lower end stands in the balsam. With this rod a single drop of the balsam is neatly placed on the slide, which is held over a spirit-lamp or laid on a tin vessel filled with boiling water. The great difficulty abont mounting in balsam consists in the trouble caused by air-bubbles appearing in it. When the drop is placed on the slide, a few of these bubbles may appear, but presently burst from the warmth; but no sooner is the object well sunk into it than a host of small bubbles 
ooze out in all directions; then more warming is done, and sometimes with success; the thin glass is gently pressed down over the object-all which is detailed in the works to which I have already referred.

I have always used, instead of a lamp or hot-water tin, a night-light for warming the slide; and I have found it necessary to pass the latter from end to end over the flame, as unequal heating would make it crack across. I sometimes found the air-bubbles dispelled by a drop of spirit of turpentine, but its introduction was generally accompanied by a great spreading of the balsam, and considerable stickiness about the whole affair; however, benzine, ether, or spirit of turpentine itself can be used to clean the slides that have suffered. The slides, when finished, so far as the placing of the thin glass over the objects, must be left to cool gradually, and then allowed to harden for some days, if in a warm place so much the better; and after that the superfluous balsam can be scraped away, and the slide cleaned with a rag soaked in benzine or turpentine. I generally cover the objects so prepared with green papers, similar to those for the dry objects; sometimes, however, "I leave them plain, with a view to employing the "Lieberkuhns" already described, which require light to be transmitted around the object. For the same reason I sometimes leave the paper which fastens on the thin glass in "dry" mounting merely large enough to answer the purpose, or make the aperture very large, employing as broad a piece of thin glass as I can find to cover the object. It is usual to write the. 
name of the preparation with a diamond on the glass; I prefer the little green labels, however, as they help to make the slide easily seen on a table, and I put these on, even if no other piece of green paper is admissible.

Many objects require special preparation, as flattening out, cleaning in ether, etc., before they are placed in the balsam. Some should be immersed for some days in caustic potash, which makes them soft and yielding; and all are rendered more manageable by leaving them awhile to soak in spirit of turpentine before placing them in the balsam. Some preparations will look badly, and even show air-bubbles when first done, and yet some months later, from their more complete hardening perhaps, be found free from defects. For this reason it is often worth while to keep apparent failures, consigning them to temporary oblivion, but scribbling upon them in ink any particulars worth recording. Slides, however, which are evidently hopeless failures can always be cleaned in spirits of turpentine, or in wood-naphtha, which dissolves the balsam very rapidly; and even the thin glasses can again be made available. Turpentine which has been used for cleaning purposes must not be employed in making new slides. And in all plans of mounting it is wise to work methodically, and have all requisites neatly arranged, or various odd matters may show themselves in the field of view with the object, such as fibres of wool, cotton, and flax from table covers and clothes; fibres of feathers from cushions, scales of clothes-moths, etc. 
And now, reader, for further information about microscopic objects I refer you to the coloured plates and the woodcuts which follow, and to my descriptions of them. The plan employed in their arrangement is this : we first go through a set of prepared objects, which could be shown on a winter evening, or at any time, and then we have an account of a summer entertainment, with the wonders to be observed in the structure of living things.

The coloured plates are all from my drawings, but for most of the illustrations of animalcules I am indebted to two or three experienced microscopists, as I have never systematically studied this class of objects, although I have repeatedly examined all to which I allude in these pages.

For the guidance of those who prepare their own microscopic objects, as all will do who possess and really value a microscope, I give a list of the objects in my plates which are mounted in balsam. It will be understood that those not included in this list are mounted in the dry method. Plate II., fig. $1, d$, figs. 8, 9 ; Plate I., fig. 8 ; Plate IV., figs. 2, 3 ; Plate V., figs. 1, 2, 3 ; Plate VI., figs. 1, 2, 3, 4, 10; Plate VII., fig. 10 . 


\section{CHAPTER IV.}

\section{STRUCTURE OF INSECTS' WINGS.}

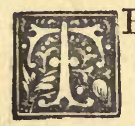

HE prettily-rounded wing occupying a central position (fig. 2) at the top of Plate II., is that of an earwig. If you feel surprised, reader, to hear that this rather unpopular creature possesses a pair of lovely rainbow-tinted wings, I must tell you that my wonder was at least equal to yours when I first succeeded in spreading them out, as in fig. 3. 'But, in fact, there are few insects without wings. The wings of moths and butterflies, of flies, bees, and wasps, and of the dragon-flies, so common every summer, are easily seen; but an almost equal variety of insects possess concealed wings, folded up beneath wing cases. And these wings are generally very beautiful and delicate, often showing rainbow colours just as a soap bubble does, in consequence of their extreme thinness; yet so well are they protected by the wing cases that they remain uninjured while their owner plunges into water, or gropes his way through the ground. Observe into how small a compass the delicate wing of the earwig can fold. Fig. 1, $a$, represents it when fully opened. At fig. $2, b$, you see it closing like a fan. Fig. $c$ shows the two 

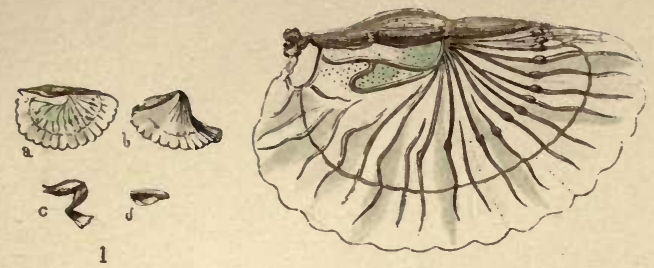

2

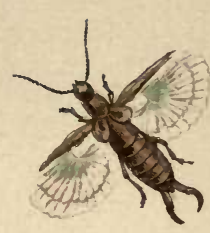

3
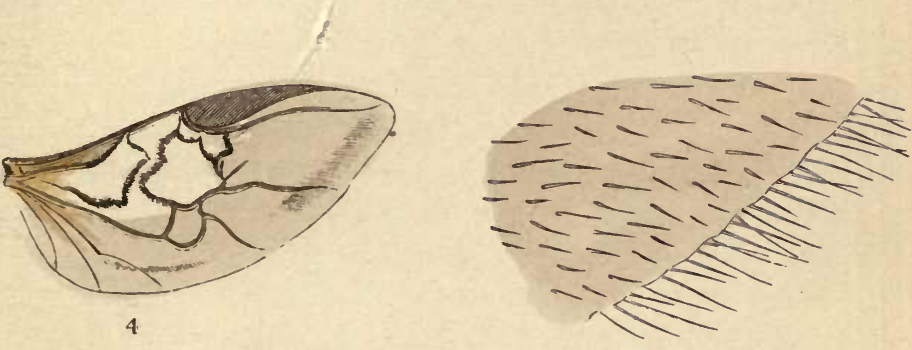

6

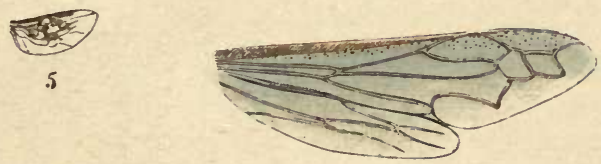

8

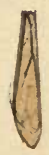

7
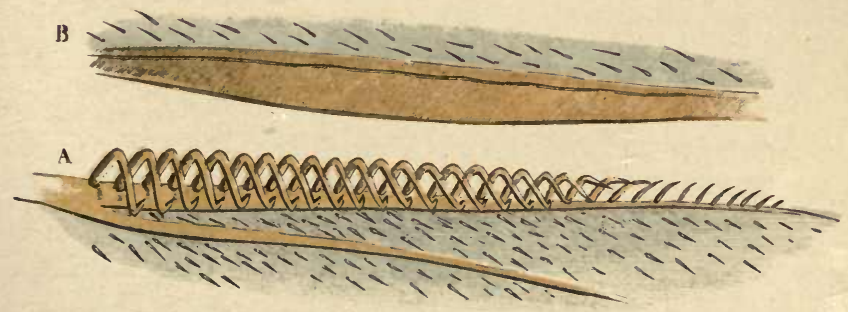

9

1. Wing of Earwig, shewing its method of folding up.

2. Wing of Earwig, magnifled 4 diameters. 3. Earwig flying, natural size.

4. Wing of Whirligig-beetle, magnified 5 diameters. 5. The same, natural size.

6. Minute portion of Beetle's wing, magnifled 420 diameters. 7. Wasp's wing, folded.

8. Wasp's wings, hooked together, magnified 3 dianeters.

9. Hooks on Wasp's wing, magnifled 60 diameters. 

bends which it then takes; and at $d$, how tidily it is packed ready to lay along the insect's back! But let us pause before we hurry it thus out of sight, and turn again to its pictured representation, fig. 2, as shown through a small magnifying-glass. The wing should be held somewhat obliquely to the light, and then the lovely colours, green, blue, red, and golden, gleam with a soft radiance.

Do you ask the reason why we examine this wing simply with a magnifying-glass, instead of with the large microscope? It is because, taking the entire wing, it is rather too large an object to be shown at once. The lowest power of my microscope is twenty diameters, and this object, you see, measures threeeighths of an inch in width, so that if magnified to twenty times that diameter, it would be shown a length of seven inches and a-half, and, turn it as you might, could not be fitted into a page of this book. And here, perhaps, the question may arise, "Is fig. 2 only four times larger than fig. 1, $a$ ?" The answer is, it is four times its diameter, and this is the measure employed in works on the microscope, and called the " linear measure." It signifies that the object, when stated to be, as in the present instance, "magnified four diameters," appears four times the height and four times the breadth that the unassisted eye observes it. The representation of the wing at fig. 2 , takes up sixteen times the space occupied by fig. 1, $a$; and that statement of the amount to which it is magnified is called the "superficial measure," or measure of the surface, and can always be calculated by squaring tho 
linear measure. Thus the wing represented at fig. 4, being magnified five diameters, is magnified twentyfive times by superficial measure, and the object represented at fig. 6, and described as being magnified 420 diameters, occupies a hundred and seventy-six thousand four hundred times more space than that of the minute structure itself. But the "linear measure" is in every way the best and most convenient method of stating the magnifying power employed.

The observer, after examining such an object as this earwig's wing with a magnifying-glass, will do well to submit it next to the lowest power of the compound microscope, when probably some minute details may appear demanding still further magnifying. A power of a hundred diameters in a good microscope is one which exhibits a great deal. The little folded wing, fig. $1, d$, is nicely shown with it; its nineteen folds may be seen squarely and neatly laid over each other; you reckon them as a shopman does the yards of silk in a folded piece. Then, see the wing itself with this power, you find it covered with very minuto round marks, and fringed round with fine hairs.

Beetles do not fold up their wings into so small a compass as those of the earwig, and accordingly tho strong ribs or nervures are differently arranged. No. 5 represents the folded-up wing of the whirligig beetle (Gyrinus natator), a little water-insect, remarkable for its habit of whirling round on the surface of ponds and brooks.* This wing, when expanded, appears as in fig. 4, Plate II. With this low magnifying power

* A figure of this beetle will be found in Chapter VII. 
we can detect on its surface some pattern or graining of wonderful delicacy and minuteness. To examine this, we apply one of the high powers of the microscope, attending, however, to the rule, to use the lowest with which we can clearly see what we require. How exquisite, how delicately finished is the appearance of this little wing. An artist's eye looks with pleasure on the bold curves and rich brown colour of the large nervures, and the beautiful regularity of the

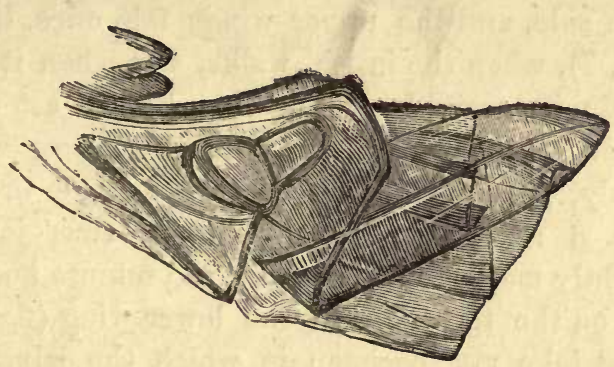

No. 5.-Folded Wing of Whirligig Beetle, magnified 15 diameters.

smaller markings. These prove to consist of tens of thousands of delicate hairs, while the wing is edged with somewhat longer ones. I have drawn a very small portion of the wing magnified 420 diameters. Were I to represent the entire wing on this scale, I must make it more than ten feet long; yet it is ornamented with the same beautiful regularity over the whole surface. Will you look, reader, at the real size of the wing, and judge what must be the minuteness of its delicate adornment? 
In the wasp's wings, represented at fig. 8, we have to admire their evident adaptation to the insect's mode of life, as well as their beauty. They are not so carefully stowed away as those of the earwig or beetle, as it wants to fly so much more frequently. Yet wasps often go into the ground - and bees (whose wings much resemble those of wasps) creep into very small flowers-therefore a pair of large broad wings would be in their way. The contrivance they are supplied with is very curious. They have four wings, two on each side, and the upper wings fold once, lengthwise (fig. 7), when the insect walks, but when it prepares to $f y$, it straightens this wing by the act of raising it, and the same action hooks the lower wing to it firmly, giving it all the force of a single broad wing. Fig. 8 represents the two wings thus joined, and slightly magnified. To show the minute hooks which are on the top edge of the lower wing (fig. 9, A,) I must take my specimen in which the wings are prepared separated from each other, and will magnify them sixty diameters. The part of the wing on which the hooks are placed is very small, not more than one-twentieth of an inch in length. They clasp firmly over a projecting ledge on the upper wing (fig. 9, B). This is best understood by observing a preparation (as in fig. 8), where the wings are mounted ready clasped, and examining them on both sides.

The dragon-fly's wings, which never require to be folded up or reduced in size, are formed for strength and lightness, and evidently for beauty too. The 
wings of the small dragon-flies, so common through the greater part of summer, with bright blue, or oftener red, bodies, are beautifully transparent, consisting of a delicate membrane, stretched, as it were, to a sort of ornamental network. Another dragon-fly, rather larger, and fith a metallic-looking bluish green body, has more minute divisions in its wings, and in each wing a brownish patch of shading, producing a very soft appearance. It has not the little black spot seen in the smaller species; it seems as if that ornament would not be in keeping with its softer shades.

But the wing which I have always thought the most curious in my collection is that of a little beetle, so small as to possess (so far as I know) no popular name, but which in learned language, boasts an appellation of no less than nine syllables-"Trichopteryx atomaria." It is a very lively, active little creature, common under moss in spring; and is to be observed like the larger insects coming forth in the summer sunshine, and taking short but energetic flights. Its wings are unusually narrow, and each fringed with hairs half the length of the wing itself. This long fringe surrounds it except in two places at the centre, where the wing doubles up so as to allow it to fold easily; here it is replaced by short hairs. I have a slide, showing the folded wing and its case prepared side by side, and I can see that there is a sharply-creased "plait" or "tuck" in this central part, which shortens the narrow shaft of the wing; then the point of this shaft is doubled up, then another fold stows all away neatly, and all the longer 
hairs point nicely downward; while the little wing occupies less space than the wing-case which is to cover it.

The hairs on this wing require minute exammation. With even so high a power as 100 diameters, we fail to make them out; but a power of 200 shows them to be each fringed again like a feather, and the same power shows that at the base of each of the little wing-cases, which measure at their broadest part only one sixty-second of an inch, there is a delicate little comb formed with beautiful regularity, and having (as I ascertained with the highest power of my microscope*) one hundred and twenty teeth! I imagine its use may be to remove all particles of dust from the long feathery wings before the wingcases close over them. The thinly-scattered strong bristles on the wing-case contrast with the regular appearance of the tiny comb.

* 900 diameters. It may interest the reader to hear that $\mathrm{Mr}$. Spence, the late celebrated entomologist, in acknowledging an account which I sent to him of some of the above objects, wrote, "I was especially pleased with the figare and description of the comb-like appendage to the elytra [wing-cases] of the minute beetle, so admirably figured, of the existence of which appendage $I$ was not at all aware, never having examined this species with a powerful lens." 


\section{CHAPTER $\nabla$.}

\section{SCALES OF INSECTS AND FISE.}

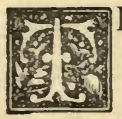

HE wings of moths and butterflies are actually very like those of flies and wasps, etc. They are thin and transparent in themselves, but covered on both sides with beautiful scales, laid in rows like the feathers on a bird, each row, in the generality of specimens, overlapping a portion of the next, so as to give to their surface, when sufficiently magnified, very much the appearance of being tiled like the roof of a house. Each scale has a small footstalk, (Plate I., fig. 8, and Plate III., fig. 10,) which fits into a minute socket on the transparent membrane of the wing. The arrangement of the minute sockets is well shown by making a preparation of a butterfly's wing nearly divested of its scales. A good deal of washing and rubbing will be found necessary to remove them, and then the object is one from which, when dry, mounted on a slide, and viewed by transmitted light, a good deal may be learned.

But the wings in their natural condition, viewed as opaque objects, are among the most lovely spectacles presented to us by the microscope. Their appearance strikes us with new wonder, as we observe the beau- 
tiful harmony of their hues, and the elegance of their adornment. The wings are the only part generally mounted for the microscope; but if a whole butterfly is examined, which may be safely and easily done by removing one from an entomologist's collection and sticking its pin into a morsel of cork, which is generally to be found in the handle of the stage forceps, it will be seen that the whole bodies of these insects also are clothed with scales.

In exhibiting the wings of moths and butterflies the effect is much heightened by a proper arrangement of the light, which should be placed so as to throw an artistic shadow from every scale. This suggestion may seem a trifle, but the trite maxim concerning trifles tending to produce perfection will excuse its being made.

Fig. 2 shows the scales of a moth very common on fine evenings in June, called the "ghost moth;" they are very like bay leaves in shape. The scales on the inside of the wing are different, and thinly scattered (fig. 3). The wings of this moth are yellowish, having (on the upper sides) what look like delicately-painted streaks of pink; these are red scales.

Some of the scales of moths and butterflies will be admired for their delicate hues; others shine with a brilliant metallic lustre, to which the best painted representation could scarcely do justice. The "little green Forester-moth" (fig. 4) is one of these; it has scales of two different shapes on its wings (fig. 5), the longer being brilliant yellowish green, and the shorter 
bluish green. When highly magnified, the scales of this moth are seen to be covered with a sort of ornamental carving; each of the larger scales has six or seven ridges on it, and rows of hollows between (fig 6). The smaller scales are very similarly ornamented with a pattern not quite so much raised.

This little moth is common in the beginning of June. There is another, somewhat like it in shape, and still commoner at the same time of year; it is called the Burnet-moth (fig. 7). Its upper wings are of a beautiful, very dark green, with round red spots; its lower wings red, edged with bluish black. The dark green scales are glossy like satin, and the red very bright in colour, but dull like cloth or flock paper. This variety of surface forms a very striking contrast. The dark scales of the Burnet-moth are sculptured in a way similar to those of the green Forester. When these scales are viewed as transparent objects, they no longer appear green, but the pattern on them, when viewed with a high magnifying power, assumes a strange and almost startling appearance.

It must be remembered how small these scales are. They are only like the finest dust or powder, and a single one could scarcely be seen with the naked eye. Yet every scale may be seen (with a magnifying power of 150) to be marked with some dozen lines, clear and sharp as staves of music, and between them are rows of characters wonderfully resembling some old Babylonish inscription (fig. 8).*

* The figure represents this object magnified 420 diameters, not 150. It could, however, be sufficiently well seen with the latter 
The scales of the green Forester-moth are somewhat similarly inscribed, but not with equal distinctness.

Let us again adjust the microscope to view "opaque objects," and feast our eyes on a few more specimens of Nature's mosaic work. The wings of butterflies and moths have been compared to patterns in mosaic ; though of course there is this great difference, that the pieces of mosaic are inlaid; whereas the scales of these insects, as I have already said, lie over each other like feathers, fishes' scales, or tiles on a roof. Still their general flatness, and the fact of their delicate shades being usually caused by hundreds of minute scales-the dark or light ones in greater or less number according to the hue required-originated the comparison.

I have examined some, however, in which the effect of the shading is heightened in a way inadmissible in mosaic work, but sometimes employed by painters. It sometimes happens, that when an artist is painting-for instance a landscape-and wishes to bring out a rock or tree very vividly, he finds it necessary to make a roughness on that part of his canvas. A painter, whose works are familiar to many, on one occasion actually made th - surface of his picture rough by causing a small quantity of sand to adhere to the canvas, and it had the desired effect of giving brightness to what was then painted over it.

Now there is a yellowish-brown insect called the

power, although the additional size gained by further magnifying makes it easier to engrave. The same remark applies to many othur objects represented in this work. 

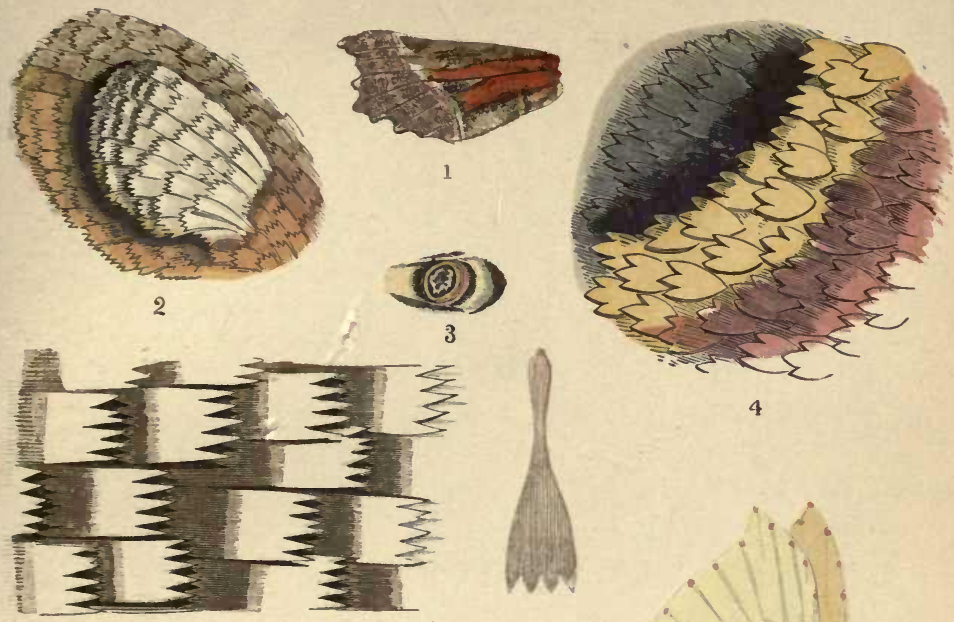

5

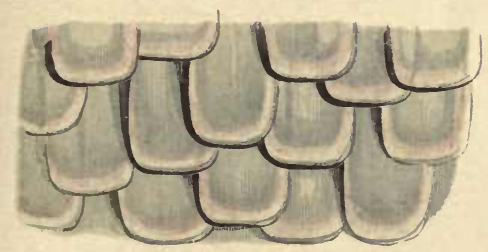

9

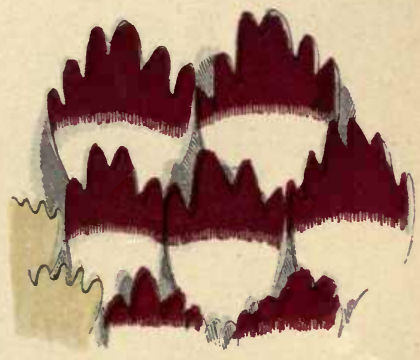

10

s

1. Wing of Herald Moth. 2. Stot on Herald Moth's wing, magnified 60 diameters.

3. Eye-like siot on wing of Emperor Muth.

4. Part of eye-like spot, magd. 60 diams.

5. Scales of Underwing Moth, magnified 80 diameters.

7. Brimstone Butterfly. 8. Scales of Brimstone Butterfly, magnified 150 diameters.

9. Seales of Red Admiral Butterfly, magnified 100 diameters. 10. Scale, magd. 150 diams. 

Herald-moth, with one conspicuous white spot on each of its upper wings, shining like a star, or with the peculiar brightness that this representation of it (Plate III., fig. 1) would exhibit if we were to prick it with a pin and hold it up to the light. On examining it with the microscope, I found that this spot consisted of a thick tuft of white scales, almost like a little brush, and standing up much higher than the surrounding parts of the wing (fig. 2).

In like manner the scales of the Emperor-moth, a large insect with an eye-like spot in each wing, are rendered much more ornamental by being set sloping upwards instead of nearly level. There is a beautiful semi-transparency in the wings of this moth, owing to the thinness with which its scales are scattered; but their sloping arrangement gives brilliancy at the same time. It is, of course, difficult to represent it on a flat piece of paper. The eye-like spots are each about the size of fig. 3, and fig. 4 is intended for a small part of one of them, magnified sixty diameters. The colours are white, morone crimson, a sort of straw-colour and black, a beautiful and harmonious mixture.

- have noticed another deviation from the plan of mosaic work in the wing of a moth-one of the tribe of "Yellow Underwing." The wing is rather dingy, but with a silvery gloss in some parts, which induced me to examine it. I found that the scales themselves were shaded. In one place, for instance, where the wing is brown and white, the microscope showed that instead of having rows of white scales and of brown 
ones, the same scale was white and brown, and a very curious and pretty effect it has (fig. 5).

The edges of moths and butterflies' wings are highly ornamented. The scales are long, and generally shaped like fig. 6 .

You have probably observed the Brimstone Butterfly (fig. 7). It appears in spring, and looks almost like a faded lime-leaf. You may observe some spots on the edge of this butterfly's wings; they are very small, and appear a sort of rust-colour, but through the microscope they are white scales tipped with pink, shaded like those of the moth described last. Fig. 8 represents a few of them magnified 150 diameters. Such a group, presenting as it does so little apparent resemblance to the object to which it belongs, often perplexes the beholders not a little, and tempts them to describe it by far-fetched comparisons. For instance, the friends to whom I first showed this object bestowed on it the name of "the Alps at daybreak" -the sun commencing to shine on the mountains covered with snow, and the yellow scales below resembling foreground vegetation!

Fig. 9 represents some scales from the under side of the red Admiral Butterfly's wing, giving an example of another and not unusual shape. Each scale is covered with a number of lines, which look as if they were ruled on it with the utmost precision (fig. 10). These fine lines are observed on the scales of many butterflies and moths. A very high magnifying power generally shows them to be slightly waved, and frequently crossed by a scond set of lines of extreme 
minuteness. The degree of distinctness with which these markings can be shown with various magnifying powers forms a useful test of the excellence of the microscope employed, and scales mounted for this special purpose are supplied by opticians as "testobjects."

So much for the scales of moths and butterflies. Some other insects, including several beetles, are also ornamented with scales. In fact, whenever I see an insect presenting the peculiarly powdery soft appearance of a moth or butterfly's wing, I always guess it has scales, and generally find my supposition correct. The Weevils (Curculionidoe is the learned name) are a tribe of beetles in which these scales may be well observed. One of them is represented at Plate IV., fig. 1. It is a dingy slow-moving little beetle; but how differently we regard it after we have once seen it in the microscope! When magnified slightly we see that it is covered, or rather sprinkled over with beautiful little roundish scales, arranged with considerable regularity. These scales, when magnified 100 diameters, gleam each like a scallopshell of burnished gold, and placed on the dark wingcase of the beetle, are truly splendid (fig. 2).

There is another Curculio, somewhat similar in shape to this one, but smaller and more promising in appearance, as it is of a silvery green colour. It is very common in April and May; I have seen hundreds on large beech-trees. Its body is really black, with green scales of surpassing brilliancy. Fig. 3 gives an idea of their shape and arrangement, but no 
drawing could convey an idea of their radiant brilliancy and lovely colour.

These two last-mentioned objects are exceedingly interesting when viewed by transmitted light; small fragments of them should be mounted for this purpose. The shell of the brown beetle (fig. 2) appears of a fine golden hue. The scales are of the same colour, but appear as if sharply drawn in pen-and-ink lines; and in the vacant spaces the whole shell is covered with a very curious system of lines, crossing each other in the way called "cross-hatching" by engravers. This same singular appearance occurs also in the shell of the green weevil, and with many variations as to arrangement and size, in all weevils which I have happened to examine. It is particularly conspicuous in the diamond beetle of Brazil, which is also one of the weevils, and well known as a splendid microscopic object when viewed by reflected light.

The green weevil's shell shows still better than that of the brown, as a transparent object. We see the same golden ground, but the scales, instead of being colourless, become a lovely red, tinged with orange when over the wing-case, and with bluish pink when they happen to show beyond the edge of the fragment.

The scales of fishes are interesting and pretty objects when viewed with the lower powers of the microscope. Fig. 4 represents the scale of the perch. When magnified four dianeters we can easily make out the graceful curving lines which cover it; these lines appear as if continuous, and parallel to each other. 
They are not quite so, however, in reality, and a sketch of them, when magnified eighty diameters, will best explain their appearance (fig. 5).

The scales of the sole, and of many other fish, are covered with similar lines. A sole's scale is represented in fig. 6. The lines on it are coarser than those in the perch's scale, except just in the centre near the ray-like spikes, where there are some finer lines curiously arranged. These spikes are the part of the scale which are outside, and give its roughness to a sole's skin. The other end is the root of the scale, and is rather deeply sunk in the skin.

The eel's scales are concealed altogether. When I first began to prepare objects for the microscope, I read in some old book that these were worth looking at; so I procured a dry piece of eel-skin, but it was long before I could find what I was in search of. I scraped and scraped with a knife, and examined the scrapings with a microscope, magnifying them 20 times -40 times-perhaps 100-but no scales appeared. I forget how I contrived to make them out at last. But if I take a little piece of eel-skin and view it as a transparent object, magnified rather more than four diameters, the first thing I see is that the skin is covered with star-like spots, and next I observe the scales lying close together (fig. 7). And this is the way to get at them:-I take the little scrap of skin and tear it in two, exactly as if I were splitting a card, for the skin consists of two layers. I can then quite plainly see the scales sticking to the under surface of the spotted piece, that is, lying between 
the two layers. I can easily lift them off with a knife, and mount them for the microscope, while the skin makes another very pretty object for it, not unlike the spotted coat of a leopard. Four of the scales, and the divided portions of the skin, are represented in fig. 8 ; and fig. 9 is the smallest of these scales magnified fifty diameters. The kind of network pattern is of the same fineness on the larger scales.

The account which Dr. Carpenter gives of this apparent network is that the scale consists of "a layer of isolated spheroidal transparent bodies, imbedded in a plate of like transparence ;" and these, he adds, "appear not to be cells (as they might readily be supposed to be), but to be concretions of carbonate of lime." These pretty little scales are white, and, viewed as opaque objects, they look like black lace; viewed transparently they are like black lace, or like white lace held up to the light. The apparent holes are the "spheroidal transparent bodies" described by Dr. Carpenter, and his remark on the transparency of the layer which encloses them is verified when the scales are mounted in balsam, as they then become nearly invisible in all ordinary . modes of illumination.

They appear, however, in much splendour in the "polarizing apparatus" of the microscope, to which I have already alluded (p. 6) as one of the luxuries which can be dispensed with by a purchaser who is limited as to the price of his instrument. It can, however, be added to most cheap microscopes of good construction, and is, as a matter of course, an 
accompaniment of the large and expensive ones. This apparatus consists of two prisms, one arranged to fasten below the stage, the other to slip over the eye-glass; and the object to be shown by transmitted light from the mirror. By this arrangement, various splendid colours are exhibited, and the effect is further heightened by placing on the stage immediately under the object, a slide containing a thin plate of the mineral "selenite," which, when mounted in balsam, is perfectly transparent, indeed invisible, in the ordinary mode of illumination. A description of the appearance of the eel's scale, when viewed with the polarizing apparatus, will serve as a specimen of the effects produced by this mode of exhibition.

The scale (fig. 9), which can with difficulty be seen by common light, now appears, in a particular arrangement of the prisms, to be projected on a black ground, and to be of a beautiful silvery grey, nearly white at the edges, and softly shaded to a deeper tint at the centre; and conspicuously placed over its surface are two large black marks, similar to two V's placed point to point, thus $\gg<$, making a figure like a St. Andrew's cross over the whole scale; and these also are very softly shaded at their edges. Now I make the upper prism revolve slightly; the two V's commence to revolve also, but presently become much wider, and gradually change to a pale brown, while the vacant part of the slide changes from black to light grey; till, on the prism having turned one quarter of the way round, two pale and nearly white marks occupy the places of the original black V's, the broad 
intermediate spaces are light brown, and the background is white. The prism continuing to revolve till half way round, exhibits the brown spaces turning, and gradually forming into vivid black V's as at first; and as it revolves through quarters three and four, appearances exactly similar to those described in quarters one and two are exhibited.

I now remove the slide of eel's scales for a few minutes, and place that containing the selenite on the stage, while the upper prism remains in the position number one. The whole field of view, instead of being simply colourless, appears of a rich yellow. I begin to turn the prism-the yellow fades into white, then this changes to pearl-colour, and then to brilliant blue, by which time the prism has only revolved an eighth. Continuing to turn the prism, I observe the blue becoming pale much more slowly than was the case with the yellow, and the prism has reached nearly three-eighths of the way round before the field of view has changed to white. Then it quickly changes to yellow, assuming the brightest shade of that colour when the prism is just half way round. Then blue comes with speed as before, and slowly fades, till yellow takes its place in the original position.

Now, leaving the selenite on the stage, I place the eel's scale over it. What a richly-coloured object it has become, all pink, orange, and green. Some traces remain of the pair of V's, which would appear there if the selenite were absent, but instead of being jet black they are orange, the inside of the V's is pink, and the broad outer spaces are emerald green, while 


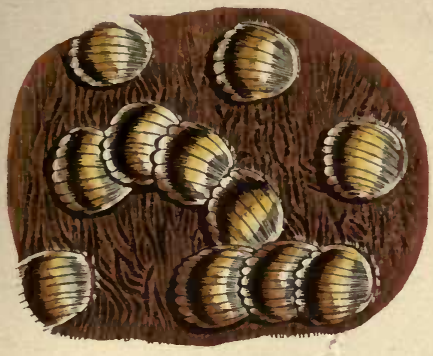

2

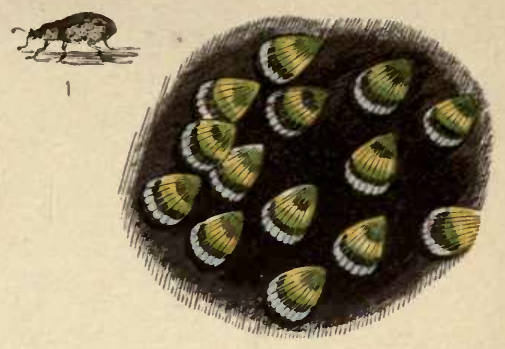

3
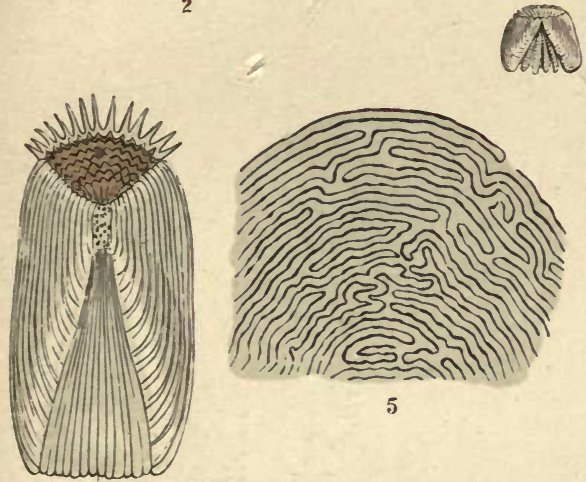

5

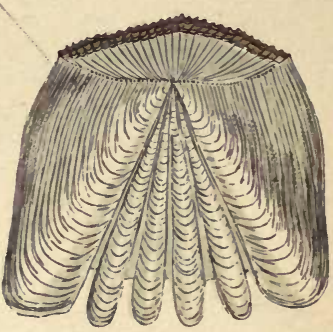

4

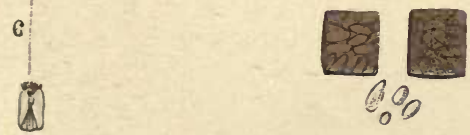

S

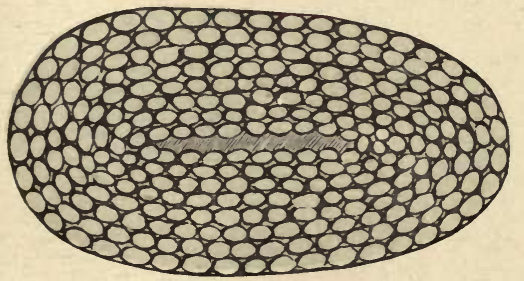

9

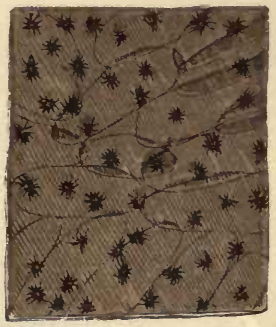

7

1. Weevil, natural size. 2. Scales of Weevil, magnified 100 diameters.

3. Scales of Green Weeril, magnified l:0 diameters. 4. Seale of Perch, magnified 4 diameters.

5. Lines on Perch's scale, magnified 100 diameters. 6. Scale of Sole, magnified 9 diameters.

7. Piece of Eel's Skin, magnified 4 diameters.

8. Upper and under layers of Eel-skin, and Eel scales. 9. Scale of Eel, magnified 50 diameters. 


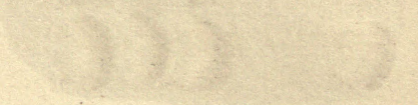


all around is the bright yellow background. As the prism revolves the coloured portions of the scale seem to revolve and change colour. When the selenite appears blue the letter $V$ 's are blue, the angle inside emerald green, and the exterior spaces deep pink; and this rotation of colours continues till the prism has gone all round. Now this is the kind of effect which the polarizing apparatus exhibits. The black cross is shown on many objects, and the bright colours appear in many others, with and without the selenite. It is an exhibition which causes a good deal of pleasure and surprise, and I have often enjoyed studying its phenomena. Yet in general I scarcely like to bring it forward, feeling that the circumstances of illumination under which objects are shown with the polarizing apparatus are so peculiar, that I could not answer the question, "Is it true?"* with the same unreserved affirmative that I should employ in vouch. ing for the appearance of objects shown in ordinary light. It may be asked, "Could not the principle of polarization be explained at the time the objects are shown, so that observers might take an intelligent interest in the subject?" To this I would answer that some very deep principles of optics are involved in the matter, and that the full explanation requires a good deal of time, and would be unsuited alike to a popular exhibition of the microscope, or to the plan of a work like the present.

A few words might however be said to give a general idea of the effect of polarization, and the

* See anecdote in the Preface. 
remarks in a recent work on microscopic objects are so much in point that I will repeat them without abridgment.*

"The effect of polarized light is not only beautiful to the eye, but of real use to the investigator of tissues, and in the researches of the pathologist, for by it the true structure of organic bodies may often be made clear, when the ordinary white light has failed to develop it." Here I may remark that a great number of structures are not acted on by polarized light; for instance, the butterfly's wing partly divested of scales, remains simply transparent during the whole revolution of the prism; and useful information may be gained by observing whether an object polarizes or not; and this holds good alike of microscopic revelations and those of the telescope. The writer continues, "Hardly in a concise manner can the question be answered which is so often asked, 'Why are these objects so coloured, and what is polarized light?' But I may briefly explain that rays of light reflected from a body under special conditions, or transmitted through certain transparent crystals, undergo such change in their properties, that they are no longer subject to the same effects of reflection and refraction as before.

"The common ray of light may be compared to a glass rod, smooth and white, uniform in texture, whilst the polarized ray is smooth on one side, rough and dark on the other. How it becomes so requires

"From "Objects for the Microscope," by L. Lane Clarke. Groombridge and Sons, London. 
too long a dissertation on the laws of light and colour; but so it is. And when this polarized ray is either thrown upon or transmitted through various substances, it is either reflected, or absorbed and extinguished, according to the structure of the object presented to it. The most brilliant colours are developed by this process, especially in crystals, feathers, sections of quill, bone, hoof, horn. A good selection of these objects is of value to the microscopist." 


\section{CHAPTER VI.}

HAIRS AND FEATHERS.

Fen scales of fishes, as Dr. Carpenter tells us, are developed in the substance of the true skin; whereas the scales of reptiles, the feathers of birds, and the hairs of quadrupeds are formed upon its surface, and allied in structure to the epidermis or scarf-skin. They are essentially composed of collections of cells, and form examples of innumerable structures in which cellular formation may be observed. In fact the microscope reveals to us that all animal and vegetable structures are developed from cells, and the reader will find a lucid and interesting account of their formation and changes in "Hogg on the Microscope," p. 527, etc.

Hairs and feathers are formed and developed on the same plan essentially. They both grow from a root, by continual additions of cells to the lower parts, which cells become elongated, and push the hair or feather farther and farther upward, and thus it lengthens. When we pull a hair up "by the root," we see a little bulb, which is filled with soft pulpy cells, and this bulb corresponds to the quill of a feather, also containing a soft pulp while grow- 
ing, the shrivelled remains of which in a fullgrown quill must be familiar to every one who has mended a pen.

The quill of a feather, then resembles the root of a hair; and in like manner, its stem, namely, the remaining part of the feather, corresponds to the shaft of the hair. When you have mended the same pen so often that very little quill is left, you will observe by cutting off its last remnant, that the stem of the feather consists of a horny sheath enclosing a white pith-like substance. These two parts have received the names of the "cortical" and "medullary" substances; and closely correspond with the component parts of hairs, as shown by the microscope. The minute size of hairs as compared to feathers is an obstacle to our readily understanding their structure; on the other hand, the beautiful transparency of the outside, or "cortical substance," enables us to view them to great advantage when assisted by a good microscope. The figures in Plate $\mathrm{V}$. give representations of the appearance of various hairs when highly magnified. Let us examine the first of them, namely, the white mouse's hair, represented in Plate V., fig. 1. Those who are shown it for the first time are sure, after a brief survey, to look round appealingly for an explanation of what they have seen, the object is so unlike anything in their previous experience. It resembles a number of beautiful glass rods of various thickness, each containing a running pattern in its centre. That running pattern engrosses all attention at first; and next comes the question, why are the 
hairs of such different sizes? But this is never asked till the first great puzzle is in some sort got over, as to the curious running patterns, resembling a sort of jointed chain in the larger hairs, and a simple row of beads in the smaller. Let us therefore now study them in the light of the remarks lately made on the structure of hair, how that it generally consists of a cortical or investing substance, of a dense horny texture, and a medullary or pith-like substance, usually much softer, and occupying the interior. Now in the hair of the white mouse both can be very well seen; the apparent glass rods are the cortical substance or rind of the hair, and the chain-like patterns which they enclose are the medullary substance or pith. This consists entirely of cells, which vary in shape and arrangement in the hairs of different animals. In the mouse you see they are large and distinct, and arranged in rows. In some hairs of the rabbit they lie like the grains on an ear of Indian corn. In the cat they are closely laid together, and this is the case also with the otter; but at this object I imagine you will pause and inquire, "What is this scale-like appearance on the otter's hair ?" and in reply I ask you to remember that " all animal and vegetable structures are developed from cells," and that the rind or cortical substance of hairs has been formed by a succession of cells, which at its surface become flattened into scales as the hair grows.

The otter's hair shows this scaly structure to great advantage.

The internal cells of the mouse's hair show in a 
marked and interesting way the pigment cells on which principally depends the colour of the hair. In the hair of the white mouse (Plate V., fig. 1) these cells cannot be perceived; but in those of the common mouse (fig. 2) there is a scrap of colouring matter in each cell, and those little dark spots, seen through the transparent surface of the hair, give to it its dark colour. Yet how is it about the position of these dark spots? for when we compare figs. 1 and 2, we observe that the remarkable projections (reminding one of a succession of vertebroe) are alike empty in both figures, the little blocks of colouring matter occupying the intervening spaces. Are these projections then not cells after all, but solid partitions of some kind? No, they are air-filled cells ; we know this by their appearance when the hair is mounted in balsam, for they absorb light, and assume a dark and decided appearance, just as the obnoxious air-bubbles which so often annoy the microscopist when mounting objects; and moreover we can often contrive by heating the glass slide over a flame to get some of the air out of the end of the hair, and completely penetrate it with the balsam. Then the white mouse's hair becomes nearly invisible, except about the point where the balsam ceases to penetrate, and there a cell or two remains only half full of air, resolved into a round bubble; and the brown mouse's hair shows the portions of "pigment" standing out in beautiful distinctness and regularity. It would seem that there are two kinds of cell in the pith of the mouse's hair, which we may call vacant cells and pigment cells, the 
former reminding one of a long corridor or gallery with numerous recesses on either side, while the latter would be represented by sundry glass cases filled with valuables, standing at regular intervals on its floor, and inserted in its walls. You will also see that the dots of pigment in the finer hairs also are placed between the strongly-marked "beads" instead of within them; and the mention of these finer hairs brings us to another question often asked by observers, Why has the same animal apparently so great a variety of hairs? For instance in the otter's, we see a large yellowish hair with brown centre, a transparent hair with lengthened scales, and three very small chain-like hairs. And human hair is of many different diameters.

This apparent variety of size, which happens to add a good deal to the effect of a group of hairs as seen with high magnifying powers, is caused by three different circumstances. Firstly, many animals have two kinds, namely, firm and long hairs, and fine down. Secondly, many hairs are somewhat flat, and therefore look narrowest when seen edgewise. Thirdly, the hairs of many animals are differently formed in different parts of their length.

The next remark may be that the distinctions of rind and pith do not seem to hold good with all the hairs. True enough; and this sort of variety meets us in many natural history researches. A general rule is stated, and then the words "frequently," " commonly," or, as the old adage has it, "almost and very nigh," have to be put in to prevent mis- 



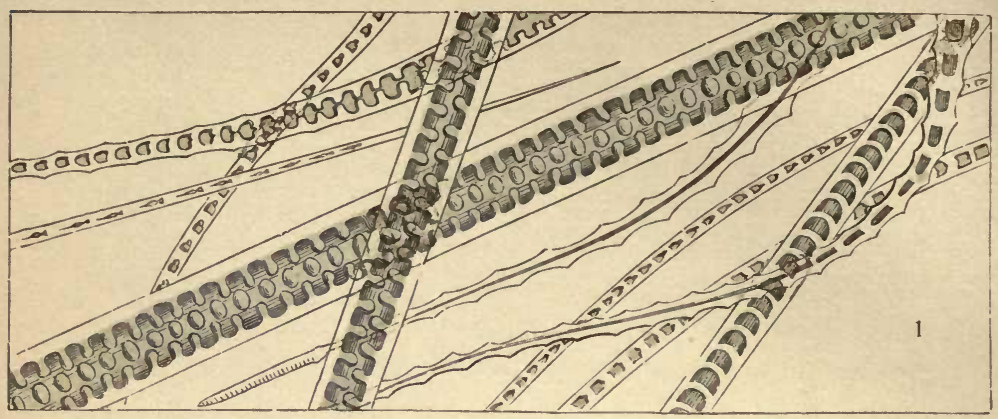

1. IIair of White Mutse.

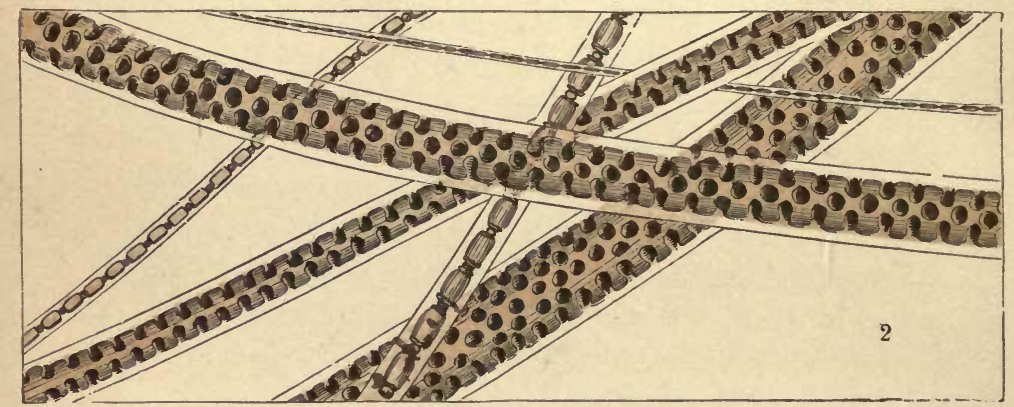

2. IIair of Common Mousc.

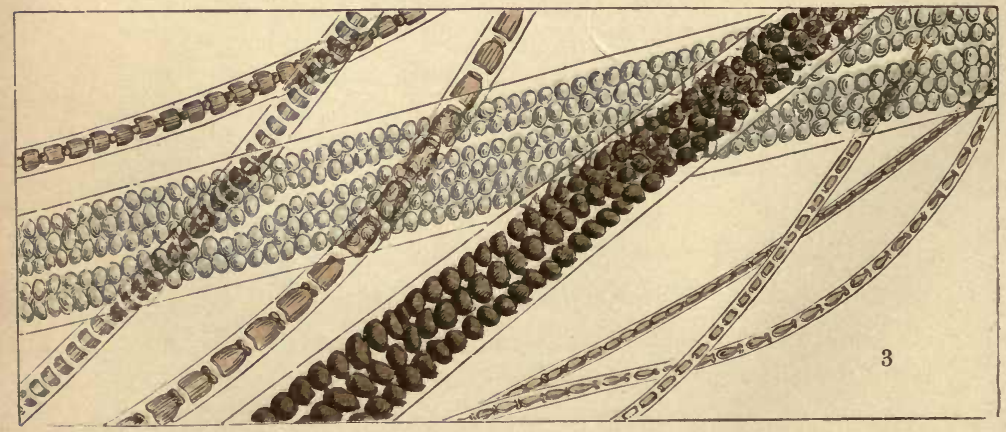

3. Hair of Rabbit. 
takes. For, observe the hair of the horse in which the pith is narrow and interrupted in two specimens, and altogether absent in a third, and some specimens of wool, in none of which it occurs ; and on the other hand, the hair of the fallow-deer, almost entirely made up of cells, and in which the rind can only be seen as a very thin layer at each side.

In that of the musk-deer (a few specimens of which reached me, after coming in a letter from India on chance of their proving interesting) the cortical substance may be said to be reduced to a minimum. For I observe the hair to be composed from edge to edge of angular cells (which have been well compared to the cellular tissue of vegetables), and I miss the thin layer of rind observable in the fallow-deer's hair. But, adjusting the microscope so as to catch the exact focus for this edge, a faint appearance of overlapping scales can be detected. On again altering the focus to catch the surface of the hair, I see the outside set of cells terminating in a beautiful kind of network, much resembling Gothic tracery, and very similar to that of the fallow-deer, and in a specimen mounted in balsam this appears to be the real outside of the hair. But on examining one mounted dry I perceive the scales as a film of utmost delicacy just concealing the Gothic tracery slightly, as a piece of tissue paper would veil the page you are reading if laid over it; and the overlapping edges of the scales appear very similar to those on the broad parts of the otter's hair.

And now, as to human hair, about which I can imagine the reader has been wishing to hear. Is it all 
rind or all pith? Following Dr. Carpenter's account of it, I have to state that it approaches most to the latter condition, but is peculiar in its structure. When the focus of the microscope is very carefully adjusted, I can see a thin transparent layer edging each side of the hair, just as in the deer's hair. Within this layer is the cellular substance that constitutes the principal part of the hair, the numerous straight lines marking the form which the cells have taken. The hair owes its hue to the pigment contained in some of the cells; and the grey colour which gradually steals through one's hair, placing a line of silver here and there, is caused by the absence of the pigment.

A section made transversely (that is, across, as you would slice a cucumber, or cut a lemon in two) shows the outer rind of the hair clearly as a transparent structure. Occasionally there is a distinct line of large cells in human hair in the centre of the small and lengthened ones, giving an appearance somewhat resembling that in the larger hair of the horse, and some writers regard these as the only portion properly called medullary; but good reasons have been given for considering both kinds of cells as equivalent to the medullary substance in other hairs, and giving the appellation of "cortical" to the thin transparent outside layer, and the delicate overlapping scales, which show on a specimen mounted dry. The examination of the root of a hair is easily managed, and interesting when a high magnifying power is at command. The root should be placed on a glass slide, with only a small portion of the hair, and in a drop of water. A 
thin glass should then be laid over it, and gently pressed down with the hand, or with some small implement, as a pencil; then the delicate rootlets extend themselves, and the central bulb, somewhat like a hollow lamp-wick, shows its complicated structure. The reader who tries this experiment will certainly be pleased and interested, and will perhaps, while admiring the traces of design and contrivance in this familiar objeci, remember the affecting words which tell us, "The very hairs of your head are all numbered."

Where minute investigation is not the object, hairs can be shown in great beauty by light from the condensing lens, when they will appear glittering like brilliant chains on a dark background; or a piece of white paper may be placed below them, which shows some of them in a very pleasing manner; and most of them are suitable objects for the polarizing apparatus.

The hairs of insects are at all times familiar to the collector of microscopic objects, as most preparations of the limbs and heads of insects bristle with them in all directions. Some of the longer hairs, however, as those of the bee, cockchafer, etc., can be mounted separately.

The feathers of birds show their cellular structure best by selecting those which are very small and thin, and mounting them in Canada balsam; and another suitable object will be found in the fine down placed next the body of the bird.

Various brilliant feathers can be shown to some advantage as opaque objects with the lower powers of 
the microscope; yet, on the whole, it may be pronounced that they are scarcely so agreeable to the eye as when seen in their natural size. The homely goose-quill affords an object likely to prove more attractive to the intelligent observer, its point of interest (in common with all firm and smooth feathers) being the mode in which its barbs or fibres adhere to each other. How often have I stroked the feathers of a quill back and forward, and wondered why its fibres parted so reluctantly; and still more have I wondered that it should be so easy to stroke them into their places again!

A little investigation will explain the mystery. I have arranged under one of the lower powers of the microscope a very flat little feather, and I find that it consists (as you know) of a central shaft, with a great many barbs springing from it. These I will call " minor feathers." On one side of the "minor shafts" (as we may call them) there is a row of smooth flat little filaments ending in tapering points. Except for the tapering point it is not unlike a blade of a knife in shape. On the other side of each of the little shafts is a row of filaments, not ending in points, but in a series of hooks.

When the feather is smoothed down, and all the minute portions of it are in their places, it will be observed that the "minor shafts" are very close together, and the rows on each side of them overlap each other. In this way every filament ending in a series of hooks lies over three or four of the little knife-shaped filaments in the neighbouring row, and 
each of these latter is held in its place by several hooks. Thus they are not easily pulled asunder, and the last thing to yield is the tapering point which the hooks pass with a jerk.

You will also see that the tapering points belonging to the filaments turn up a little; this adds to the firmness with which the latter are held by the hooks. The hooked filaments are set near the upper edges of the plank-shaped shafts; the knife-like filaments on the opposite sides are lower down, and both stand out very stiffly.

Thus the natural position of these hooks is above the neighbouring row, and duly fastened to it. When we begin to smooth down the feather, the filaments cannot fail to clasp each other. They do it, like a released spring, in the act of straightening themselves, and when they have resumed their natural shape the feather has regained its beautifully level smoothness. Such are the curious self-acting hooks on the feathers of birds. 


\section{CHAPTER VII.}

\section{EYES AND OTHER OBJECTS.}

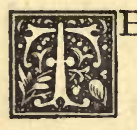

HE boiled eye of a fish provides an object singularly well-adapted to the higher powers of the microscope, and one which can be prepared with little difficulty. Probably some of my readers in their childish days, seeing a cod-fish or haddock placed on the dinner-table as a head dish, have begged for one of its eyes -not the whole jelly-like mass, but the pretty white thing inside, the size and shape of a marble. The prize gained, they have-if old enough to be trusted with a penknife - cut away the white brittle outside of the ball, and discovered the beautiful little transparent sphere within. And then they have found that they can peel a transparent delicate rind of fibres off this little sphere, but only to find beneath it another layer exactly similar, and another below that, and so on till it becomes almost too small to hold. Our present business is with this little sphere and its peelings.

I will suppose that I have placed a few of these on a glass-slide, and have fastened a thin glass over them, as they would quickly become brittle if left 
exposed. But before you look at their appearance when magnified, shall we pause for a few minutes to inquire what place the white ball occupied in the economy of the fish's eye? and what was the jellylike mass which surrounded it? Both may well occupy our attention, as having united to form that most beautiful piece of mechanism, an eye. The jelly-like mass is the dismantled frame-work of an exquisite miniature camera-obscura, of which the little white sphere (transparent till boiling rendered its outside portion opaque) was the lens: for the eyes of fishes, as well as our own eyes, and those of all the other vertebrated animals, are constructed on a plan exceedingly similar to that of the camera-obscura. Its plan is not difficult of comprehension; here I speak not of its portentous form as a photographic engine, but when it is literally a dark room for the exhibition of a landscape. It was first described so long ago as 1589 , by a Neapolitan philosopher, Gianbattista Porta; his first plan was a simple dark room, with a closely fastened shutter, in which a small hole should be made, and the light permitted to fall on a white screen or wall ; for he found that an image of the outside view would be thus obtained. And that this effect would follow, we can easily show, by holding a card pierced with a round hole near a lighted candle, when we shall see an image of the candle flickering on the wall, in the card's shadow. But Porta bethought him of a great improvement in his dark room contrivance, and states it as a secret, which he had long concealed, and had at one time intended always to conceal, that if a 
convex lens be applied to the aperture, all external objects will be shown in the vivid brightness of nature, so "that those who see it can never enough admire it."

We can imagine the astonishment and delight of the earlier spectators of Porta's camera-obscura; but what would have been their amazement to be told that they themselves, and every bird, beast, and fish, already possessed two optical instruments similar in principle, and far superior in refinement of construction.

The eye-ball is a little room, nearly spherical in its form; its outside wall is white, except at the front, where it has a large, round, and slightly-projecting window, called the cornea; much like a watch-glass. Behind this window is a permanent circular blind, with a round aperture in its centre; this is the Iris, and the aperture is called the Pupil, and if you look through it and try-disregarding your own chubby image on the cornea-to get a glimpse of the little room's interior, you will see that this is lined with black, as every camera-obscura is or ought to be to prevent confusion and indistinctness from double reflections. The white outside circle is what $\mathrm{I}$ have called the outside wall, and you can see at the left where it is interrupted by the cornea, behind which you can make out the section of the iris and its aperture. The cornea is kept distended by a fluid like water, and a similar purpose with regard to the rest of the eye is served by a jelly-like transparent substance, called the vitreous humour. The line imme- 
diately surrounding this is the black lining of the eye, and the remarkable structure suspended in the vitreous humour, not in its centre, but near its front, is the crystalline lens-spherical in fish, but of the form called double-convex in man and in various lower animals. The shaded appendage at the right of the eye is the optic nerve, which expands inside the eye-ball into a delicate cup-shaped membrane called the retina, exactly answering to the slightly concave round table inside a landscape camera.

I have seen all this mechanism shown with a cow's eye, cleverly arranged by a physician, who exhibited it to a large party. The front view of the iris in a detached eye is not a very agreeable sight; but I believe most of the lookers-on forgot its unpleasantness when the section of the eye was made, and the crystalline lens displayed in its brilliant polish and transparency

The lenses in our own eyes (according to an interesting article in the "Penny Cyclopædia") are " composed of an infinite succession of thin concentric laminæ, arranged with the utmost regularity one within another, like the coats of an onion, and every such stratum or elliptic shell is made up of a series of exquisitely minute fibres laid side by side." The writer goes on to say that similar though not precisely the same arrangements are observed in the eyes of other animals; and that in fish these fibres "are curiously hooked together by fine teeth." The lens is always enclosed in a delicate skin or capsule-this can easily be made out in the boiled eye of a fish; so 
can another circumstance, believed to be very import. unt to the optical perfection of the eye, namely, that its lens, composed all through of a substance principally consisting of albumen (like white of egg), gradually increases in density from its surface to its centre. And now let us see these curious peelings, which are no other than collections of the fibres above described.

One of these layers, which extend from top to bottom of the lens, like the meridians on a globe, and in the cod-fish, haddock, and many others, meet at points to which the name of "poles" has been given. Magnified six diameters, as you will see, nothing remarkable appears. There are some indications of its being covered with fine lines, so we will therefore examine them, magnifying them 130 diameters.

They now appear on every part of the layer, and are beautifully regular. Look at the real size of the fragment, and think how delicate these lines must be!

We can just distinguish that they are waved lines with a magnifying power of 100 diameters; but we see the real form of the lines very distinctly on magnifying them 670 diameters. Every line is toothed in this way, and every fibre which your pen-knife strips off the lens, could be divided into as many narrow pieces as it contains lines. I have frequently torn them into minute threads, which proved to be single fibres, or two or three together. The little teeth lock into each other, very much in the manner in which 
the outside portions of a "dissected map " are fastened together.

These lines present slight dissimilarities of appearance in the lenses of different kinds of fish, and specimens of a number might gradually be collected. Opticians also supply interesting preparations preserved in fluid, of the minute fibres from the eye of a cow and other animals, also of the iris, and the black pigment lining of the eye-ball. I have before me as I write, a specimen labelled "Fibre of Lens of Human Eye," and I naturally view it with interest, mingled with reverence, because it once formed part of that which has been aptly named the "window of the soul." It consists of a multitude of separate fibres, broader than those of the cod-fish, and with comparatively smooth edges, exhibiting, however, sufficient roughness to enable them to catch the edges of the neighbouring fibres.

These fibres, it is stated, converge in the human eye to a $\mathrm{Y}$-shaped figure instead of to poles, as those of the cod-fish do. The fibres in a trout's lens meet at straight lines, and various other forms have been observed and noted.

A considerable resemblance to the plan which has just been imperfectly described may be traced in the eyes of crustaceous animals, as the crab and lobster, in those of insects, of spiders and other creatures.* There may be the greatest diversity of arrangement: the eye may be fixed or movable, single or immensely

* See Dr. Spencer Thompson's interesting work on "The Structure and Functions of the Eye." Groombridge and Sons. 
multiplied; yet something will generally be found answering to the lens, the retina, and the pigment.

The eyes of the dragon-fly, cricket, and lobster, all resemble each other in being composed of a very great number of minute lenses joined into a single group, each one of these lenses being (according to the best naturalists) "a distinct organ of vision." The lenses are arranged side by side in a form that allows of their being close together without loss of room.

If they were in circles a great deal of space would be wasted, and so there would be also were they eight-sided. But they are usually formed with six sides, just the same shape as the cells in a honeycomb, so that no room whatever is lost. Naturalists have counted twelve thousand lenses in each eye of the dragon-fly. These lenses can be mounted in such a way that they will keep their shape.

It may sound like a difficult thing to count so great a number; but they are arranged with such extreme regularity that their amount is readily calculated. Magnified 36 diameters, they are like a piece of lace ; and there is another thing which they also much resemble-the wire-netting that is often put round garden plots to keep out rabbits, just like gigantic lace with holes about the size of half-crowns.

Let us imagine an experiment with a piece of this wire-netting. Suppose we should provide ourselves with several dozens of round spectacle-glasses, and set one in each of these holes, and hold the piece of wire-netting at a certain distance from a wall-the 
effect would be that we should see on the wall several dozens of pictures of whatever there was behind the lenses. Now, with the solar or oxy-hydrogen microscope, a result very similar to this can be obtained with an insect's eye. With the former instrument, as already described (chapter 1), the shadows of objects can be shown (when the sun shines) on a white screen held up to receive them. And when I place a scrap of the dragon-fly's eye in the solar microscope, I see in every compartment of its shadow a brilliant point of light, which is a little picture of the sun.

This proves them to be lenses; and it can be shown in another way. If we had a piece of wire-netting with spectacle-glasses mounted in its holes, and we held it between our eyes and a window, we should see a great number of little windows, and whatever view appeared through them, just as many as our machine contained of spectacle-glasses. If we held our eyes too close to it we could see the net-work well enough, but the view through it would be hazy. By removing our eyes farther off we should see the little pictures quite clearly.

We can imitate all this with a scrap of dragon-fly's eye; the piece I select contains about fourteen lenses.

I am sitting in a room opposite a window, though at some distance from it. The window is thrown up nearly as high as it will go, and there is an old arm-chair standing close to it at the left-hand side. Through the window I can see a range of farm-offices with a slated roof; there is an archway in this range of buildings, and over it an old carved stone is let 
into the wall. There is a large elm-tree beyond the buildings, and I can see its branches over the roof, standing out against the sky. I have the microseope on the table before me, inclined as much as if it were a telescope, and facing the window, and I am looking through it at the scrap of a dragon-fly's eye, with a magnifying power of 250 diameters.

First, I screw the microscope very close to it, that I may see the beautiful hexagons clearly. Next, I gradually move the microscope a little farther from the object; the hexagons now become indistinct, and, as it were, melt into each other, but in the centre of each appears every particular of the view I have just described! There are the sashes of the window, the arm-chair, the slated roof, the archway, the carved stone, and the distant tree!

A sight of this singular object suggests various questions to the mind of the thoughtful observer. How did the insect see through all these eyes? Why did it possess such an extraordinary number? and, To what part of our eyes did these numerous little lenses correspond? A few words then may be acceptable on the structure of insects' eyes.

The hexagonal lenses correspond to the combined action of the crystalline lens and cornea of our own eyes. Behind each of them is a little "dark room," not spherical, like ours, but shaped like a very long hollow cone or pyramid. These thousands of pyramids are all completely isolated, from each other by layers of dark pigment, and at the inner extremity of each there is a delicate filament, which is no other than a 
branch of the optic nerve, and its position is exactly at that distance from the lens at which experiment has shown the proper focus would be found. Thus we see in these eyes arrangements closely corresponding to the lens, black lining, and retina of our own; there is also a resemblance to be found to the iris and pupil, as the figment closes in behind each lens, leaving only a small aperture. And by all these contrivances, the rays which have passed through the several lenses "are prevented from mixing with each other; and no rays, save those which pass in the axis of the pyramids, can reach the fibres of the optic nerve."* It is therefore believed that in looking at an object, an insect can see clearly only the point exactly opposite to the centre of each lens. "The image on the retina may be compared to a mosaic composed of a great number of small images, each of them representing a portion of the object seen. The entire picture is, of course, more perfect in proportion as the pieces are smaller and more numerous." $\dagger$ And the reason why the dragon-fly (as well as other insects) has so great a number of eyes may well be concluded to be this-that its eyes are not capable of turning round, as ours are, but being supplied with this prodigious number, the greater portion of its head being studded over with them, it suffers no inconvenience from having them fixed and immovable, as it is thus enabled to see at once in almost all directions.

The interesting structure, above described, of the

* Carpenter's "The Microscope and its Revelations," p. 672.

† Agassiz as:d Gould's "Comparative Physiology," p. 70. 
interior mechanism of an insect's eye can be examined in a section, mounted in fluid; its preparation is a matter of much nicety, but the outer lenses (also known as "corneules") are hard and easily managed. They require only to be washed at the inside with water, applied by a camel's-hair brush, which removes the fibres and pigment. The whole of one mass of lenses can be detached with a pair of scissors, and when washed, can be mounted by nicking its edges to make it lie flat: It is then ready to examine with one of the lower powers of the microscope, and I know no more extraordinary and splendid object. It is really like twelve thousand well-polished lenses, beautifully precise in their hexagon forms about the front part of the mass, and largest there; while their form accommodates itself to their position near the edges. The arrangement of light known as " back-ground illumination," shows this object in peculiar splendour. Some additional apparatus is supplied for affording this sort of illumination; but even without this addition, the effect can be produced sufficiently for many purposes by placing the lamp as low as possible, and at some distance from the stage, and throwing light upwards with the condensing lens placed obliquely, so that no rays reach the observer's eye except those that are caught by the object, which accordingly appears in extreme brilliancy on a dark field of view.

To show the experiment of the multiplied views, a very small fragment of the eye will be found most convenient, and different little pieces of management must be used to add to the effect. It is well to have 
but one window in the room, or to darken the others; to choose one which commands a few conspicuous objects, and to close its shutters slightly, so as to avoid the glare from their panels. The microscope must be raised on a box, and put as near to the horizontal position as it can be without causing the slide to fall against the object-glass; or this result may be prevented by fastening the slide to the stage with elastic bands, or an atom of wax. I have tried to devise a plan for showing the action of the lenses by lamp-light; and can recommend that of inclining the microscope raised on a box as for the daylight experiment, and looking directly at the shade of a moderateur lamp, on which some device, cut out in black paper, is temporarily attached-for instance, two initial letters, about an inch and a half in height, cut from a printed placard. They are to be seen repeated in beautiful clearness all over the object, and like the little views, in their true position, not inverted, for the very interesting reason that each lens is acting as an additional object-glass to the microscope.

A similar experiment may be shown with the eyes of most other insects, but scarcely so conveniently with any as that of the dragon-fly, its lenses, especially at the front of its eyes, being larger than those of most others. A considerable difference will be found in the number of lenses belonging to insects' eyes. It is calculated that the ant has 50 lenses, the housefly 4000 , while as many as 34,650 have been counted by the naturalist Geoffroy in the eyes of a butterfly. 
Where these are few in proportion to the size of the eye, they are less regular in shape than when they are numerous. This appears in the eye of the cricket. The irregularity appears most near the edge, where it takes a sudden bend, and where a set of regular hexagons could not pack together; and still nearer the edge, some of the lenses have only five, or even four sides.

Crabs' eyes are composed of hexagons; those of lobsters and shrimps of squares.

The eyes of lobsters, crabs, etc., are mounted on a foot-stalk, so that they are rather more movable than those of insects. They are, however, smaller in proportion to the size of the creature's whole body than those of insects usually are.

And now, passing from the mechanism of the eye to the multitude of other wonders from the animal kingdom, to be observed in any good collection of microscopic objects, we naturally feel embarrassed with riches. See them all-understand them all-would be the aspiration of many an enthusiastic microscopist; and no unworthy wish, nor one altogether unattainable when the privilege of leisure time is added to the advantages of a good microscope, well-prepared objects, good books of reference, and the requisite amount of industry and intelligence.

I will conclude this section by an account of three curious feet-those of the common spider, the housefly, and boat-fly, the two latter being insects properly so called, and the former belonging to the more highly organized family of the Arachnidoe. 
The last joint of the spider's foot generally terminates in two or three hooks or claws, with comb-like teeth, as you may see in Plate VI., fig. 1. Fig. 2 represents them on a larger scale-they are shown as "transparent objects," and for this reason you can see part of the far claw through the centre one.

This group of claws has been well described as a "sensitive small hand, which twists, and spins, and weares, and builds nests for its young, and snares for its food."* It is also observed to be a cleaning instrument. A spider has been seen to spend an hour or more in scraping the delicate threads of its web, when dust or soot had collected on them; and if they were too thoroughly incrusted, these little claws broke the thread, rolled it up, and threw it away. $\dagger$

What a different foot is the fly's! (Fig. 3.) It is an object almost certain to be found in any microscopic collection, however small; and yet there has been considerable uncertainty about the nature of its mechanism.

Naturalists have always wished to explain how flies can walk up a window, or even upside down on the ceiling of a room; and there is no doubt that the curious flat appendages at the last joint of the foot enable them to do so. These appendages appear to be of the quality of parchment; and air-tight, and the

* On the "Feet of Arachnidø." By L. Lane Clarke. "Intellectual Observer," April, 1863.

† See "Objects for the Microscope." By L. Lane Clarke, p. 65. 
theory which was long held about them was thisthat they are suckers ; that the air presses on them, and that no air can get under them, as a vacuum is formed beneath by the raising of their central parts.

There appears much to be said in support of this theory, and the sucker is an instrument by no means unknown in nature. The feet of a lizard-called the Gecko-are supplied with a contrivance of the kind, and this is also the case with some of the waterbeetles; I have seen one of them hold on quite tightly to the edge of a basin by means of the suckers on its feet. It would appear, however, that the fly cannot "support its position" in this way. An acute observer of nature, Mr. Blackwall, at Manchester, noticed that flies under the glass of an exhausted airpump were still able to adhere to it, and, in fact, could not be detached without the employment of a small degree of force. This observation led to many experiments being tried; and it was found that the adhering power exists, not exactly in the flat appendages, or pulvilli, but in the minute hairs which surround them, and, being tubular and terminating in minute disks, partly act as suckers, and emit a fluid which makes the adhesion perfect.*

Fig. 4 represents a foot of the boat-fly, so called from its rowing itself in the water with a pair of feet much resembling oars. This is one of its hind feet, and it will be observed that, besides being very flat,

* See Mr. Hepworth's communications to the "Quarterly Journal of Microscopic Science," Vols. II. and III. 
it is fringed with long fine hair, which adds considerably to its force as an oar. The insect (fig. 5) is a very singular one altogether, and very common in ponds all the year round, I believe; at least, I have seen it in January composedly rowing about under the ice. It is amusing to watch its movements when at

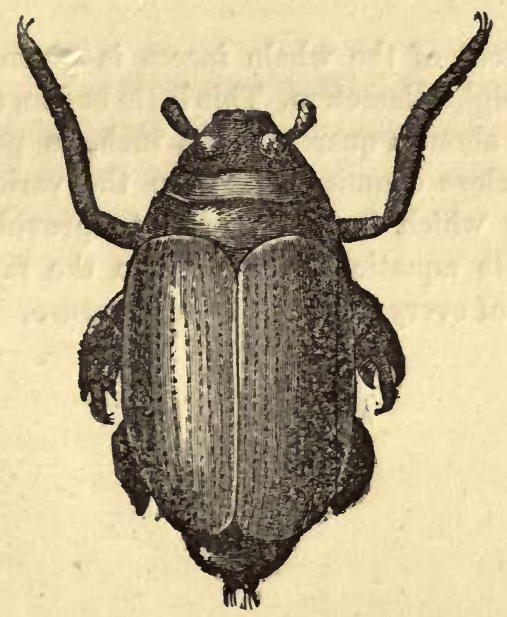

No. 6.-Whirligig Beetle.

liberty; its natural position, when at rest on the surface of the water, is like that represented at fig. 6 , floating on its back, with oars stretched out, and bright eyes on the alert, so that, on the approach of an enemy, it can quickly dive below with a few powerful strokes. It can also $\mathrm{fly}$, as represented in 
fig. 7, and possesses a weapon of defence, in the shape of a pointed beak or proboscis, capable of inflicting a very sharp prick. Like the bouse-fly, and scores of other insects, this single specimen would afford a considerable number of microscopic objects. The same may be said of the little Gyrinus, or whirligig beetle, the wing of which is already figured (Plate II.).

A woodcut of the whole insect is given on p. 77, magnified eight diameters. This little beetle, the length of which is about a quarter of an inch, is particularly worthy of close examination, from the various appliances with which it is endowed to provide for the wants of its aquatic life, and from the rare beauty and finish of every portion of its structure. 


\section{CHAPTER VIII.}

\section{VEGETABLE PRODUCTIONS.}

REMARK in Hogg's "Treatise on the Microscope" shows the important part which that instrument has performed, in adding to our knowledge of the vegetable world: "Since the introduction of the achromatic microscope," he says, "we have obtained nearly the whole of the valuable information which we now possess relative to the minute structure of vegetables." The discoveries which have been made in this branch of study are detailed in a most instructive manner in that work, and in Dr. Carpenter's, and would probably give some help even to an advanced student of vegetable physiology; while, to those who know nothing of plants beyond their external beauty, they impart a half-depressing glimpse of the world of truth unknown to them, and yet discovered by the diligence of others. Yet an attentive study of their observations on a few familiar microscopic vegetable objects gives much additional interest to a subsequent examination of them.

As mere objects of display, few things give more 
pleasure to the young than the exhibition of whole flowers (small ones, of course,) with the lowest power of the microscope. Some little weeds rise to the apparent splendour and importance of hot-house plants ; almost any weed, blossom, or grass is worth looking at, and sure to delight the younger ones of a family, while it suggests to them how well worthy of examination are the common things by which they are surrounded; a thought which may prove of great value to them at a future day.

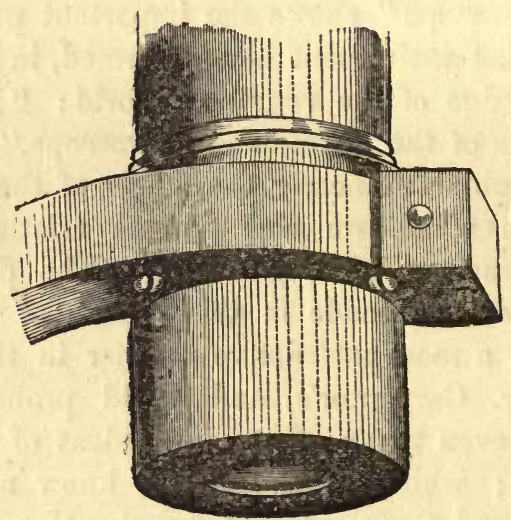

No. 7.-Additional Object-glass for viewing Flowers.

I found the lowest power of my microscope still too powerful to show as large a field as I desired, and I therefore made a (somewhat indifferent) extra objectglass, to magnify about twelve diameters, by simply cut- 
ting a round hole in a cardboard box, blackening the latter, placing a lens inside, and slipping it on to the lower end of the tube (No. 7). It answered exceedingly well for opaque objects, though showing its non. achromatic short-comings when used with transmitted light.

For the benefit of those who wish to go deeper into the interesting subject of the structure of plants, I will name a few of the most characteristic objects which can be procured from the vegetable kingdom.

Cuticles.-The cuticle is that transparent skin which peels easily off the leaves of the lily, and various other plants, and off the petals of flowers. The microscope shows that it is formed of one layer of cells, containing air, and serving to protect the fluid-filled cells within; yet, as these latter require the entrance of a due proportion of outer air, the cuticle is fitted up with ventilators in the form of pores, called the stomata, curiously arranged to open and shut.

The internal cells of plants.- " The origin of every plant is a single cell; the perfection of a plant, from the tiniest moss to the loftiest oak, is in a countless multitude of simple cells, containing various substances needful for its growth, and of an infinite variety of shape and substance."*

Cell-contents. - Starch-granules abound in the cells of a good potato, and (according to Dr. Carpenter) " in some part or other of most plants." Oil is con* "Objects for the Microscope," p. 13. 
tained in the well-known red globules stilted on little stalks on the stem of the moss-rose. It is also to be found in some internal cells in an orange-rind, and in the leaves of the myrtle and magnolia. Some plants contain crystals in the cells of their cuticles; the hyacinth affords an example. Wax, gum, and sugar are also to be detected in cells.

The rotation of cell-contents is one of the most
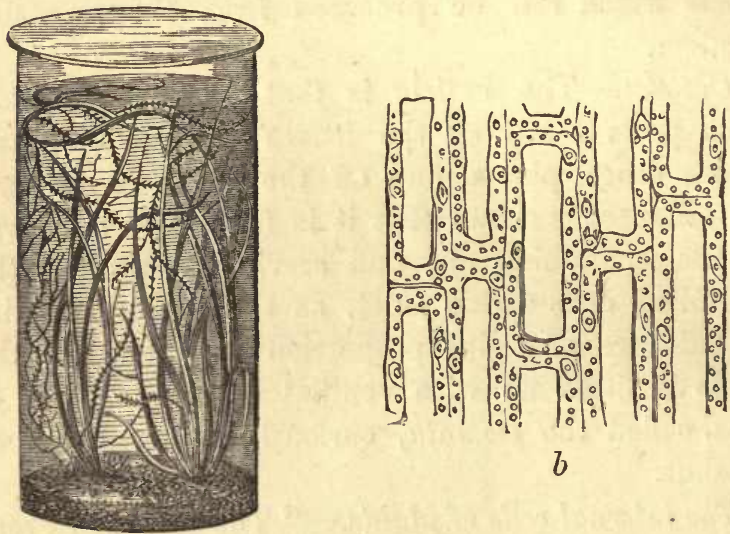

$a$

No. 8. - Vallisneria spiralis ; $(a)$ the plant growing in a jar of water; (b) portion of the leaf, magnified.

curious and beautiful spectacles afforded by the microscope. The best examples of it are found among plants which grow under water; and of these the Vallisneria spiralis is peculiarly fitted for its exhibition. The Vallisneria is an aquatic plant that grows abun- 
dantly in the rivers of the south of Europe, but is not a native of this country; it may, however, be readily grown in a large glass jar with a little mould at the bottom, No. $8(a)$. Its long grass-like leaves are too thick to allow the transmission of sufficient light without some special preparation. It is, therefore, requisite to make with a sharp knife a thin slice or shaving of the leaf, not of the outer surface, but of that next to it; and this must be placed in a little water in the live-box. A power of 200 diameters should be used. The whole field of view will then appear occupied by cells similar to the small number figured at No. $8(b)$, with bright green particles revolving in each, in a steady and regular motion, strictly limited to the boundary of each cell. It sometimes happens that the slicing operation will have put a temporary stop to the rotation; but a slight warming of the live-box will quickly cause it to recommence.

Spiral fibre.-A substance often deposited in the interior of cells, tightly coiled up till a little moisture applied causes it to uncoil suddenly. It can be very curiously shown by cutting a thin and small slice off the outside of a collomia seed, and placing it in the live-box of the microscope, with a magnifying power of about sixty diameters. The cover of the live-box should be placed over it at first without water, that the focus may be nicely arranged. Then the cover is to be lifted up, a small drop of water put on its under surface, and this pressed down over the slice of seed. This being done, the spirals will spring 
out in all directions with a strange appearance, as if of life.

Woody fibre.-To be seen by examining thin sections of wood, of which beautiful specimens can be procured from opticians, and in which may be traced the process of their formation. Sections of roots and stalks are also interesting.

Hairs.-These are formed of lengthened cells; the variety in their forms is wonderful, and many of them are objects of great beauty. For instance, the little purple tuft of them in the centre of the spiderwort looks like numerous strings of amethysts of oval shape-that in the centre of the scarlet verbena like a tiara of pearls. The rotation of cell-contents can be observed in some of the finer hairs of the spider-wort, as well as in those of dock and groundsel.

Pollen.-The fine powder which is to be seen on the anthers of full-blown flowers, has long been known as an excellent object for the microscope. It can be mounted on slides, but looks best when fresh-best of all when scattered on the velvet-like petal of the flower to which it belongs.

Seeds.-Many of the smaller seeds are beautiful objects in their natural state for the lowest power of the microscope, being sculptured with sundry pits, knots, and network patterns. Some are furnished with wing-like and other appendages, which can be highly magnified with good effect; and the outside fibres of many are interesting; for instance, the collomia, already described, and the outer covering of 
E.

4

$x^{2}=$

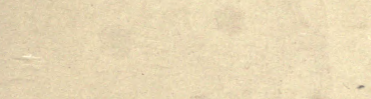

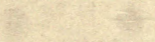

in 

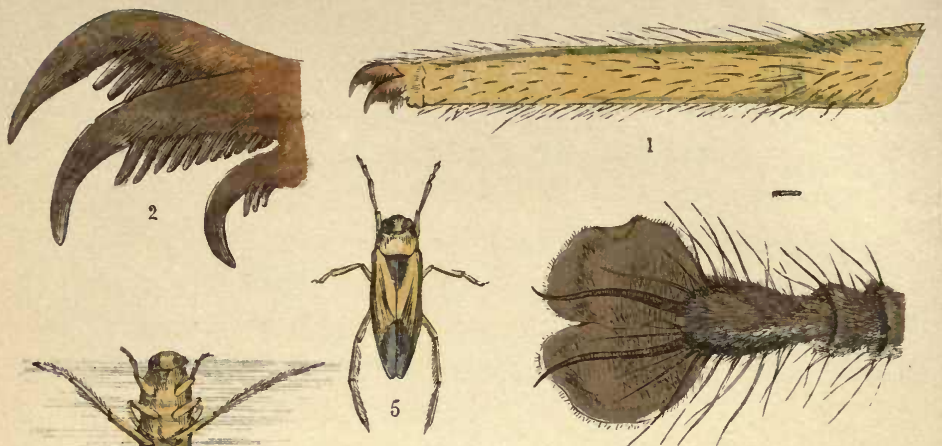

हn

6
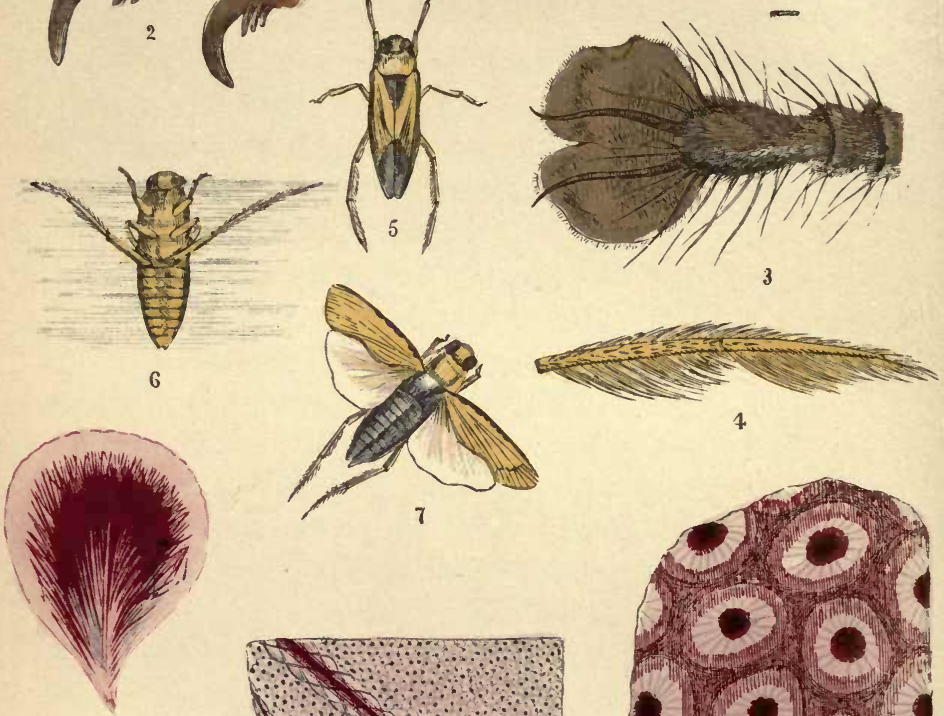

4

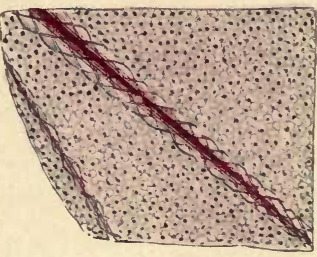

9

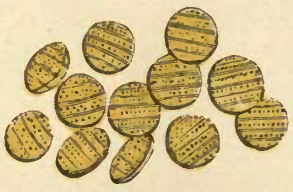

14

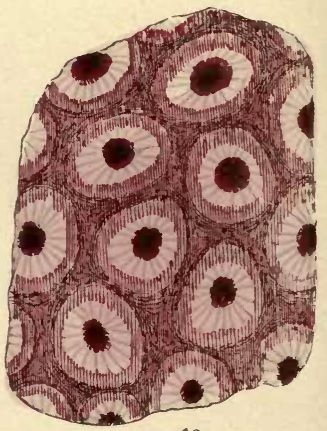

10

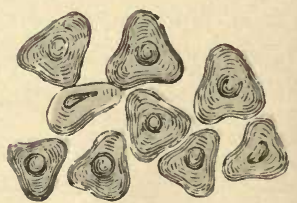

II

13

1. Foot of Spider, magnified 18 diameters.

3. Foot of Fly, magd. 20 diams.

2. Claws of Spider, magd. 100 diams.

4. Foot of Boatfly, magd. 4 diams.

5. Boatfly. 6. Boatfly floating. 7. Boatfly on the wing. 8, l'etal of Geranium.

9. Piece of Geranium l'etal, nagd. 8 diams. 10. Minute portion of P'etal, magd. 150 dians.

11. Pollen of Clarkia pulchella, mag. 100 diameters. 12. Pollen of Crown-imperial, inag. 100 ciams.

13. Grain of the above, magd. 300 diams.

14. Pollen of Sulvia patens, magd, 100 dians. 
wheat and grass-seeds, known as bran, and composed of remarkably regular and dense cells, which continue distinguishable even after the grain has been roasted and ground.*

Ferns, mosses, sea-weeds.-These examples of the lower orders of vegetation are all particularly suited to microscopic research; so also are those vegetable growths, familiar to us under the names of fungus, mildew, blight, and mould; as well as certain microscopic vegetables found in water-the desmids and diatoms, interesting as being on the border-land between the lowest form of vegetable and of animal life, showing a singular power of locomotion which has caused many naturalists to describe them as animalcules, till subsequent researches have seemed to prove their vegetable nature.

It will bo seen that a few of the objects referred to in the preceding list, are figured in Plates VI. and VII. In the former, fig. 8 represents the petal of a geranium, which, when viewed without the microscope, appears of a beautiful shaded pink colour.

Fig. 9 represents the little space marked $A$ in fig. 8 , as it appears when magnified eight diameters; and fig. 10 shows an extremely small portion of it-such a piece as might be enclosed as in a frame in the eye of the finest needle-as seen through one of the higher powers of the microscope. The points in the centres of the interstices are of a very deep rich red; the rays proceeding from these points are of a lighter 
tint, and so also are the lines of the network of cells.*

Fig. 11 represents the pollen of "Clarkia pulchella." A small quantity of it looks, when highly magnified, like an immense heap of glass rings, of three-cornered form (fig. 11). That of the crown imperial is more like grains of wheat. Fig. 12 represents some of this, and fig. 13 shows some of the grains, magnified 300 diameters; and it is wonderful to observe that their surfaces are covered with a delicate pattern, just perceptible with this high magnifying power.

The pollen of "Salvia patens" is flat and round (fig. 14). These pollen-grains can be viewed either as opaque or transparent objects. They appear to great advantage by the "background illumination," described at page 72. A single grain of the pollen of "Salvia patens" happening to be alone in the field of view, with a dark background, curiously suggests the planet Jupiter to one's mind, with its round yellow disc, and belts stretching across.

The figures of Plate VII., with the exception of fig. 10, might be said to represent "the seed-vessels observable on the backs of fern-leaves." But so different in structure are ferns from the true flowering plants, that the expressions "leaves" and "seeds" are not considered admissible in these days of careful investigation, when objects are no longer classified by

* It should be observed that the drawing (Plate VI., fig. 10) was made from a dried specimen, in which the lines of the network are more sharply marked, and the different shades of red appear more detached from each other than in the fresh petal. 


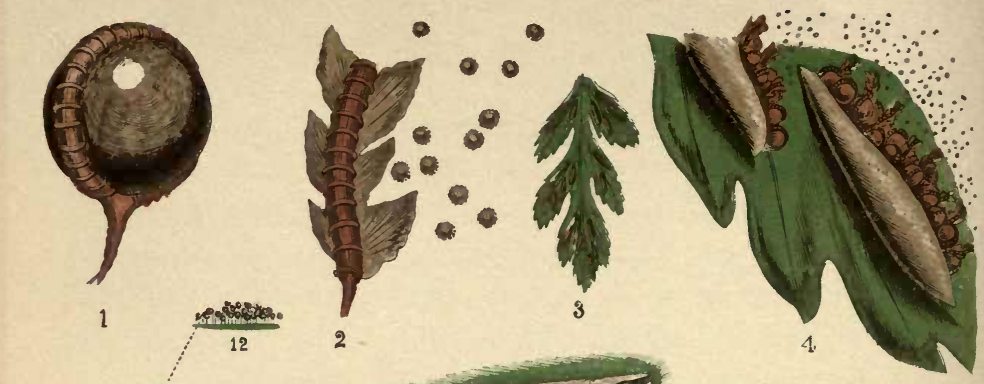
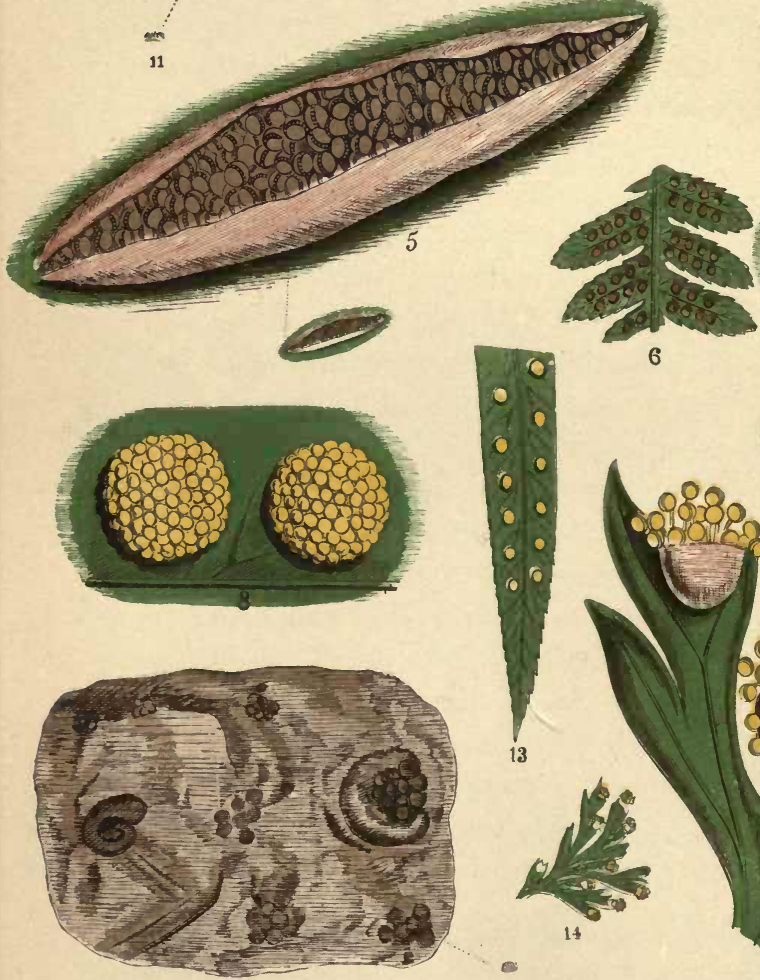

10

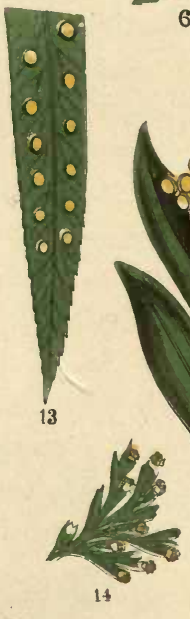

e

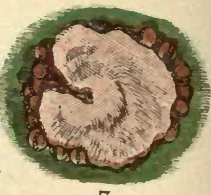


mere external characteristics. It appears that we should say "fronds" and "spores," because the former are produced in a different manner from the leaves of other plants, being rolled up in a crosier-like form, which gradually unfolds, and the spores do not by any means correspond to seeds, seeing that in their nature they rather resemble buds; as in due time, when placed on a damp surface, and exposed to sufficient warmth, they enlarge by the addition of cells, and produce singular structures somewhat agreeing in nature with the stamens and pistils of flowering plants. These curious facts, discovered in 1848, by Count Suminski, are described with beautiful figures in the work of Dr. Carpenter. We see the bud-like spore, the elongating cells, the structures that have been likened to stamens and pistils; and there are also strange moving filaments, which may be likened to pollen-grains; but fern-seed itself appears to be even more unattainable than it was considered in Shakspere's time,* for there is indeed no such thing, nothing which truly corresponds to the idea of a seed, as we understand the term in speaking of most other plants.

Almost all ferns have their seed-vessels, or to speak more precisely, their theco, on the backs of the

* "We have the receipt of fern-seed, we walk invisible." $-\mathrm{K}$. Henry the Fourth, Part I. Act II. — "Fern-seed was supposed to have the power of rendering persons invisible. The seed of fern is so small as to escape the sight; to find it, therefore, was supposed to require a magic operation; and in the use, the seed was supposed to communicate its own property.-Note in "Illustrated Shakspere," vol. iii. (Tyas.) 
fronds. These vessels are exceedingly small-smaller, indeed, than the seeds of most plants-and they are arranged in a great variety of ways in the different kinds of fern; but in nearly all ferns they are globular, contain a number of extremely minute spores, and grow from the back of the frond on a curiously-jointed stalk, and this stalk runs up one side of the theca, and bends round it like a ring.

This ring is elastic, and so long as the spores are unripe, and the theca soft and green, it maintains its bent shape, and acts as a band. But when the theca becomes stiff, and the spores ripe, the elastic ring suddenly straightens itself with a great jerk, tears the theca open, and scatters the tiny spores in all directions! Plate VII., fig. 1, represents one of the thecæ of a fern, called the Black Maidenhair Spleenwort; and fig. 2 a similar theca with the ring in the act of straightening itself.

I have often brought a number of fern-fronds into the house to examine while fresh with the microscope; and as the heat of the room hastened their drying, the rings soon began to straighten themselves, the thecr to tear, and the spores to scatter about. I have shown this to friends, and been asked, "What are those live things?"

Fig. 3 shows part of the frond, of the size of the original; the slit-like marks are the groups of thecæ. In fig. 4 one of these groups of thecæ and part of another are shown magnified twelve diameters. From this an idea may be gained of the animation of the scene. 
Each group of thecr in the tribe of spleenwort ferns is protected on one side by a "cover," as it is called, shaped somewhat like one half of a peapod. Another fern called Hart's-Tongue, a strong, large, showy plant, somewhat resembling dock, has two covers, one on each side of the group (fig. 5). The Common Polypody fern has no covers at all; its thecæ stand up in round groups, very like heaps of oranges, their colour being bright yellow (fig. 8).

The "Shield-fern," common in dry ditches, has its "cover" constructed not unlike a little umbrella standing up in the centre of each group of thecæ. Fig. 6 represents part of a leaflet the size of nature, and fig. 7 one of the groups of thecæ magnified.

There is a very great diversity in the shape of these "covers," and a collection of the native ferns, arranged for the purpose of showing these, forms a beautiful series of objects for the microscope. They should be gathered before they are quite ripe, and placed at once in blotting-paper to dry, if the object is to mount them as slides for the microscope; in which case some sort of little raised frame must be placed on the glass, as without this the thickness of the specimen would prevent the covering-glass from being easily fastened down.

But ferns examined in a fresh state are objects of great beauty, and are readily prepared, as nothing has to be done farther than to lay a portion of the frond on the microscope's stage. 'The richness of the greens and browns will attract the eyo pleasantly; 
and the soft juicy appearance of the thecæ when unripe, the pretty effect, when, farther on in the year, some will be unripe and pale, some ripe and dark in the same group, and the fairy-like aspect of a group of thecæ when they are detached with the cover, and placed in view like a miniature dish of fruit, are all sights sure to gratify the beholder.

The common Brake fern has its thecæ curiously concealed round the edges of the fronds, the margins of which turn down over them. Another little native fern, the Scaly Spleenwort, has its whole stalk as well as the backs of its fronds covered with scales resembling bits of lace; and the thecæ lie thickly between them, like ribbons in the border of a cap.

The collector of native ferns will naturally feel inclined to examine foreign ones also; and this can be easily done, as beautiful exotic ferns are in much favour in the conservatory.

Fig. 9 represents part of the frond of a foreign fern, that known as the Hare's-Foot, or Davallia. Its groups of thecæ are on the tips of the leaflets; the covers are somewhat like little pockets, and, when filled with thecæ, resemble baskets of flowers.

It will occur to the reader, that there must be a very great number of spores on the fronds of ferns. This is the case ; and in the Hart's-Tongue fern, which has remarkably small spores and thecæ, the amount is quite prodigious. Each frond bears on an average 80 sori (collections of thecæ), containing from 3000 
to 6000 -that is, on an average containing 4500 thecæ in one sorus, making 360,000 on the whole frond. And these thecæ each contain about 50 spores. So that a single frond of Hart's-Tongue fern carries no less than eighteen millions of spores ! 


\section{CHAPTER IX.}

ORGANIC REMAINS, CRYSTALS, AND ARTIFICIAL OBJECTS.

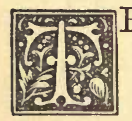

HE microscope affords a great deal of information to the geological inquirer, not only with regard to the real nature of various animal and vegetable remains which are found as fossils in the different strata, but also with regard to the composition of the strata themselves.

Fossil trees have been found in various strata, more or less perfect. Sometimes their fibres have been completely penetrated by the mineral "silica," sometimes by carbonate of lime, and when this has occurred, their minute cells and vessels are well preserved, and it is quite possible to make thin sections of them capable of being compared with those of recent wood. There are certain markings of cells and fibres by which the wood of a cone-bearing tree (larch, for instance,) may be readily distinguished from such trees as the oak and elm. Other characteristics mark the palm tribe, and all these structures may be observed in the fossil woods of the newer strata. In the earlier strata, the cone-bearing trees and the palms are, with rare exceptions, the only forms discovered; and in coal, which the microscope has 
Organic Remains, Crystals, and Artificial Objects. 93

proved to be nothing else than a mass of decomposed regetable matter, the arrangement of its minute internal structure shows that it must have belonged exclusively to the cone-bearing tribe of trees. In some coals, the structure can only be indistinctly discerned; in others it is very plainly to be recognized; and it would appear that the Araucaria is the modern plant to which coal makes the nearest approximation. The decomposed wood of which coal consists appears to have "been reduced to a pulpy state by decay, before the process of consolidation by pressure, aided perhaps by heat, commenced."*

And just as these productions of the vegetable world can be referred to their true classes by the microscope's help, so certain fossil spines, bones, and teeth, found in so fragmentary a state that but little of their form could be traced, have been identified by an examination of their minute structure with that instrument. In a somewhat similar way, the microscope has assisted in throwing light on the past history of the earth's strata.

The little microscopic vegetables named diatoms, or, at greater length, Diatomacece (to which allusion has already been made), are found living both in fresh and salt water, and their remains, hardened by the presence of silica, are also to be found in quantities at the buttom of fresh-water lakes, or on the bed of the ocean. When a geologist therefore meets with an 
extensive stratum of earth, which, when examined with the microscope, turns out to be entirely composed of fossilized diatoms, he feels no doubt that it has once been the bottom of a lake or sea.

And there are minute animals which give similar evidence with respect to the great chalk formation, and to the limestone rock which forms so considerable a portion of the earth's crust.

As I write, a slide is placed on the microscope stage, containing a little mud apparently, obtained some years ago by deep-sea soundings from the bed of the Atlantic Ocean, one thousand eight hundred and thirty fathoms deep, to wit, more than two miles. I view it with a magnifying power of twenty diameters, and see that it consists of a multitude of minute nautilus-like shells, some broken, some perfect, and of several shapeless fragments. These little shells are not of the nautilus species, their inmates having been discovered to be widely different from those of the nautilus shell. They are of the very numerous class designated Foraminifera, and Dr. Carpenter states that they are found living on the upper surface of the "ooze" forming the bed of the Atlantic, while its lower layers are almost entirely composed of dead shells of the same type.

A section of limestone will be found to present an appearance somewhat similar to that of the ooze of the Atlantic; for all limestone is composed of a mass of extremely minute animal remains, among which the Foraminifera abound, as also in chalk. It is not very difficult to make a section of limestone. A small thin 
Organic Remains, Crystals, and Artificial Objects. 95

fragment is to be selected, and ground down on a hone till its surfaces are tolerably flat. When too thin to be held longer in the fingers, one of its sides should be fastened with Canada balsam to a glass slide, and the grinding process gone on with till the limestone becomes so thin as to be a pale grey and partly transparent.

Plate VII., fig. 10, represents a portion of a section of nearly black limestone, which I saw prepared in this way; and its resemblance to the slide of Atlantic mud is interesting.

From the consideration of coal, chalk, and limestone, which, although they are in the mineral domains, bear evidence of organic composition, we may turn to the substances which are truly inorganic. When these present any appearance of symmetry in their forms, it is because their particles have arranged themselves in that peculiar manner known as crystallization. Each substance which crystallizes at all, does so after a certain type or plan. Not that all crystals of the same substance will surely look alike; but it will be found that the same plan of crystallization will exhibit itself under a great variety of forms. Various natural specimens are interesting, when shown in thin sections; granits and agate may be mentioned as examples; and crystals can be obtained artificially by making strong solutions of various salts, placing a drop of each on a glass slide, and allowing it to evaporate slowly. Such crystals are in many cases splendid objects for the polarizing apparatus.

The actual process of crystallization may be ob- 
served with the microscope, and that in a variety of interesting ways. For instance, the formation of the metallic crystals of silver may be thus viewed, and few objects give greater pleasure. A solution of nitrate of silver is laid on the slide, a few copper filings are dropped upon it, and instantly each grain of copper becomes the centre of a brilliant tree-like crystal of silver, growing rapidly as one views it, till it reaches and perhaps shoots across another branch, and the whole field is soon covered with glittering foliage. And this is interesting as a chemical experiment, showing the effect of "affinity." The copper robs the silver of its nitric acid, obliging the silver to appear in the metallic state.

Or we may simply watch the effect of crystallization in a salt without further admixture. Let us place a drop of muriate of ammonia, rather thinly spread out upon the slide. In a few moments some needle-like crystals, straight and keen, dart across the field, and then minor needles dart from them at right angles. Now some half-dozen large darts spring forward-we think of a charge of bayonets, when suddenly every weapon turns into a spruce-fir tree, with branches of unusual straightness.

This object is not altered by polarization; but saltpetre polarizes well. A drop of the solution remains inert for a while, scarcely visible on the black ground which we have obtained by a particular arrangement of the prisms. Suddenly at the edges of the drop we notice a few bright little crystals, like small books seen in perspective, floating just within the boundary. 
Organic Remains, Crystals, and Artificial Objects. 97

While we look, they have grown imperceptibly, and new ones have joined them; presently all the edges of the drop are crowded with these brilliant little books, pink, green, blue, orange, and other fine colours. Suddenly there come down upon them certain long keen sabre-like crystals, which we may liken to papercutters : this occurs when the film is nearly dry.

Dr. Carpenter's and other works give the names of a great number of crystals suitable for microscopic observation. Referring the reader to these, I shall now only describe the arrangement which I have found satisfactory for displaying them. A reader happy enough to have a considerable knowledge of chemistry will easily find out how to vary the experiments.

Such a reader will very probably have various little appliances at hand preferable to those which I describe; mine may, however, be commended as answering their purpose, and enabling the exhibitor to avoid disfiguring stains from the nitrate of silver. To proceed, then; the various solutions, of which a small teaspoonful will be quite sufficient to prepare, may be made in one of those colour-trays generally accompanying paint-boxes, and containing half-adozen hollows. It is well to write neat little labels, and gum one near each hollow, say "nitr. silver," "sulph. copper," "sugar of lead," "saltpetre," "muriate amm." You should have at hand a bottle of rain-water, a few slips of glass of the usual size, and some narrow pieces of glass, or glass rods; also two or three rags; one as a complete drudge to wipe off 
nitrate of silver when required, regardless of the black stains which will presently appear upon it. The salts will dissolve quickly in their compartments, and as they will (except coloured ones, as the sulphate of copper,) appear like clear water, you will find the convenience of having each labelled.

The microscope should now be properly arranged, because in many cases the process of crystallization is very rapid, and the best effects would be lost during a few minutes of delay. The tube should be inclined slightly, and the power employed should be about sixty diameters, which serves for most crystals. A slide should be laid on the stage, with a scrap of paper or some small object placed upon its surface. The focus must be adjusted on this, and if the crystallization is to be viewed as an opaque object, a good light must be thrown upon it from the bull's-eye lens. All being ready, the scrap of paper may be removed, and a drop of the solution lifted by one of the glass rods or narrow slips, and placed on the slide. For exhibiting metallic crystals dark slides will be found very convenient.*

The copper or zinc filings for dropping into the solution must be in readiness. It is worth while to make deep little envelopes to contain them, like those in which small garden-seeds are sold. A little of the filings can be shaken on to the flap of the envelope,

* Mr. Dancer, of Manchester, has kindly presented some of these dark slips of glass to me, and has furnished me with infornation on the subject of crystallization, as well as of microscopic photography. 
Organic Remains, Crystals, and Artificial Objects. 99

while the rest is kept back; the few loose grains are dropped on to the solution, and the lovely crystallization at once commences; but it requires a little practice to show it with certainty, and at the best moment.

If a simple salt has to be shown by transmitted light, the microscope's mirror must be arranged accordingly, and then, the solution being placed on the slide, must be watched, especially at its upper part, which will appear in the microscope to be the lower; the film being thinnest there, the crystallization will probably commence in that part. Some salts require the slide to be more or less warmed, and a wax nightlight always occurs to my mind as the very tidiest and simplest way of duing this. A few trials will show whether warming is advisable or not. The process of crystallization can be shown over and orer again by wiping away the solution each time, and cleaning the slides; and considering the powerful destructive tendencies of some salts, it might be well to end the performance by wiping the colour-tray itself, lest its contents might get on clothes and do mischief. It may chance that some of the crystals will have been more than usually beautiful, and the experimentor may wish to preserve them; this can generally be effected by dropping Canada balsam over them, or a little oil, after which they can be covered with thin glass, and mounted in the ordinary way.

We are presently to imagine ourselves enjoying a summer entertainment, observing living creatures in the animalcule cage, in the "ample field" of a watch- 
glass, or otherwise arranged as may seem best. But before taking leave of "prepared slides," a few words must be added on a class of microscopic objects which the reader has most probably met, and viewed with surprise and curiosity. I mean the Microscopic Photographs. They may be classed as wonders of the photographic camera, rather than of the microscope; but as they cannot be seen without the help of the latter instrument, a notice of them may be considered not out of place in the present work.

A few specimens of these may generally be formed in collections. To the unassisted eye they look much like other objects mounted in balsam; all that is visible on the slide is a neat little disc of thin glass, with a tiny grey dot in its centre, smaller than a pin's head. But the slide bears a label, oddly contrasting with the scientific matters suggested to us by the slides which we have hitherto considered, and showing that the object is a miniature of some well-known engraving, portrait, or inscription. We place it on the stage, and see it magnified to the dimensions of an ordinary book illustration, and appearing like a tolerably good lithograph. An observer unaccustomed to the microscope can scarcely believe that a number of well-executed faces and figures, or several lines of clearly legible printing, can be contained in a space so extremely small; and the ocular proof that it really is so, affords much interest and surprise, and at the same time conveys a tangible idea of the microscope's power. These little photographs have acquired considerable popularity; and I do not wish 
the reader who looks in this book for some account of their history, the method of their production, and the use (if any) which has been made of them, to look in vain.

The idea of employing the photographic principle in producing specimens of printing so small as to be legible only with the microscope, occurred to $\mathrm{Mr}$. Dancer, of Manchester, so long ago as the year 1839. This was several years before the discovery of the collodion process, and accordingly these were daguerreotypes. Mr. Dancer reduced a bill twenty inches in length to one-eighth of an inch; but as the nature of the deposit on silver plates prevented the lines being fine enough to admit of being viewed with any but the lower powers of the microscope, he laid the matter aside, till the year 1852, when Mr. Archer's discovery of the collodion process enabled him to produce far minuter specimens. He paid considerable attention to the subject, and has since that time executed some specimens which are indeed marvels of photography.

At a meeting of the Manchester Photographic Society, on April 6th, 1859, a microscopic photograph by Mr. Dancer was exhibited, consisting of two pages of "Quekett's Treatise on the Microscope," reduced to one sixteen-hundredth part of a superficial inch (that is to say, if the two pages made a square, such square was one-fortieth of an inch in diameter.) They included three thousand six hundred and thirty. one letters, and at the same rate the whole volume of five hundred and sixty pages could be contained 
in a space of three-eighths of an inch square* (No. 9).

These photographs are taken with a photographic camera, in which, instead of the large lens which has stared at most of us in these days of cartes-de-visite, one of the object-glasses of a microscope is used.

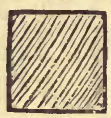

No. 9. The pictures are taken on very carefullyprepared iodized collodion, and developed by pyrogallic acid or sulphate of iron. When dry, they are mounted in Canada balsam to protect them.

Microscopic photographs were also the independent invention of Mr. Shadbolt, in the year 1854. He exhibited a number of them in that year, ranging from the one-twentieth to the one-fortieth of an inch each way, one of which was a pretty extensive view of Paris.

There is another class of objects which may be described along with the microscopic photographs, although the method of their production is quite different. These are some exquisitely minute specimens of ruled lines and of writing done upon the glass with a diamond point.

Many microscopes are furnished with what is called an eye-piece micrometer, used, as the name imports, for measuring minute spaces. It consists of a series of delicate lines, ruled by ingenious machinery on glass at regular intervals, and crossed with others. So many as ten thousand lines have been ruled in this way in the diameter of an inch. The test-objects " "Photographic Journal," for April 15th, 1859. 
Organic Remains, Crystals, and Artificial Objects. 103

known as "M. Nobert's" afford another example of this process of machine-ruling. "As at present supplied, they consist of a slip of glass (No.10), on which, bycareful observation with the naked eye, may be observed what looks like a single shadowy line, sparkling in bright light with the play of prismatic colours. By moderate power (fifty diameters), with good glass and careful illumination, twenty distinct bands may be counted (that is, in the breadth and not the length of the line); the finer, however, very shadowy and evanescent. With 100 diameters, the four coarsest should be shown in distinct

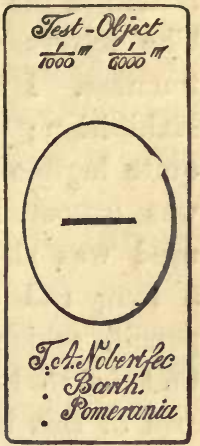

No.10.-Nobert's Test-Lines. lines; as the power is increased, more and more of the bands will be resolved, till with 500 diameters, the separate lines composing all but one or two of the finest of the bands should be clearly seen"* (No. 11).

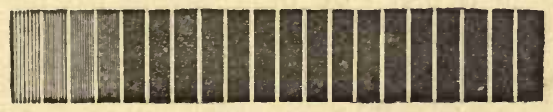

No. 11.

It is calculated that the coarsest lines are about the thirteen-thousandth of an inch from each other, and the finest the eighty thousandth.

Of microscopic writing, some remarkable specimens were shown at the International Exhibition of

* From an article on "Nobert's Test-Lines," by Mr. Tuffen West, F.L.S., in " Recreative Science," vol. i. 
1862. One of these was a piece of writing, containing four thousand one hundred and thirty-seven letters in the one thousand and fifty-fourth of an inch. The letters were filled with black-lead of extreme fineness. I was shown this specimen when at the Exhibition; the writing was a clear text hand, and quite legible through a high magnifying power. It was executed by Mr. W. Webb. The instrument used was also exhibited, and may be described as a long rod or lever, carrying at its lower end a pencil, which is traced over the original writing that is to be reproduced in miniature. The short arm of this lever is concealed in a box above, and acts upon a second lever, the arrangement being repeated until the motion which originates with the hand below is reproduced in the required degree of minuteness. The extremity of the lever moving through this small space carries a diamond point, which is pressed against a plate of glass, producing by its action a piece of microscopic writing, corresponding with the full-sized design over which the long arm of the lever is traced below. This sort of instrument is called a pantograph, or pentagraph. Still more wonderful were the specimens produced by Mr. Peters's pantograph, and exhibited by the Microscopic Society.

I am informed that M. Froment, of Paris, produced specimens of this kind of writing so long ago as 1851, and that some executed by him exhibit all the symmetry of copper-plate engraving. 


\section{CHAPTER X.}

THE ANIMACULES AND OTHER MINUTE INHABITANTS OF WATER.

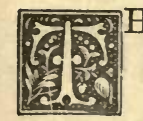

HE animacules in water-what, in the water we drink? Such, perhaps, is your question, reader, on observing the title of this chapter; and I hope you will simply feel pleasure, and not a shade of regret at the loss of a long-believed horror, when you hear that animalcules do NOT inhabit springwater, and you might look in vain for them in many a clear pool or flowing stream. It would be difficult perhaps to say whence we have each derived the tradition that all water is full of animalcules; but my impression is, that some worthy Oriental in a story-book impressed my young mind with the belief. He was a Brahmin, and boasted to a European sage that he never ate anything which had life. The sage forthwith demanded a glass of water, and exhibited the supposed swarming animalcules with a microscope, whereupon the Brahmin dashed the too-instructive instrument on the ground. With my present experience I should feel but little alarmed for the fate of my microscope, if its destruction were to 
follow on the discovery of animalcules in a drop of pure-looking water; but the case was different when I first used the microscope, till by slow degrees I discovered that these minute creatures inhabit stagnant water, occurring in countless numbers around decaying plants, and also in ponds where submerged weeds are growing, and, like the large and visible animals, must be sought out and found, some in one place and some in another.

It has so happened that I have never systematically studied their ways, or endeavoured to draw their likenesses.* My fishing in the ponds and streams was undertaken with a view to obtaining the beetles, boat-flies, shells, and other comparatively large denizens of the water, and also suitable objects for exhibiting the wonderful spectacle of the circulation of the blood in the unhurt and living animal. But as the same water which produced the water-beetle, the stickleback, and the newt, was likely to furnish also the wheel animalcule, the Bell-flower, and a host of smaller restless creatures, I became familiar with their appearance, and hoped at some time to study them, and profit by the discoveries which of late years have been made concerning them by various eminent observers. To a certain extent I have realized this wish; but am rendered independent of the task of drawing them by the

* The figures here given of animalcules, with the exception of No. 13, and a few others, are taken by the permission of the publishers from Mr. Slack's "Marrels of Pond-Life." But in each case I have examined the object depicted, and can vouch for the accuracy of its representation. 
many accurate and beautiful illustrations which can now be obtained of all the remarkable kinds which I have seen, and of many which I have not hitherto observed. Mr. Slack's work, "Marvels of Pond-Life," figures the animalcules with much spirit and accuracy, aided by descriptions alike faithful and graphic. But, more than this-though the book is small, and the style anecdotal, the subject is fully treated in its various bearings, with all the lights obtainable from contemporaneous reséarch. A microscopic student, anxious for pleasantly-given information about the animalcules, can hardly do without Mr. Slack's book.

And this being the case, I shall give but a short account of them here, merely indicating their principal classes, and the methods of obtaining them, which I have found successful. To tell the story of my pond experience in the spring and summer of the present year, will be as good a way as any for introducing the subject.

I was particularly anxious last March to obtain some young tadpoles, during the few weeks in which specimens could be had, showing the circulation in the "branchiæ," or external gills, an object which I had carefully watched and figured several years ago. I had observed a promising supply of frog-spawn in a kind of pond, at a few hundred yards' distance from one of the large peat-bogs so characteristic of this country; and I sallied forth to secure a small quantity of it, and at the same time to fetch some water likely to contain animalcules.* My implements were a

* The locality was in the King's County, a few miles from the village of Clara. 
group of apparatus somewhat similar to those represented in woodcut No. 3 (page 22), only that instead of a single small phial-I brought about four-for the purpose of obtaining samples from other ponds and ditches; for some ditches nearer to the bog abounded in confervæ

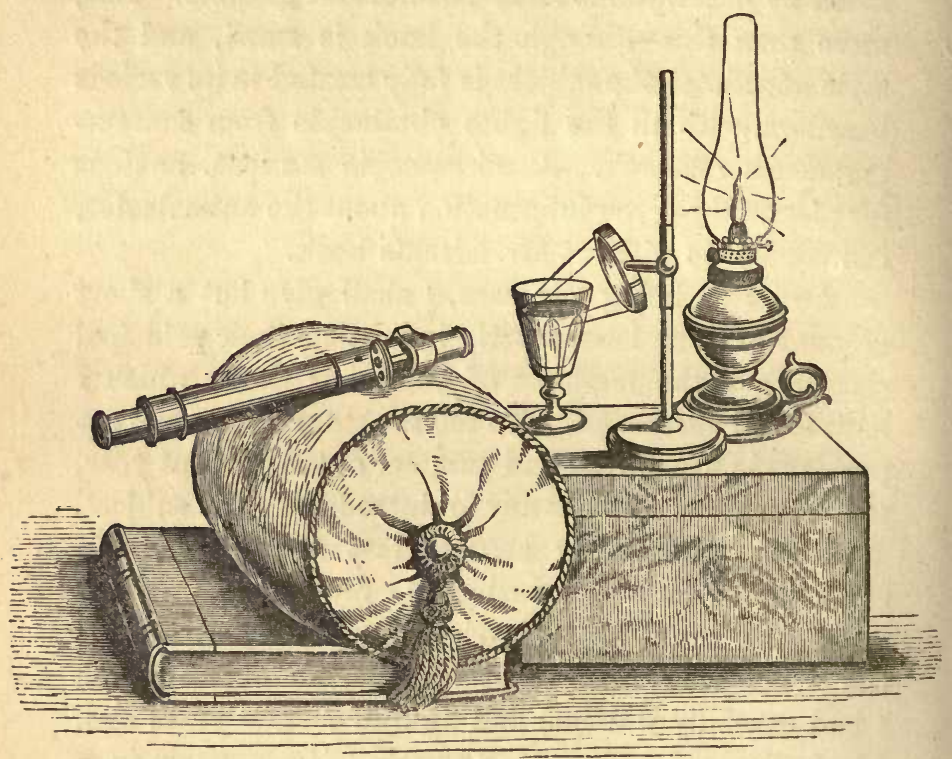

No. 12.-Arrangement of Microscope for viewing minute Water Animals. 
into the water; some pieces of weed from each place were dropped in, and a larger bottle was employed for holding a little of the frog-spawn, which for the informa-

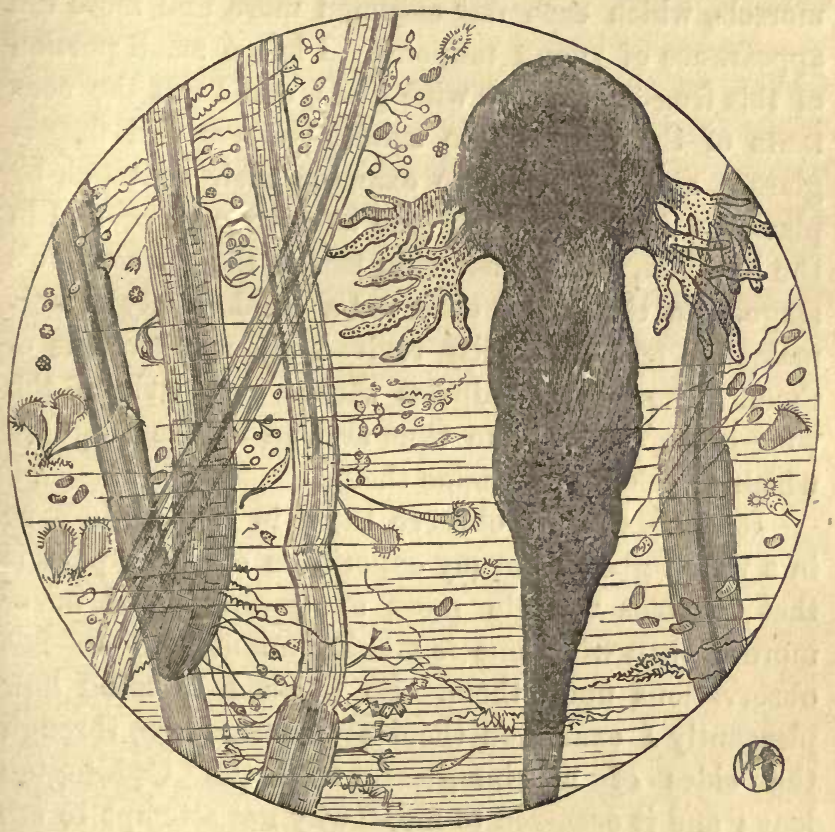

Nat. Size:

No. 13.- Young Tadpole, Stems of Duckweed, and various Animalcules magnified twenty diameters.

tion of those who have not seen any, is a jelly-like substance, looking not unlike a quantity of white currants laid closely together, and containing a round black 
shot in the centre of each. At least such is its early form; for the frog-spawn which I brought into the house had begun to change its aspect, and instead of little black shot-like balls, contained bean-shaped morsels, which each day assumed more and more the appearance of young tadpoles. I left a small portion of this frog-spawn in a wine-glass, and I put the contents of the bottles into sundry saucers and fingerglasses, and proceeded to examine their contents, by placing a drop from each (one at a time of course) in the live-box, and transferring this to the microscope's stage. In this way I observed a good variety of animalcules, and pleasantly revived my recollections of them. The young tadpoles throve very well in the wine-glass, and in due time arrived at the stage in which I wished to examine them.

It is possible to observe these in the live-box, or in a watch-glass; but my experience of either plan is that tadpoles wriggle most unpleasantly, and never more so than when one is making minute and difficult observations upon them. So I called to mind how pleasantly I examined them some years ago, through the sides of a wine-glass, with the Coddington lens; and it occurred to me, "why not attempt to use the tube of the microscope in the same way?" For the young tadpole, when about the size of a grain of oats, though very fidgety when under constraint, has a habit when left to its own devices of resting motionless for several minutes at a time. It possesses a fringe-like arrangement around its mouth, enabling it to hold on to any filmy remnants of the frog-spawn or 
other floating matter, and thus suspend itself in an upright position. Several of the tadpoles in the wineglass were generally to be seen suspended in this way; and some of these were quite close to its inner surface.

I removed the microscope tube from the stand, and mounted it, as shown in No. 12, upon a cushion raised on a large book, so that I could look as through a telescope into the wine-glass. The drawing represents the arrangement for lamp-light, but I preferred using this plan in the daytime. It answered exceedingly well, much better than the Coddington lens, and my observations about the tadpole will be given in the concluding chapter. Those observations at first engrossed my attention; but presently it struck me, how picturesquely are the animalcules shown, in perfect liberty, threading their way amidst the transparent forest of duckweed stems, or growing plant-like upon them, or on the inside of the glass itself, and how great a variety of them appears in the field of view! I commenced to make a list of them; it may serve as a sort of inventory of the set likely to be found in a duckweed-covered pond. Other kinds - to be presently named-were in the additional vessels, but all here were actually in the wine-glass along with the tacipole (No. 13).

1.-The Stentors. Trumpet-shaped and bright green. Sometirnes like a post-horn, almost as slender as a horse-chestnut leaf-stalk, sometimes shorter and broader; some are thimble-shaped, and moving freely about. One of them pale brown, nearly colourless. 
2.-The Vorticelloe (bell-flower animalcules). Sometimes double-headed, sometimes swimming freely, with no stalks.

3.-The short wheel-animalcule, creeping leech-like by arching its body and drawing up its foot to its head, then putting its head forward, and so on. It carries a pair of wheels, apparently on its head, and can swim freely through the water.

4.-The astonishing, transparent, bagpipe-like creature, rolling over slowly.

5.-The swan-like little creatures.

6.-The bright green animalcules, covered with bairs, very common.

7.-The colourless animalcules, bean-shaped, like the green, and commonest of all.

8.-Sinaller colourless animalcules, also very common.

9.-Animated straw-mat, very bristly, and apparently hot-tempered, always making sudden darts. Ornamented with three or four little movable commas. It was sometimes to be seen in side view, darting along stalks.

10.-The stiff-branched pillar, almost like a plant, thongh resembling Vorticelloe; standing on the duckweed stalk, and occasionally moving one of its bells slightly.

11.-The animated blackberries-brown, however, not black-solemnly rolling over and over.

12.-The chain-like filaments, their links fastened generally at opposite corners.

13.-The little wedges on branched stems. 
There were a few others besides these, which appeared when a small portion of the duckweed and a drop of the water were examined in a live-box; but the above were all seen with the microscope through the wine-glass's side. I found it not difficult to remove for closer examination, any particular group of stentors, or tolerably large animalcules, by raising them with a shovel-like wedge of paper. Another well-known and excellent plan for securing small objects in the water is to use a " dipping-tube." This being made of glass, and open at each end, you place your finger on its top, and gently push its lower end close to the object; then slightly raise your finger, and a little water will suddenly rise into the tube, probably carrying the object with it, which you can then lift on to a slip of glass, or to the live-box.

A glass trough has been contrived for holding animalcules and growing plants, and allowing these to be examined from outside, it looks not unlike one of the "baths" used in photography. Dr. Carpenter figures it, and also gives a view of an "aquarium microscope," the instrument's tube being mounted on a stem which can be attached like a vice to a table; still I have described my own plan, as it may be said to require no apparatus.

And now for a little book-lore on the subject of the tadpole's small neighbours. In the infancy of microscopic knowledge, all the minute water-animalk which were too small to be discerned without a microscope, and which could not be very clearly examined even with the microscope, that instrument being then 
in an imperfect state, were classed together. The name Animalculæ was given to them, and applied to a heteregeneous assemblage, including not only the true animalcules, but a number of minute plants, crustaceans, and larvæ. One by one these have been removed, and referred to other positions. It was an easy matter to do this with regard to many of the crustaceans and larvæ, but the case is different with a few of the plants, and also with some of the animals; naturalists are by no means agreed about the classification of these, because thorough and complete observation of each species is necessary, to trace out its lifehistory, before its place in the scale of creation can be ascertained. There are numerous animalcules about which this kind of observation has never been made; a wide field of research is therefore open to the microscopic student.

The word animalcule, if we look at its derivation, is nothing more than "wee animal," but it has a distinct meaning; for it includes just two well-marked tribes of minute living creatures, to which the names of Rotifera and Infusoria may be given, and excludes certain perplexing little forms which are seen to move, and yet generally set down as plants; and also certain small animals which are essentially different in structure from the rotifers and the infusoria, and are designated the "root-footed," or Rhizopods.* These

* The classification adopted by Dr. Carpenter is here followed. The two gronps of animalcules, "having scarcely any feature in common except their minute size," and one being of very low and the other of comparatively high organization, were first recognized 
last-named creatures are of very simple organization, and akin to the sponges, which, as Dr. Carpenter says, have "been banded from the animal to the vegetable kingdom, and back again several times in succession."

None of these Rhizopods chance to occur among the crowd represented at page 109. Some of the plants, however, which once passed as animalcules, may be observed. The "animated blackberries" of my list are specimens of "Protococcus," a plant, the development of which was observed by Dr. Cohn, who published its "memoir" at Bonn, in 1850. Its powers of rolling over and over, and even of impelling itself forward, are not singular among microscopic plants. The several forms assumed by protococcus in different stages of its growth, have led to its being taken for a number of distinct genera of animalcules, and described under several names.

The "chain-like filaments" in my list are two specimens of Diatoma vulgare, represented on a larger. scale in the figure on p. 116.

It belongs to the numerous and widely-spread tribe of the diatomaceæ, a long word, which simply means "cut (or broken) through," and appears to

as distinctly separate in structure by Professor Ehrenberg. He named these two groups Polygastrica and Rotifera. The former name was based on a theory which is now pronounced to be erroneous and Dr. Carpenter substitutes for it the name Infusoria, once applied to all the animalcules, from the prevalence of many of them in infusions of hay and other regetable matter; but to the higher group he still gives Ehrenberg's name of Rotifera, as appropriate to the "wheels" carried by many of its members. 
indicate the readiness with which their component parts separate. They were set down as animals by the eminent Professor Ehrenberg; but are now classed as plants by a number of careful investigators.

The "little wedges on branched stems," No. 13

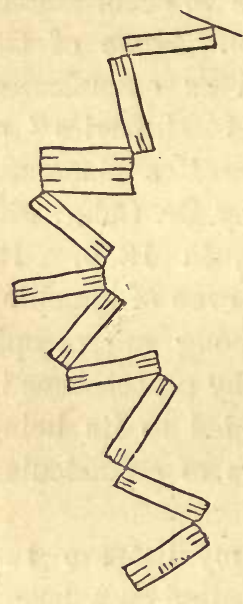

No. 14.-Diatoma vulgare. in my list, are also diatoms, by name Gomphonema geminatum.

The diatoms might in strictness be excluded from a chapter on animalcules; still as some naturalists continue to class and describe them as animals, some notice of them may be considered admissible ; especially as many examples of the tribe, when dried and mounted on slides are well-known microscopic objects of extraordinary beauty; and the reader may look at these with added interest, after comparing them with these humbler specimens found in a living state.

A great variety of form occurs in the different species of diatoms. In the Diatoma vulqare, represented above, which gives its name to the whole group, its component cells are oblong, and generally in a state of partial separation, being joined by a gelatinous hinge at the corners. Sometimes, however, two or more cells may be seen side by side, as in the third link from the right in the figure. Other diatoms, besides this one, have the same curious arrangement for joining at their corners; two of these, 
called Isthmia and Biddulphia, inhabit sea-water, and are very beautiful. But in some diatoms the cells are closely joined, and form a nearly straight filament. If the sides of the cells (generally called the "frustules" of diatoms) are not parallel to each other, a curved filament is produced.

Sometimes diatoms have stalks to which they grow singly, or in a branched arrangement, as seen in Gomphonema; others have a mucous or gelatinous covering, in which a number of the frustules lie. Some are quite free, appearing singly, and these are of various shapes-oval, triangular, boat-shaped, and round; these last seeming like disks, and to be found (when in their living state) adhering to sea-weeds.

These free diatoms have a strange power of moving about. Those of the genus Navicula are familiar objects to the microscopic observer. Several of them may sometimes be seen together in the field of view; they are shaped like the decks of tiny ships, reminding the beholder of the plan of some great sea-fight, where the vessels appear in various directions; and while we look, we notice that they are gliding along, but with no visible means of propulsion. This motion is well described by Mr. Tuffen West, artist of the beautiful illustrations to the late Professor W. Smith's "Synopsis of the British Diatomaceæ."

He says, "It is not the rapid meteor-like whirl of the infusorial animalcules, but a gentle gliding in one direction, the distance and the time occupied in traversing it being clearly defined, and readily nozed by a good watch; there is then a brief period of rest, 
and the return journey is duly proceeded with." $\mathrm{He}$ adds, "The reasons for, and way in which these motions are effected, are involved in some obscurity."** Professor Smith has suggested that forces operating within the frustule may combine to impel it; but it would seem that nothing upon the subject has been proved.

The shape of a diatom cannot always be ascertained
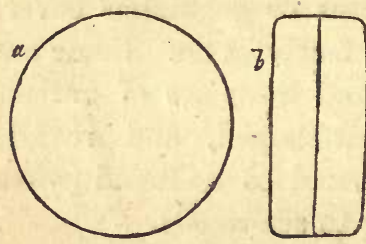

No. 15.-Coscinodiscus in outline- $a$, side view; $b$, front view. by looking at it in one direction, as it is often of some thickness (comparatively speaking), and its front view very different from that of the side. It is made up of two portions or valves, exterually convex, and hollow within.

No. 15 represents the front and side view of one of those which appear as disks, when their sides only are observed. A dissimilarity of appearance corresponding to this may be observed on a close inspection of the lowest groups of Gomphonema, in No. 13 ; their frustules seen in front resemble a figure of 8 rather than a wedge. The valves of the diatoms are sculptured with lines, dots, and other markings, arranged so as to form patterns of exquisite tracery. Some of these are of such extreme minuteness as to be among the most difficult tests for the higher powers of the microscope; of these Pleurosigma (formerly called Navicula), hippocampus is a well-known

" “Diatoms" by Tuffen West, "Recreative Science," vol. i., p. 69. 
example, though by no means the most " difficult" of these test-objects.

The most remarkable feature of the diatoms may be said to be this, that their valves are made of flint; the contents are soft, but the flinty part remains, skeleton-like, even after the diatom has been immersed in nitric acid, or exposed to the action of fire.

Mr. Tuffen West, in the article already referred to, says that a good way of readily observing the markings on diatoms is to place them on talc, and expose this to a gentle red-heat. Accordingly one day, happening to observe some roots of duckweed festooned with a quantity of diatoma and gomphonema filaments, and some specimens of navicula moving about near them, I placed them on a little disc of talc (found among the apparatus of an old microscope), and bearing well in mind the vegetable nature of diatoms, and their consequent absence of feeling, carefully laid the talc on a red-hot poker. I removed it when the latter had become cold, and at once mounted the talc, by turning it downwards on a glass slide, and fastening it with paper in my usual way. The effect of the fire was interesting; the duckweed had turned into a faint heap of ashes, but the numerous diatoms showed in great clearness both of outline and markings.

Dr. Carpenter remarks that the flinty covering of the diatoms may rather be described as consolidated with silex (flint) than altogether composed of it. $\mathrm{He}$ states that Professor Bailey contrived to dissolve the silex with hydro-fluoric acid, and there remained a delicate membrane, bearing all the markings of the 
siliceous envelope; and he considers that this is a cellulose coat, which becomes interpenetrated by silex. It will be remembered that the delicate cells can be traced in fossil wood (page 92), when their walls have been similarly penetrated by silex or by carbonate of lime; and, just as they remain almost indestructible, so do the tiny diatoms, testifying of their existence in past ages, as they occur fossilized in countless myriads in different parts of the world.

An extensive stratum of earth, eighteen feet in thickness, underlies the whole city of Richmond, in Virginia. When specimens of this earth are examined with the microscope, they prove to be almost entirely composed of the shells, broken and perfect, of diatoms, in great variety, and exquisitely beautiful. A similar stratum of so-called "infusorial earth" occurs in Bermuda, and a group of the diatoms from the latter are on the microscope's stage while I write. They are all circular, and named Heliopelta-" shield of the sun," and round as Norval's shield! See a specimen of Heliopelta, reader, if you can; and if you will examine it with various magnifying powers and modes of illumination, you will be at once astonished and delighted at the perfection of its structure, and the wonderful delicacy of its tracery; and will feel pleased at being in some degree informed as to its nature.*

* The reader will find all the most beautiful diatoms named and briefly described in L. Lane Clarke's "Objects for the Microscope." 


\section{CHAPTER XI.}

TIIE ANIMALCULES, CONTINUED.

ND now to proceed with, or rather commence, our identification of the animalcules in No. 13. The two orders spoken of by Dr. Carpenter are both represented here, although the latter class is in a minority, as it has but one example, number 3, the "short wheel-animalculæ." We shall consider it last, along with some fine examples of the same class which occurred among water-plants in my other collections.

The beautiful vorticellæ, or bell-flower animalcule, shall claim attention first. You may see them (for the bell-flowers congregate together like so many campanulas in a flower-border) mounted on their delicate hair-like stems, occasionally swaying to and fro. There! one has disappeared with a sudden movement; has it dissolved? No; it has only drawn back; and here again it comes slowly forward, its head globular, instead of vase-shaped, and its stalk coiled into an elegant corkscrew form, which gradually straightens itself. Then the globular head, by some movement 
difficult to follow, again becomes a vase. Meanwhile, another and another of the group draws back, disappears, and again advances, till the observer is half perplexed by the multitude of corkscrew stems and moving bells. But this is not all; for all the little chance particles in the water are in lively whirlpool movement around every stationary vase. We connect this in our minds (and rightly) with the little tuft-like structures visible at the edges of each; these seem to stir with a motion that can best be described by the phrase "twiddling."

Such is the appearance of these structures at first sight, and when special arrangements are not made for illumination. But when this latter point is duly attended to, we can observe that the bells are surrounded by a complete wreath or border of transparent moving filaments, called "cilia;" and we shall meet these curious organs again and again while observing the animalcules. They serve for attracting their food from the surrounding water; and in many animalcules they act as a means for propelling themselves where they will-if such an expression can be used with reference to the infusoria, whose movements seem scarcely dictated by a conscious will. And that these "ciliary movements" are not indicative of consciousness seems possible, since, as Dr. Carpenter observes, "we know that ciliary action takes place to a large extent in our own bodies without the least dependence upon our consciousness, and that it is also observable in the structures developed by the spores of some plants." 
Be that as it may, the movement of the cilia gives an air of peculiar liveliness to a group of animalcules. Some possess them around their mouths only, like the vorticellæ, but around those mouths the particles dance like sparks from a revolving firework. A vorticella, too, sometimes detaches itself from its stalk, as observed at page 112, and it then uses its cilia for propulsion through the water. Others again, as the stentors, and the lively infusoria numbered 6, are nearly covered with them. Their shape and size can only be made out when they chance to move slowly; it then appears that each filament bends from its root to its point, returning again to its original state, and that there is a sort of "feathering" action, like the stroke of an oar. This being repeated all round a wreath of cilia, conveys a strange likeness to a really progressive movement. It is with an effort of the better judgment, based on a recollection of their appearance when detected in slower motion, that the observer manages to rest assured that the object looked at does not consist of a number of little filaments, chasing each other round a circle, or, in the case of the rotifers, of a little toothed wheel, revolving bodily upon a fixed axle. But the same illusion will take place occasionally with regard to other moving objects, each of which we know experiences no progressive change of place. The appearance of moving waves caused by "the wind that shakes the barley" is a familiar instance; and one which impressed me forcibly, was the apparently wheel-like movement of some circular devices in gas, when the principal strects 
in London were illuminated some years ago, in honour of a distinguished visitor. It was not till I had clearly ascertained that each jet was fixed, but subjected to a whirling motion from the air, that I realized that the whole thing did not turn on a central pivot.

The expansion of a vorticella's cilia, after its sudden retreat and gradual emerging, can be detected by a little practice and management of the microscope's focus screw. It will swing its globular head into full view, and suddenly its rim will open out, and the fringe of cilia show for an instant in extreme delicacy; and then, off they go, in their rapid whirling movement.

The portly stentors, however, show the cilia in splendid style. The one which is represented thimble-shaped, and careering along at the right of No. 13 , is using its cilia as paddles to propel it, while the three temporarily fixed, and generally of trumpet shape, are attracting food to their mouths. This animalcule (that is to say, the bright green species of stentor, Stentor polymorphus, or the many-shaped,) is quite visible to the unassisted eye. They will often occur in great numbers (and the same may be said of other animalcules) in a piece of water on one fishing occasion, and be quite scarce, or apparently altogether absent, at another time.

Number 4 is another animalcule. It is the "bagpipe-like creature" of my list, and I believe was Trachelius ovum.

The "stiff-branched pillars," so described in my list in contradistinction to the slender waving stem of 
the vorticellæ, are called Epistylis, and are allied to the vorticellæ. They bear a considerable resemblance to the branched vorticella, called carchesium - a really splendid object. I have seen it occasionally, and Mr. Slack describes it very truly when he says, "A group of these creatures presents a spectacle of extraordinary beauty -it looks liké a tree from fairyland, in which every leaf has a sentient life." Ten or more bells, with long thin stems, exactly like the ordinary vorticellæ, will be seen mounted on a stalk; and, in the specimens which I examined, the stalk, which was four or five times the thickness of the other stems, had to a considerable degree the contractile

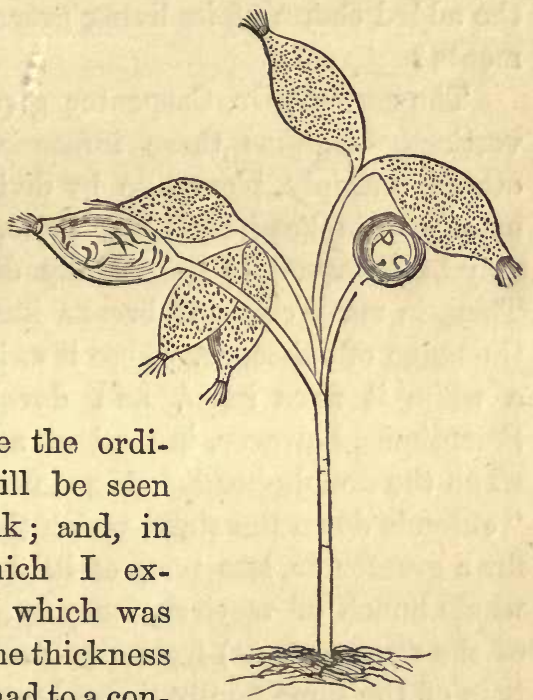

No. 16. -Epistylis. power. It would draw the whole set of bells backward with a force and suddenness quite startling; and then, ever so gently and gracefully, the elegant spiral stalk would unbend, and all the bells extend themselves. And this can be well shown in the mode of background illumination, when the beautiful stems and vases, at all times transparent, and but slightly tinged with a greenish or straw colour. appear as if 
moulded in sparkling glass, and every stem seems twisted into a graceful spiral pattern. One almost speculates as to the possibility of modelling the whole thing on a large scale, with black velvet background, as an ornament of rare elegance; but where would be the added charm of its living grace and varied movements?

The account Dr. Carpenter gives of the branched vorticellæ is, that these infusoria, as well as many others, multiply, plant-like by division. One sees an usually wide head, and the same, after some hours, may be observed to be actually double (see p. 112). Then, in many cases, it breaks itself off, and reaches the stage of existence, where it swims freely, and after a while it fixes itself, and developes a new stalk. Sometimes, however, instead of at once breaking off when the double-headed stage is attained, the dividing " extends down the stalk, which thus becomes double for a greater or less part of its length; and thus a whole, bunch of vorticellæ may spring (by a repetition of the same process) from one base. In some members of the same family, indeed, an arborescent structure is produced, just as in certain diatoms, by the like processes of division and gemmation." Here Dr. Carpenter refers to a figure, which is no other than that of the diatom "Gomphonoma geminatum;" and, on finding this, the reader may ask, "Why is that diatom called a vegetable, and epistylis and vorticella animals?" There are certain considerations regarding the different manner in which plants and animals extract nourishment-the former directly from the 
elements that surround them, the latter from sub. stances already organized-which afford a method of drawing a distinction; but, as Mr. Slack tells us, "the learned do by no means agree" on the question "What is an animal? and how does it differ from a vegetable?" and he amusingly characterises the difference as being "observable enough if we compare a hippopotamus with a cabbage, but which grows 'small by degrees and beautifully less,' as we contemplate lower forms."

Something of the interest of a riddle, then, attaches to these researches; but, more than this, there is an especial charm in the contemplation of these simply-framed plants and animals, which seems to conduct us near to the elementary law or principle on which all organized beings are formed.*

Passing over numbers 6,7 , and 8 of my list, which I did not re-examine, but which I believe to have been, the first a Paramecium, characteristically covered with long rows of cilia, which I described as "hairs," and the last two members of the Kolpod family, there remain the rotifer, the swan-like animalcules, and "animated straw-mat." This last was Stylonichia, and I find No.17.-Stylonichia. that Mr. Slack makes mention of its bristles and its comma-like appendages, both of which are developments of cilia, and known as * See "Marvels of Pond-Life," Introduction, and chap. xiii. 
styles and uncini, or little hooks. They are also described at considerable length by $\mathrm{Mr}$. Gosse, in his most interesting book, "Evenings at the Microscope." The swan-like creatures appear somewhat similar to, but not identical with, an animalcule represented in Mr. Gosse's book and elsewhere as "Trachelocerca olor."

And now we turn to the rotifer; and in so doing we get at once (it would seem) into very high company. They are as far removed in complexity of structure from the other animalcules which we have been considering, as the mosses are from the very simplest plants; yet they have ever been described along with their humbler neighbours. Had they a voice to complain of this treatment, we could but make an answer similar to that which Esop's husbandman made to the expostulating stork, "Show me your company, and I'll tell you what you are;" an animalcule, though possessing various exalted characteristics. For, in the wheel-animals, we witness what the learned call a "differentiation" of parts and tissues, and a "specialization" of organs. The head is plainly distinguishable from the body, the skin or integument is distinctly different from the internal tissues, "we can detect a nervous ganglion or miniature brain, the gizzard in a complicated piece of vital mechanism, such as we have not met with before, and in various parts of the transparent inside we see organs to which particular functions are assigned."*

The rotifers form a numerous tribe, and many * " Marvels of Pond-Life," p. 35. 
of the species are exceedingly abundant, occurring in water where vegetable substances have decayed, but rather to be expected when the active stage of decay is over. Like the infusoria, they will appear after a while in water where hay or leaves have been infused - a fact which Dr. Carpenter connects with the circumstance that these animalcules can be completely dried, and will yet return to activity on being moistened; for he says they may be wafted in a dry state in the atmosphere, and thus removed from place to place.

No. 18 represents the common wheel animalcule (Rotifer vulgaris) which I found repeatedly near the duckweed, as well as among other water-plants. The wheel-like organs show particularly well in this specimen of the tribe. Their appearance has been so often and so well described, that I need only remark that they do indeed look exactly like a pair of pretty little.

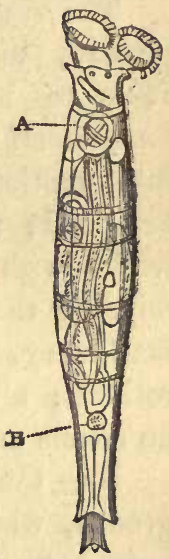

No. 18.- Rotifer vulgaris. A, gizzard. B, con. tractile vesicle. toothed wheels, revolving at a rapid rate. All this is caused by the independent movement of the separate cilia, as already explained, but the illusion is so perfect, that we are not surprised to find that the old microscopists thought these were really wheels; thus the writer of the article "Animalcule," in the Encyclopædia Britannica, edition of 1790, regularly describes them as such, but informs us, what wo 
might not unnaturally expect, that the difficulty of understanding how the rotation could be contrived, "hath caused many people to imagine that there was a deception in the case;" and it is interesting to observe how those incredulous people in due time have arrived at the truth.

The singular organ, $A$, is variously known as the gizzard, masticating apparatus, jaws, and mouth. It is to be observed, especially when the rotifer fixes itself by its tail-foot and puts its "wheels" into motion, working away actively as if grinding the food; and, no doubt, it is thus employed. It works with a peculiar force and smoothness, reminding the beholder of the movement of well-oiled machinery. This organ is characteristic of the rotifers; all possess this, though the wheels are by no means universal among them.

Dr. Carpenter divides the Rotifera into four groups, which I shall name, having been fortunato enough to meet with specimens of each. He follows the division propounded by M. Dujardin, which is based on the several modes of life of the different rotifers. For some always continue attached by the foot to a leaf or other permanent resting-place; others can thus attach themselves, but are also able to move, leech-like, or by rowing themselves by means of their cilia through the water; a third group habitually swim, and rarely attach themselves; while a fourth creep slowly, and indeed seem to resemble Rotifer vulgaris in little except the possession of somewhat similar jaws. 
Of the first of these groups, the Beautiful Floscule (Floscularia ornata) and Melicerta ringens are most interesting examples. I found both of them in April, single specimens of each, and examined them with sufficient care to enable me to appreciate the bookdescriptions of them, which had already excited my curiosity.

The floscule was among a débris of water-weeds, and appeared like a brown bulb on a stalk when viewed with a low magnifying power; but the moment it greeted my eye, I thought "here is a floscule, and I shall see it thrust out its long hairs like an oldfashioned drawing-room hearth-brush!" The next instant, it was plain that this had occurred; I well remember the feeling of interest with which I substituted a power of 200 diameters for the lower magnifier at first used. The floscules possess a gelatinous tube, quite like a confectioner's glass jar; this I did not contrive to see, but I realized the rest of Mr. Slack's description.

"She slowly protruded a dense bunch of the fine long hairs, which quivered in the light, and shone with a delicate bluish green lustre, here and there varied by opaline tints. The hairs were thrust out in a mass, somewhat after the mode in which the oldfashioned telescope hearth-brooms were made to put forth their bristles. As soon as they were completely everted, together with the upper portion of the floscule, six lobes gradually separated, causing the hairs to fall on all sides in a graceful shower, and when the process was complete, they remained per- 


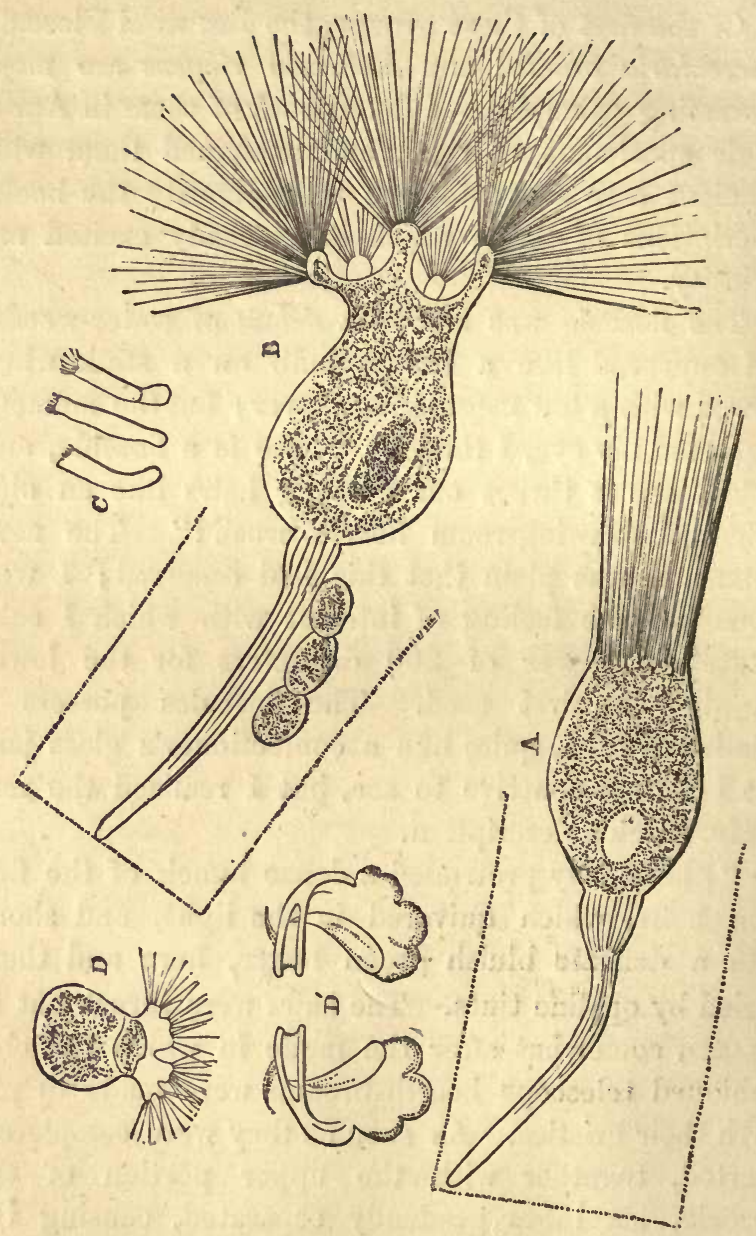

No. 19.-The Beautiful Floscule. A, partially, B, fully expanded. C, D, young Floscules. D', jaws of Flosenle, as figured by Mr. Gosse. 
fectly motionless, in six hollow fan-shaped tufts, one being attached to a lobe." A slight knock given to

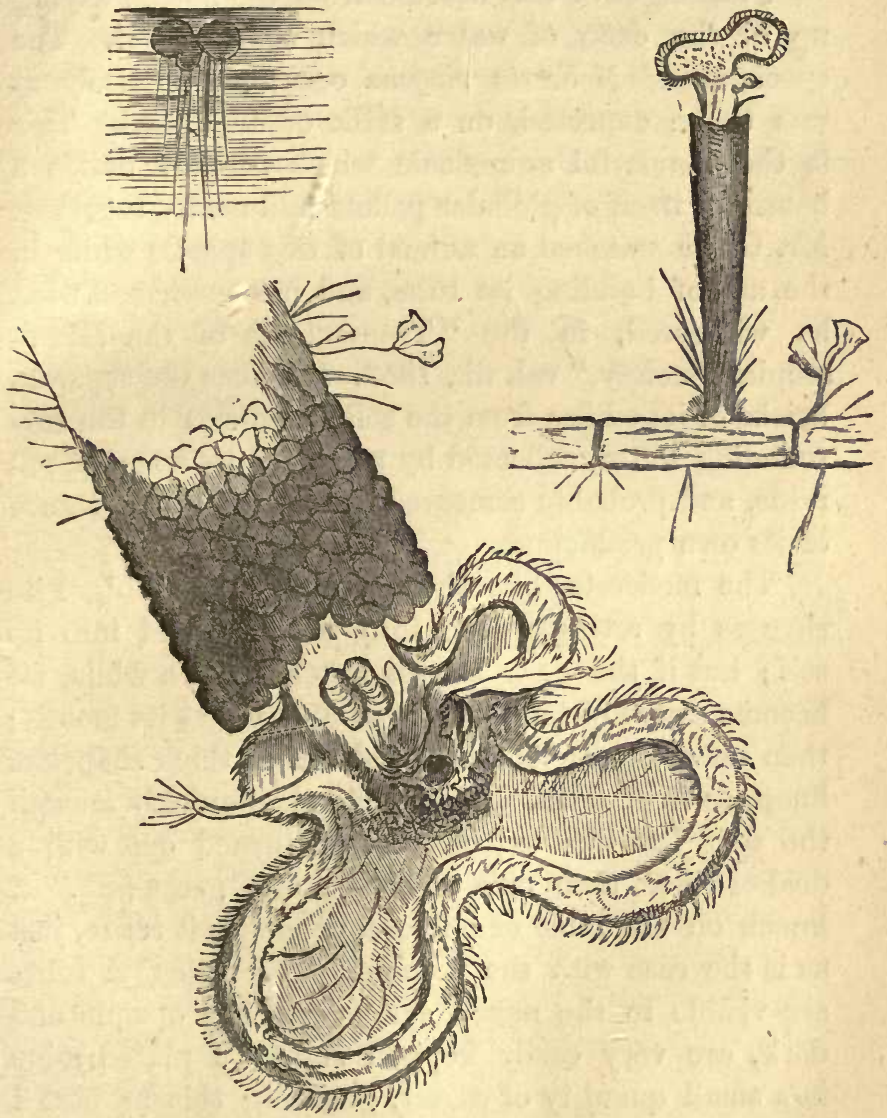

No. 20.-Meiicerta ringens.

any part of the microscope always caused the floscule 
to draw itself in; but it would immediately recom mence the beautiful process of expansion.

I lost sight of this floscule from the partial drying up of the drop of water which contained it. The specimen of Melicerta ringens occurred, precisely as was to be expected, on a stalk of duckweed. This is the wonderful animalcule which actually builds a house for itself of globular pellets laid neatly together. Mr. Gosse watched an animal of this species while in the act of building its tube, and has described what he witnessed, in the "Transactions of the Microscopical Society," vol. iii., 1863. It makes the separate bricks of its edifice from the solid particles in the surrounding water, collected by means of its wheel-apparatus, and probably cemented by a glutinous substance of its own producing.

The melicerta, like the floscule, often indulges its shyness by retiring deep into its tube, and into its self; but if the dark tube is watched for a while, we become aware of some sort of commotion at its mouth; then some feelers look out, and next a thick shapeless lump, as if of flesh, appears, and then quickly enough the four leaf-like expansions are turned out with a deal of force, their cilia revolving at a great rate. A knock on the table or microscope makes it retire, just as is the case with the floscule. The melicerta tubes are visible to the naked eye, and, being opaque and dark, are very easily kept in sight. I placed mine in a small quantity of water, guarding this as best I might from evaporation, when called for a few days from home, but on my return the tube proved to have 
lost its tenant. I tried the experiment of mounting it in balsam, which answered perfectly. The object is now before me, under a high magnifying power. It stands like a tower, its front battlements showing well, and those farthest from the eye appearing in distant perspective. The round bricks, by mutual pressure have assumed the hexagonal form, giving an ornamental appearance to the little edifice.

The second tribe of rotifers, namely, those which
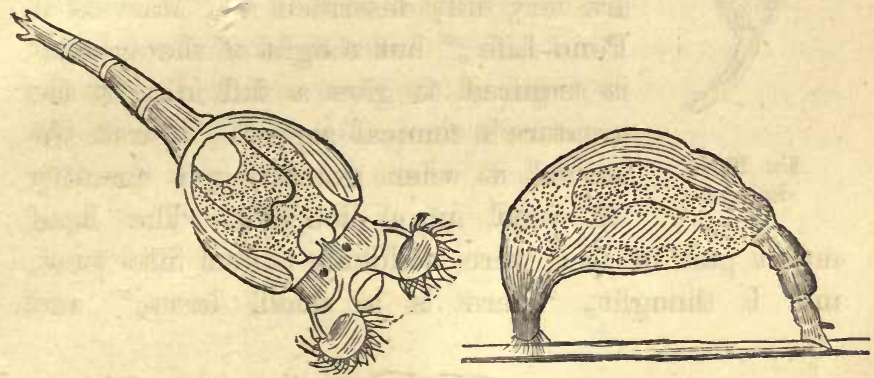

No. 21.-Philodina.

frequently attach themselves by the foot, but which are able to swim, has been represented by the common wheel-animalcule. The rotifer represented in No. 21, philodina, is another example. Its method of walking is similar to that practised by the common rotifer; and, like it, this rotifer can draw itself into a globular and rather uninteresting form when at rest, and disinclined for wheelexercise.

The third tribe are pretty little animals, often possessing a cuirass or carapace of hard material, 
somewhat resembling the shell of a crab. No. 22 represents salpina, one of the species. I have occa-

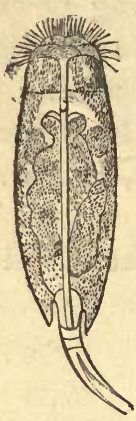

No. 22.-

Salpina. sionally found the empty shells of some of these rotifers, and contrived to mount one of them in Canada balsam.

The fourth tribe which M. Dujardin has included among the rotifers consists of the Tardigrada, or slowsteppers, popularly called "water-bears." They are very fully described in "Marvels of Pond-Life;" but a sight of the original is required to give a full idea of the creature's comical aspect. I first observed it when examining a quantity of weed in a live-box. The head and a pair of feet were suddenly poked into view, and I thought, "here is a small larva," and

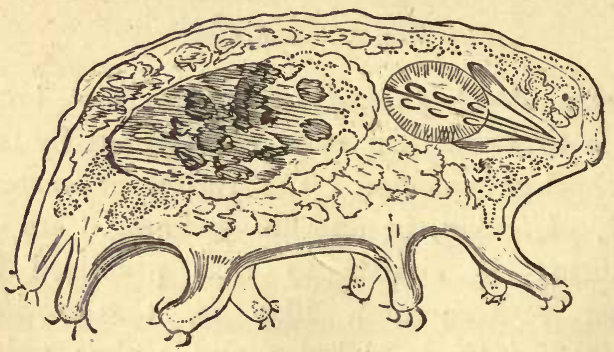

No. 23.-Water-Bear.

expected a long body in several joints to follow, when all at once the creature showed in its completcness, walking along a stalk, and more like a young 
puppy with eight legs than can easily be believed! Mr. Slack says his specimens had no visible eyes, and that these organs are, according to Pritchard's book,* "variable and fugacious." My water-bears had eyes, and of very respectable size and blackness. The first specimen which I met, being given sufficient room to climb by slightly raising the live-box's cover, seemed for some minutes as if staring at me, and in that position not a little resembling the white polar bear, its colour being somewhat pale. I felt inclined, when looking at this animal, to side strongly with those naturalists who (as Dr. Carpenter mentioned) regard the Tardigrada as altogether distinct from the true rotifers. Mr. Slack's account of them is, that they are, physiologically speaking, poor relations of the great family of spiders.

* Pritchard's "History of Infusorito" 


\section{CHAPTER XII.}

CIRCULATION OF THE BLOOD.

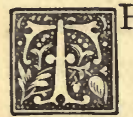

HE little tadpole suspended in the water at No. 13 now claims our attention. $\mathrm{He}$ is an individual of far higher standing than the animalcules, being a vertebrated animal, and is the tadpole of Rana temporaria, the common frog-which I mention because young toads and newts are also called tadpoles when in their aquatic state.

The microscopic spectacle which it presented to especial advantage on April 10th, and for some days later, was the circulation of the blood in the branchir or external gills, those four hand-like appendages which may be seen, two on each side of its head.

Plate VIII., fig. 5, represents a few of the capillaries in the web of a frog's foot, under a very high magnifying power. Each of these is filled by a transparent fluid, in which are to be seen the "isolated floating cells" known as the "blood-corpuscles." These are of two kinds, the "red" and the "colourless." The red always present the form of flattened discs, which are circular in man and in most of the beasts, and oval in the birds, reptiles, and fishes. They are hollow, and contain a coloured fluid. The colour- 
less corpuscles occur only exceptionally among the host of red ones. Dr. Carpenter states that for a time they appear identical with the corpuscles found floating in "chyle" and "lymph," but are liable to change their form ; and that their size is to a remarkable degree similar in all the vertebrated animals, whereas there are great differences in the dimensions of the red corpuscles in the various species. One of the colourless corpuscles may be seen in fig. 5 at the right, and near the top. The "red" corpuscles of the frog are exceedingly thin and flat, except at the centre, where there is an oval or almond-shaped thickening, which can be observed in a few of those in fig. 5. These corpuscles are very pliable, and are to be seen rolling over and over, and bending themselves at angles; and occasionally a single one will be observed caught for a few moments by some projection, till other corpuscles in passing sweep it into the current; and this description will also apply to the movement of the corpuscles in some other animals as observed with the microscope.

Circulation may be observed in various creatures not belonging to the vertebrated classes; to which, however, the red corpuscles are peculiar.

Two objects were always kept in mind-namely, to get a sight of the circulation in as many different stages as possible; and to do it without tyranny or violence. Never yet have I injured fish, frog, or newt on the microscope's stage; their joyous return to comparative liberty has gladdened me also, and many a walk I have taken up hill and down dale for the ex- 
press purpose of releasing them at the identical place where they were captured.

I took notes at the time of a few facts which I observed, and I made some rather elaborate drawings, from a small number of which Plate VIII. is taken. 'I also noted down, and will now relate, the manner which I found convenient for securing the different creatures, and which I still prefer to any other methods.

The animals which are most easily obtained are small fish, as sticklebacks, frogs, and (during spring and a part of summer) tadpoles.

The stickleback being, according to Mrs. Glass's immortal maxim, "first caught," can be secured in this way:-A glass slide should be got ready, also a little lump of jeweller's cotton, and a piece of soft thread, about a quarter of a yard long. Then the fish can be taken out of the water, and laid on the glass, its head near one end, so that its tail might come near the centre of the slide (No. 24, a). The cotton is to be made quite wet, and laid over the fish, leaving only its tail visible, and the thread, also made wet, is to be wound round, $b$; no fastening will be necessary. The fish can move its tail a little, but will probably seldom do so, and the tail-fin can be spread out, if required, by a camel's-hair-brush. The use of the lump of cotton is to prevent the threads from pressing the fish anywhere too sharply, and also to retain as much moisture as possible around the gills. Thus arranged, the fish may be kept several minutes on the slide, a few drops of water being occasionally spilt over it. 
When making the drawing from which Plate VIII., fig. 2 , is taken, I often put the fish back into the water, choosing for the purpose the interval when I required to go over my sketch with pen-and-ink. After a while, I placed the fish again on the slide, sketched more, and ascertained points that had been doubtful in the inking. There was no difficulty about
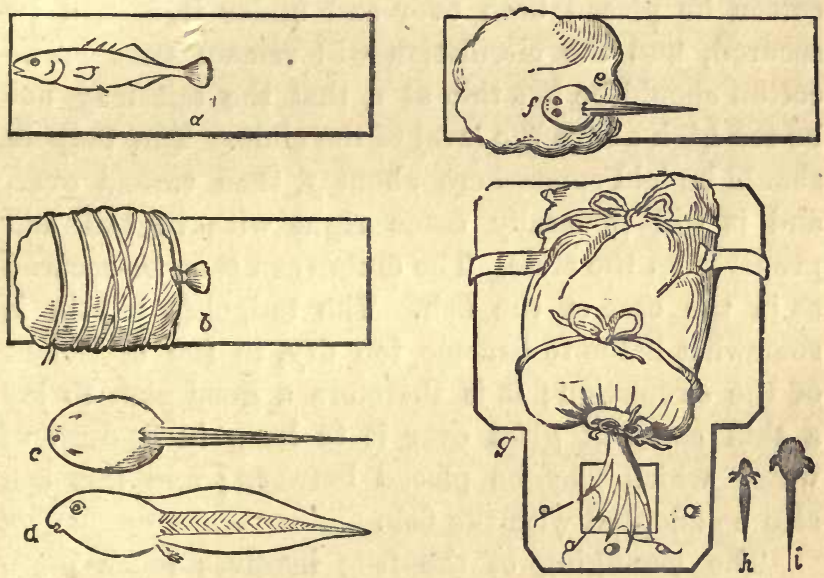

No. 24.-Arrangements for exhibiting the circulation.

finding the portion wanted on its tail-fin. The "achromatic condenser," which I always use when viewing the circulation, makes a disc of light exactly where the object is placed; so that with the unassisted eye I could judge when I had placed the right part of the fin over the light, and some familiar por- 
tion of it was sure to be in the field of view when the microscope's tube was lowered.*

A tadpole cannot be arranged in exactly the same manner as a stickleback; for if it be tied down by merely placing it on the glass, with cotton over it, the circulation stops, because this creature does not naturally lie on its side, its body being flat horizontally rather than vertically (see $c, d$, No. 24). But if cotton be placed both over and under it, it will be secured, and the circulation will remain free. The cotton should be left thin at $e$, that the tail may not be too high above the level of the slide. The tadpole should be laid somewhere about $f$, then turned over, and it will generally come right with its tail laid properly on the slide. The cotton can then be secured as in the case of the fish. The tadpole's tail-fin is somewhat liable to become too dry, to the detriment of the circulation; it is therefore a good plan to lay a thin scrap of glass over it to keep in a drop of water which may be placed between; and this can also be adopted with the fish.

The arranging of the frog involves much more trouble, but being a most interesting and indeed splendid object, it is worth taking some pains to exhibit it. When once it is arranged, too, there is none which can be shown with more certainty; and the frog being not out of its element the while, can be kept longer in view than one would like to attempt

* The achromatic condenser is an arrangement by which the light from the mirror can be directed with great clearness upon the object examined, by placing an object-glass below the stage. 
with a fish or tadpole. It is to be placed in a little bag, and this is to be tied on the brass "frog-plate," sometimes supplied with a microscope, or on the wooden imitation of it, which can be very easily cut out with a penknife. The shape is shown at No. 24, $g$, and the bag may be also seen, containing the frog with one foot left out, the claws of which are fastened by bits of thread to some little wooden pegs. The frog-plate must have two other pegs on the under side to fasten it to the holes generally to be found in the microscope's stage; it should also have a square hole over which the frog's foot is to be extended, and I found it convenient that it should have some fixed strings attached to it. The great point is not to give the frog room to draw in its foot, and the pair of strings tied in front of its head generally insure this.

The circulation in small water-newts, and various water larvæ and crustaceans, may be easily shown by placing them in the live-box with a drop of water. No. 25 represents a small and singular crustacean, called Daphnia pulex. The remarkable branching appendages over its head are antenno, or feelers; and it has but one eye, consisting of several lenses enveloped in a single cornea, which encloses them all. The whole of the circulation may be seen, though in a vague and rudimentary manner, in this little crustacean. There is a rapidly beating heart near its back, and from this colourless particles may be seen flowing and performing a circuit of the whole frame. Daphnia breathes not exactly by gills, "but by means 
of fringed plates on the outside of the third and fourth pairs of legs.'*

The circulation shows to vastly more advantage with the vertebrated animals. Plate VIII. fig. 1, repre-

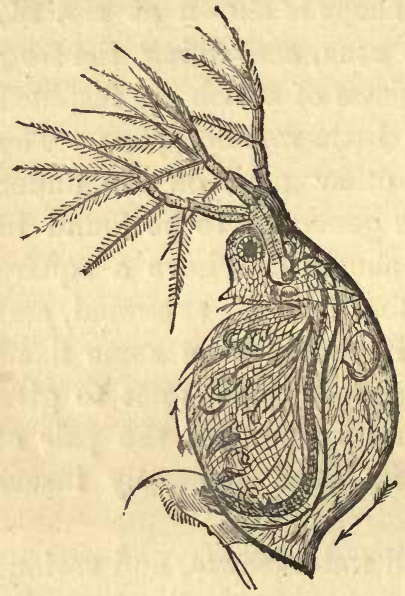
sents the three-spined stickleback, slightly smaller than nature, and fig. 2 represents a portion of its tail-fin when magnified thirtyfive diameters. The flat white spaces represent the bones, and it will be observed that in four places the bloodvessels are carried across these in fur6 rows excavated as it were in the substance No. 25.-Daphnia pulex, magnified 16 of the bone. A vein diameters. $b$, natural size.

and artery, placed in pairs, may be observed at each side of the bones; and in some places these may be seen crossing and recrossing each other in a fantastic manner. The arteries may be recognized by their flowing from the heart, and the veins by their flowing towards it, as indicated by the arrows. The narrow vessels connecting the large ones are the capillaries.

The pale, or rather colourless, appearance of the corpuscles may surprise the observer. The fact is,

* Baird's "Nat. Hist. of British Entomostraca." 

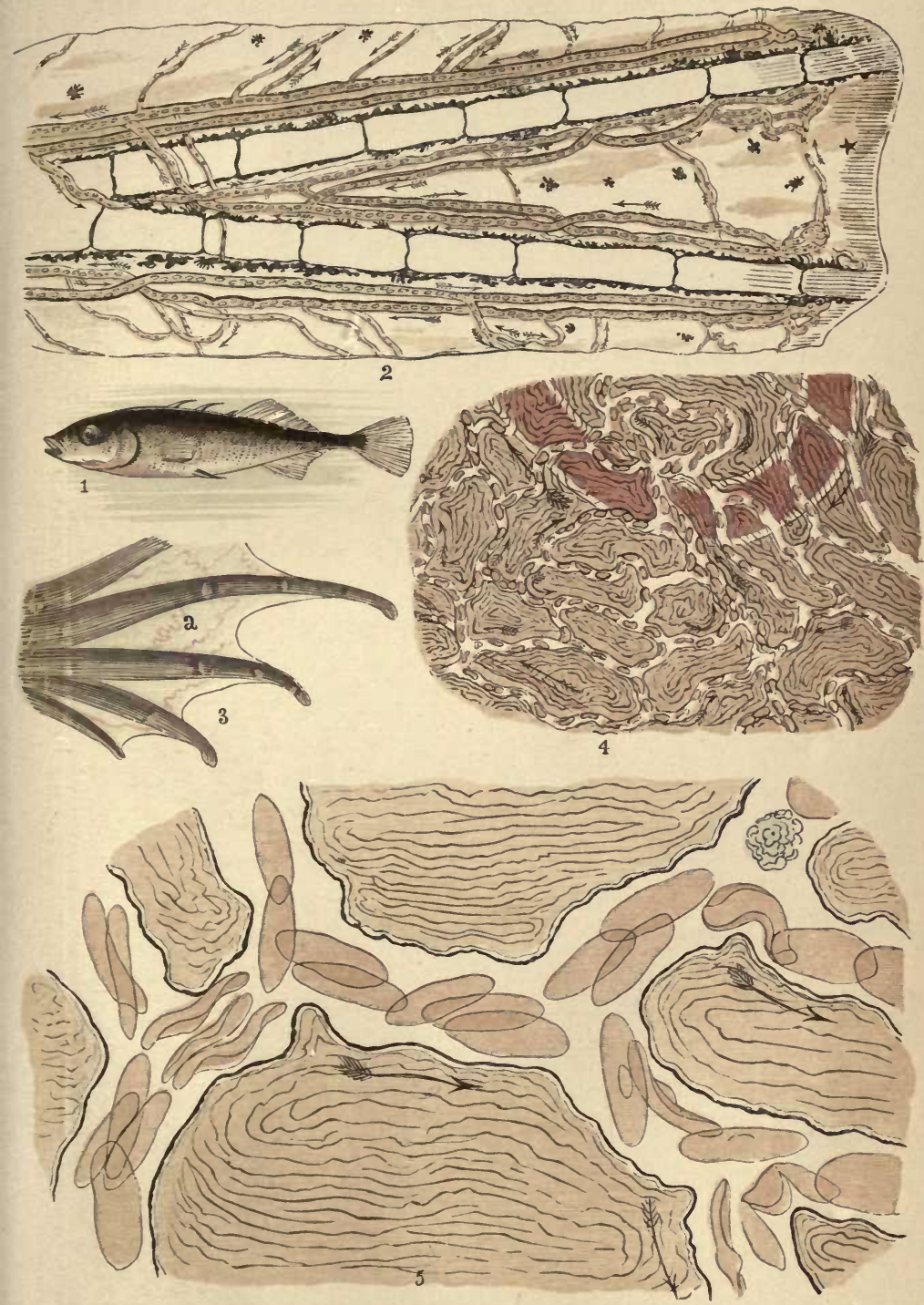

1. Stickleback. 2. Small portion of Stickleback's tail-fin. magnified 35 diameters.

3. Part of Frug's foot.

4. Minute portion of the web, magnified 100 diameters.

5. Capillaries in web of Frog's foot, magnified 530 diameters. 

that taken singly, they are but slightly tinged with colour, and it requires the presence of several layers of them to exhibit the well-known redness. A single corpuscle, however, when seen edgewise, if it be a large one, as that of a frog, will exhibit some depth of colour, and the larger veins, where a great number of corpuscles are flowing together, will appear of a decided red. To illustrate this by an example familiar to the microscopist, a dozen glass slides laid on each other, or a single slide viewed edgewise, will appear green, although any of these when laid flat and looked through singly, will, if made of good glass, appear nearly colourless.

The black markings and the star-like spots on the fin are collections of pigment. Similar spots are scattered over the web of the frog's fout on both sides, but scarcely interfere with the view of the circulation, because the lively movement of the latter contrasts well with their stillness. But, as this contrast is wanting in a drawing, I have in the figures omitted these spots, to allow the course of the circulation to be traced without interruption.

The curious observer who will catch a full-grown frog, and like to hold it when caught, may observe a few little pink blood-vessels crossing the web. The foot being tightly held, they will probably appear quite as evident as in fig. 3 ; and the reason of this will be that they are veins, and that the grasping of froggy's ankle has impeded their circulation. If the frog, reptile-like, shows signs of preserving an upathetic stillness, the grasp may be relaxed, and 
the vessels will presently become much paler, because the arrested blood will have recommenced its progress. When the web is magnified about thirty-five diameters, it affords a most curious spectacle. The largest web in fig. 3 contained two principal veins and an artery. This latter crossed the web where the letter $a$ is marked; it ran with amazing rapidity in its broader parts, but at length ramified into capilaries, and slackened its pace. The two veins moved much more slowly. They were well supplied in their centres with corpuscles from the capillaries, and each vein flowed from about the centre of the web towards the large veins placed above to the frog's third and fourth toe. Thus the sinuous vein to the left of $a$ flowed downwards from a point parallel to $a$, and upwards in a contrary direction; but I noticed that the point of separation was not uniformly in the same spot.

When a portion of the web is viewed with a power of 100 diameters, it becomes evident that some of the eapillaries lie near the surface of the websome deeper in its substance, and some close to the under surface. Some of these latter again, often seem to find their way suddenly to the upper surface, and cross over and under others without communicating with them. Some of them are very small and sparingly supplied with corpuscles; and these are only visible occasionally when their existence is shown by two or three stray corpuscles passing through them. The substance of the web is not perfectly, transparent, and seems, when the microscope is at the 
right focus for showing the capillaries, as if marked with a sort of grained pattern (figs. 4 and 5).

The capillaries represented in fig. 4 are only those which lie near the surface. An examination of the arrows which mark their directions will show how they all flow to a twisted vessel, which pours the corpuscles received from them into the large red vein. The large red vein !-for, as viewed when highly magnified, it is indeed a torrent-and they who use a microscope learn to regard the distinctions of great and small as only relative. But let us consider, relatively speaking, how small these vessels must be. The space represented at fig. 4 is magnified 100 diameters. In the drawing it is two inches and a quarter wide, by rather less than an inch and three quarters high. The hundredth part of that is about one forty-fourth of an inch by one sixtieth, a space that could be included, with room to spare above and below, in the upper loop of any small " $\mathrm{g}$ " in the page you are reading!

Remembering this extreme minuteness of the capillaries, the feeling with which we look on them when magnified, as in fig. 5 , becomes one of deep reverence, and the more so because we observe them ministering to a directly beneficent purpose. It may seem like a mere "dealing in the marvellous" to draw attention to the fact that the whole of the capillaries represented at fig. 5 , could be covered up by one of the full-stops at foot of the plate; but I do so, because by no other method could I so readily convey a correct impression of the real size of these vessels, and that of the corpuscles which they contain. 
The young tadpole's gills begin to be sufficiently transparent for microscopic observation when it is about the size represiented in No. 24, $h$. At that time its tail is opaque, and the tail-fin or web very slightly developed. The same tadpole's gills will on the following day be seen to have grown, and during about two days more they will show well, the tailfin also becoming broad and transparent, and circulation showing well in every part of it. After this time the gills begin to shrink in size (a process called. "absorption"), and can be observed (as I found) during about six days in the same tadpole. No. 24, $i$, shows the tadpole on the last day in which the branchiæ are worth examining. The interesting spectacle can, however, be observed each spring for about three weeks in all in any locality, because families of tadpoles in various stages of advancement can be found in different ponds. By the time the tadpole's gills have disappeared (being for a while concealed under gill-covers, somewhat like those of fishes) the circulation in the tail-fin, $d$, No. 24, has become a most beautiful object, and it continues to be so till after the tadpole has developed all its feet, and assumed much of the angular outline of the frog. After this time the tail begins to shrink in size, becoming absorbed just as was the case with the gills. The frog (as the creature must now be called), is a droll-looking object, when leaping with about a quarter of an inch of tail remaining; and in a few days even this remnant will have dwindled away.

The circulation seen in the web of a tadpole's tail 
is that of the capillaries of the system, as in the fish and frog. More than this can, however, be seen, as appears by Mr. Whitney's account of "The Circulation in the Tadpole," in the "Transactions of the Microscopic Society," vol. x. 1862. The heart was distinctly observed with its various vessels, and the narrative may be read in Dr. Carpenter's work on the microscope, accompanied by a figure of the tadpole. Dr. Carpenter adds that it shows the structure just at a time when the animal is neither fish nor reptile, and is the more remarkable in a physiological point of view. The great interest attaching to such an observation, when conducted with due knowledge of the true points of inquiry, may excuse the training, or rather starving process which was used to render the tadpole transparent, and which is politely described as an exclusively water-diet. For myself, I should feel satisfied with the spectacle presented by the beautiful little water-newt, which possessed the requisite transparency without any special treatment.

The newt is called by Linnæus Lacerta aquatica, or the water lizard, but is now correctly classed with the amphibia, from its affinity to that group in various respects, including the completeness of its transformation from the condition of a fish to that of a reptile. For although it continues in its full-grown state to be rather more aquatic in its habits than the frog, and retains its long tail instead of losing it by absorption, it exactly resembles the frog and toad in the early possession of branchiæ, which are subsequently lost and replaced by lungs, suited for breathing atmospheric air. 
The name lissotriton, or smooth newt, has been given to this species, to distinguish it from a larger one called triton, which has a rough skin. The lissotriton is a beautiful and harmless little creature. When full grown it is about three inches long. The male and female are curiously dissimilar. The former is spotted like a trout, and during the spring and summer possesses a handsome keel-like crest along its back, and a broad tail, both of which shrink considerably in the autumn. Its underside is tinged with orange, and altogether it is a great beauty among the amphibia; whereas its mate is brown and unornamented, except by two narrow lines of gold colour, bordered with black. I describe them from drawings made some years ago on the 26th and 27th of March.

The young smooth newt retains its external branchiæ to a much greater period than is the case with the frog-tadpole; although it would seem, from what I have observed, and also from Professor Bell's remarks on this subject, that there is a great variety in the period at which the branchiæ disappear in this species. I have, however, constantly met these young newts when nearly two inches in length, still possessing these beautiful appendages, which, instead of being pale, as at first, appear of a fine chestnut-orange colour; but they have lost much of their early transparency, and therefore for microscopic observation the newts answer best when of a smaller size. The great size of the corpuscles, as compared with the size of tho animal, makes the object exceedingly striking. They are oval, like those of the frog, but larger, being (in 
round numbers), one eight-hundredth of an inch in length, while those of the frog are one eleven-hundredth; and both these are singularly large compared to those of man; these latter are but one three-thousand two-hundredths of an inch in diameter.

The little newt was much more tractable than the tadpole when placed in the live-box. It would remain perfectly still for several minutes at a time and showed no signs of discomfort. It was so small, and in appearance so fragile, that I never touched it with my hands, but always caught and lifted it with an extemporized paper spoon, and poured it on to the livebox. On looking attentively one day at its under side, before placing it for inspection in the microscope, I could distinguish a delicate pink spot apparently fading and reappearing a number of times every minute. The circulation in the branchiæ was then a familiar object to me, and was similar to, but more beautiful than, that of the young tadpole. I was also familiar with the appearance of the circulation in the little newt's broad tail-but this pink spo' was something new to me, and was doubtless the heart, centre and origin of the movement which I had hitherto traced only in detached portions. My sup. position proved correct; and I hope some reader may be led by these remarks to capture and examine a little water-newt-and proceed much further than my limited knowledge permitted me to do, in recording the details of the wonderful spectacle which it presents to view. 
And here my Microscopic Teachings end. But, reader, shall we not rather say, HERE THEY BEGIN? A teacher who truly loves his art or science is best pleased when those whom he has instructed outdo in after years their early lessons. And such is my feeling about this little book. I wish that those who read it may enter on many fields of observation to which I have not directed them-for instance, the productions of the sea, a mine of interest! - and also that they may study the objects which I do describe in more completeness, and with a far deeper understanding of their meaning than I have done. If my book has helped to place them on the way to such studies, as may enable them to add to the general stock of knowledge, I shall not regret the time and application it has cost me-not as it might once have been, as the delightful employment of abundant leisure, but, on the contrary, a serious occupation, done amidst interruptions and under pressure of numerous home duties, in the feeling that I had a few things to say which might be pleasant and instructive to some readers at the present time, and to my own dear children by and by. To those readers I commend it, hoping that it will assist them in the study of Nature; hoping, too, that it will suggest thoughts which the heart can feel more readily than the tongue can speak them, of the unsearchable greatness of Him who made these things. 


\section{N D E X.}

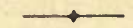

Animalcules, abodes of ..... 106

Aquarian Microscope ......... 113

Bell-flower Animalcule...112, 121

Birds, down of ............ 59

Blood, circulation of ......... 138

Boat-fly ................... 76

Brimstone Butterfly ........ 42

Burnet-Moth ............... 39

Camera Lucida ............. 20

Camera Obscura, eye compared to ................... 64

Canada Balsam ............... 26

Carchesium ................ 125

Cells, development from ... 52

Cilia ............................ 122

Coal ........................... 93

Coddington Lens............... 3

Collomia Seed, spiral fibre of 83

Compound Eyes of Insects... 68

Corpuscles, paleness of ..... 141

Condensing Lens............... 11

Cricket, eye of ............... 74,

Crustaceans, circulation in... 143

Crystalline Lens, fibres of ... 65

Crystallization, to view ...... 96

Crystals ....................... 95

Cuticles of Plants ............. 81

Deer, hair of ............... 57

Diameters, meaning of ...... 31

Diaphragm Plate............... 16

Diatoms and Desmids.......... 85

Diatoms as Test-objects ...... 118

PAGR

Diatoms fossil ................ y3

- recent ............9., 115

Dipping Tube, to use ......... 113

Dragon-fly, eye of .......... 69

wing of........... 34

Drawing ...................... 20

Earwig, wing of .............. 30

Eel, scales of ................. 47

Emperor Moth ............... 4i

Epistylis ....................... 125

Eyes, care of the ............. 1is

Eye, structure of .............. 64

Feather, hooklets of ........ 60

Fern-seed ...................... 87

Fishes, circulation in ......... 140

Fish, eye of .................... 62

Floscule ....................... 131

Flowers, mode of viewing ... 80

Fly, foot of ................... 75

Foot of Frog to observe, 138

$142,14.5$

Foraminifera ................ 94

Fossil Trees ................... 92

Frog Spawn..................... 108

Geranium, petal of .......... 85

Ghost Moth ................... 38

Glare, plans for moderating.. 13

Green Forester-Moth ........ 38

Hair, root of ................ 58

- structure of ........... 53

Hairs as opaque objects ...... 59 
Ifeliopeltr ................... PAGR 120

Herald Moth ................. 41

Human Hair $\quad . . \ldots \ldots \ldots \ldots . . .65$

Illumination of Objects ...... 11

Infusoria ...................... 114

Insects, concealed wings of... 30

- eyes of.................. 68

- hairs of ............... 59

Jaws of Rotifer ............. 130

Lamp for Microscope ........ 11

Lieberkuhns.................... 16

Limestone, animal remains in 94

-inear and Superficial Measures

31

Live-box

17

Lobster, eye of................. 74

Magnifying Glass ........... 2

Melicerta Ringens ............ 131

Micrometer .................... 102

Mirroscope, binocular......... 8

—— care of the ...... 18

- compound ...... 5

\begin{tabular}{r}
$\square$ \\
$\square$ oxyhydrogen .... \\
\hline simple .............. \\
\hline \\
solur ............
\end{tabular}

iNicroscopic Objects, L. Clarke on .....................

Microscopic writing .......... 103

Mirror, use of ................ 11

Mounting Objects ............. 20

Mouse, hair of ................. 53

Musk Deer, hair of........... 57

Navicula ..................... 117

Nobert's Tests ................... 103

Object-glasses, powers of $\ldots 7$

Objects, collection of ......... 20

Otter, hair of ................. 54

Perch, scale of .................. 45

Philodine

PAGR

Photographs, Microscopic ... 100

Polarization .................... 46

Pollen ........................ 84

Pond-life, Marvels of ......... 106

Protococcus .................... 115

Quill, internal structure of... 53

Red Admiral Butterfly ..... 42

Rhizopods ................... 115

Rotifera ........................ 114

Salpina ......................... 136

Scales of Insects .............. 37

Sole, scale of .................... 45

Spider, foot of ................. 75

Spring Water, no animalcules in..................... 105

Stage-forceps $\quad$................. 17

Stentors ...................111, 124

Stickleback, to observe ...... 140

Stylonichia .................. 127

Tadpole, to observe circula-

tion in ...............138, 148

- - to observe gills

of ......................110, 138

Tardigrada .................... 136

Test-objects ................43, 119

Trichopteryx, wing of......... 35

Vallisneria, rotation in ..... 82

Vorticellæ .................112, 121

Wasp's Wings................. 34

Water Bear ..................... 136

Water Newt, circulation in... 143

Weevils, scales of........... 43, 44

Wheel animalcule ............ 129

Wheel-movement, apparent 122

129

Whirligig Beetle ........... 32, 77

White Mouse, hair of ........ 53

Yellow Underwing Moth ... 41 



\section{RETURN \\ TO $\longrightarrow$}

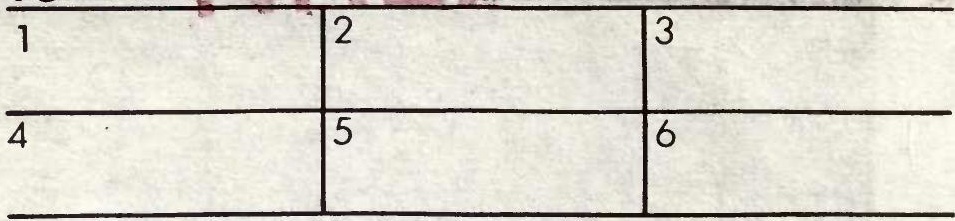

ALL BOOKS MAY BE RECALLED AFTER 7 DAYS

DUE AS STAMPED BELOW

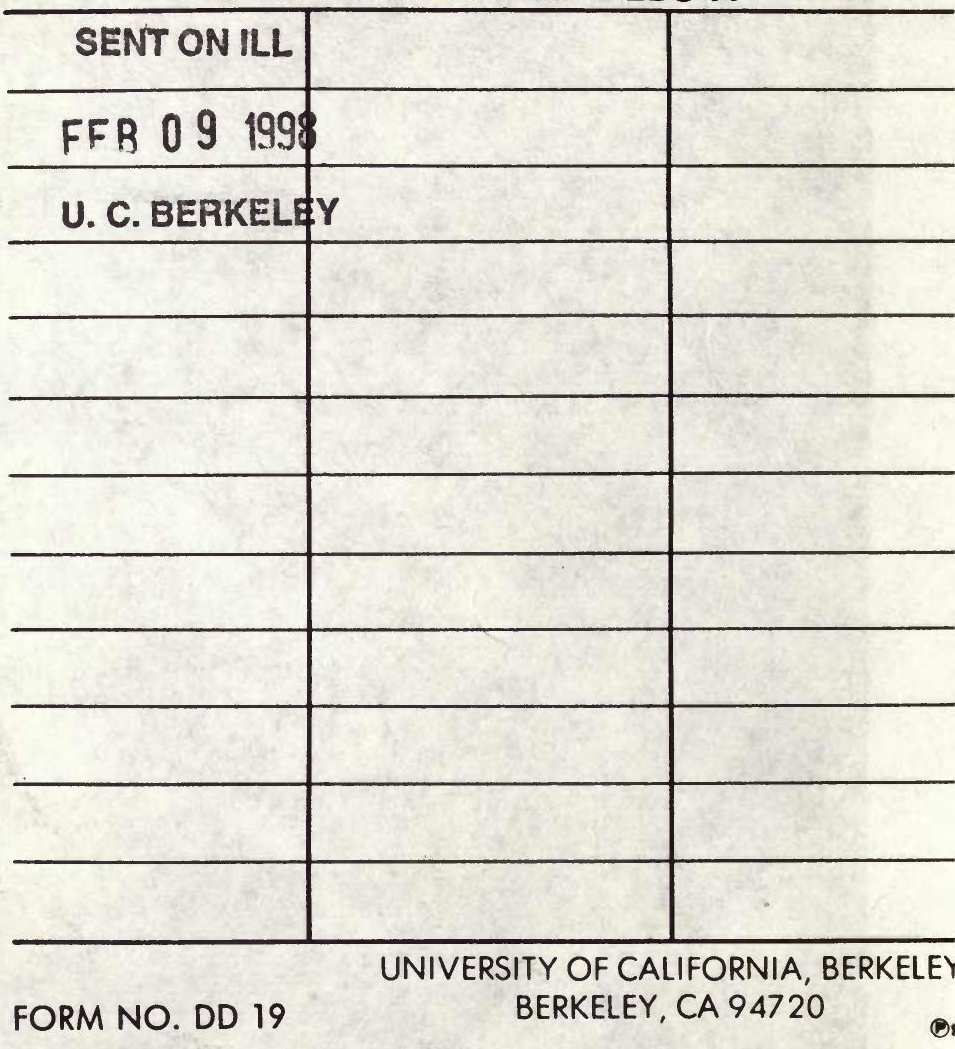




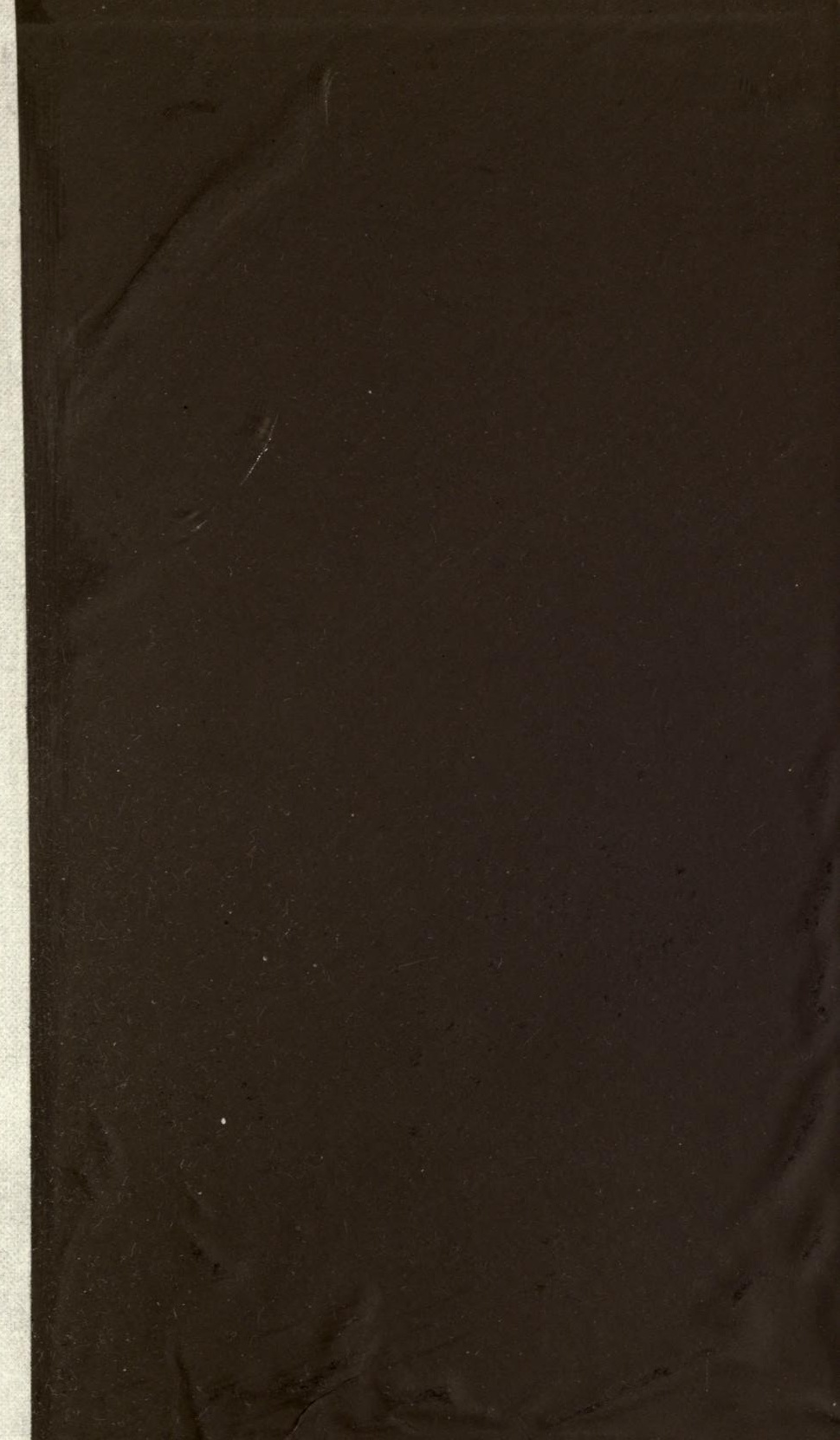




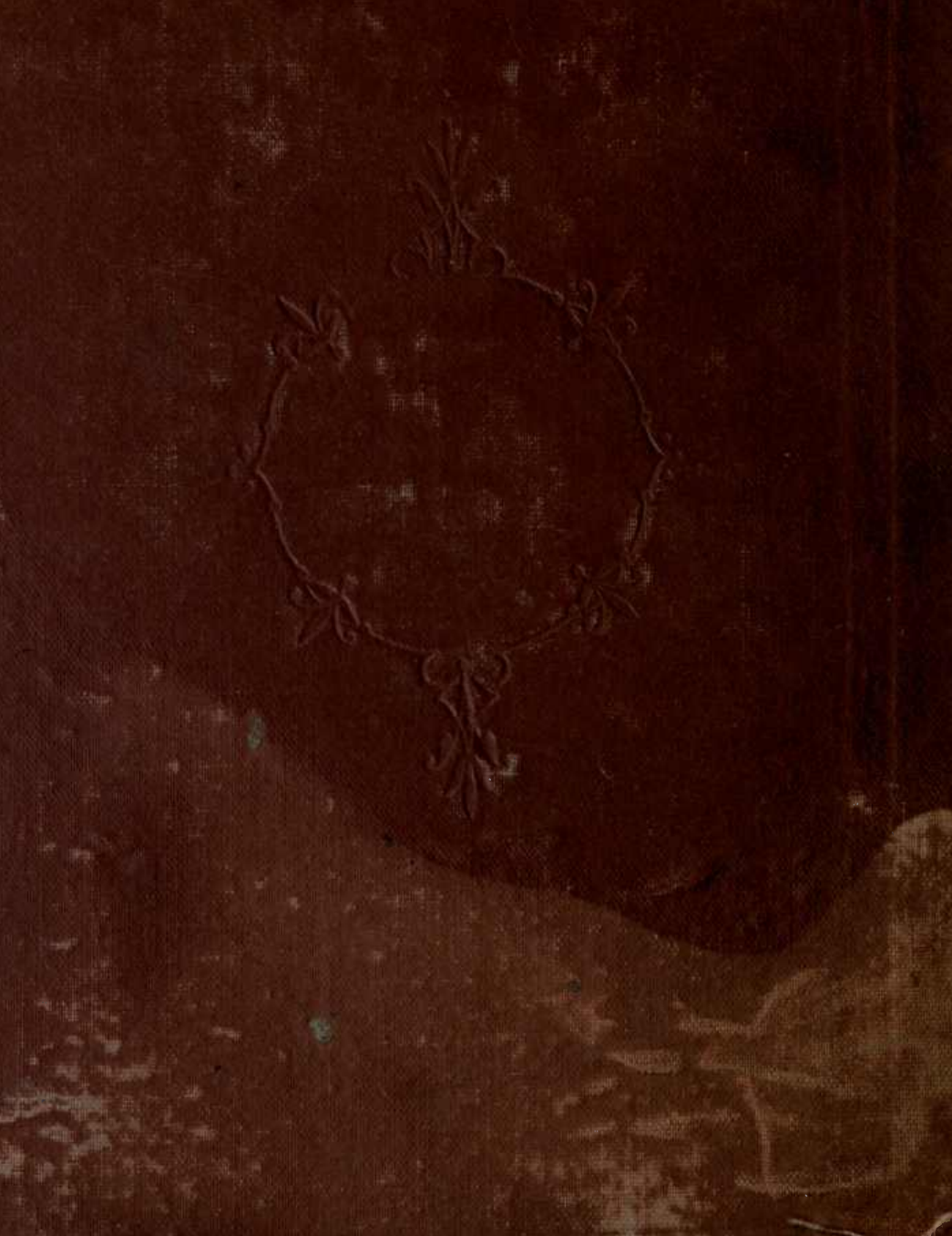

